\title{
Técnicas tomográficas aplicadas à Ortodontia: a evolução do diagnóstico por imagens
}

\author{
Rejane Faria RIBEIRO-ROTTA*
}

\begin{abstract}
Resumo
O diagnóstico por imagens tem passado por grandes transformações nos últimos dez anos, determinadas especialmente pela revolução tecnológica no campo da informática e da descoberta de novas fontes de energia para obtenção de imagens do interior do corpo humano. As imagens seccionais ou tomográficas, como a tomografia computadorizada (TC) e imagens por ressonância magnética (RM), reúnem muitos princípios e qualidades da modalidade ideal, o que inclui a obtenção de imagens eficientes, precisas em relação aos aspectos anatômicos, com riqueza de detalhes tridimensionais. O objetivo desta revisão, ilustrada por casos clínicos, é fornecer ao profissional uma noção geral da importância e das principais aplicações dessas técnicas tomográficas no contexto da Ortodontia.
\end{abstract}

Palavras-chave: Tomografia computadorizada. Ressonância magnética. Ortodontia. Diagnóstico por imagem.

\section{INTRODUÇÃO}

O diagnóstico é um processo que poderia ser representado pela pesagem de probabilidades em uma balança. Essas probabilidades estariam representadas pelas informações clínicas obtidas através do relato do paciente (anamnese) ou daquelas detectadas pelo profissional (exame físico). Quando um determinado número de informações soma em favor da doença/lesão ou condição clínica, a chance dela estar presente está próximo de 100\%. Quando as informações são contrárias, a chance de ocorrência daquela doença/lesão ou condição clínica tende a zero. $\mathrm{O}$ desafio do profissional é coletar informações que permitam avanços sucessivos nesta escala de probabilidades, até que o problema seja confirmado (diagnosticado) ou excluído, para o subseqüente estabelecimento do prognóstico e tratamento ${ }^{18}$. Além disso, torna-se fundamental o entendimento de que, dentre as várias etapas do "processo diagnóstico", as agressões responsáveis pelos sinais e sintomas, que levaram o paciente a procurar ajuda, possuem caráter bio-psico-socio-cultural. Assim, nem sempre existirá uma alteração anátomo-funcional visível em um exame complementar, associada ao problema. Durante o diagnóstico de uma doença, novas agressões podem requerer o reinício das etapas desse processo (Fig. 1).

\footnotetext{
Especialista em Radiologia Bucomaxilofacial e Mestre pela FO/USP-Bauru; Doutora em Diagnóstico Bucal pela FO/USPBauru - Hospital das Clínicas/FM/USP e Eastman Dental Center, Universidade de Rochester, NY, EUA; Professora Adjunta do Departamento de Ciências Estomatológicas e Coordenadora do Centro Goiano de Doenças da Boca da Faculdade de Odontologia da Universidade Federal de Goiás (CGDB/FO/UFG), Goiânia-GO
} 


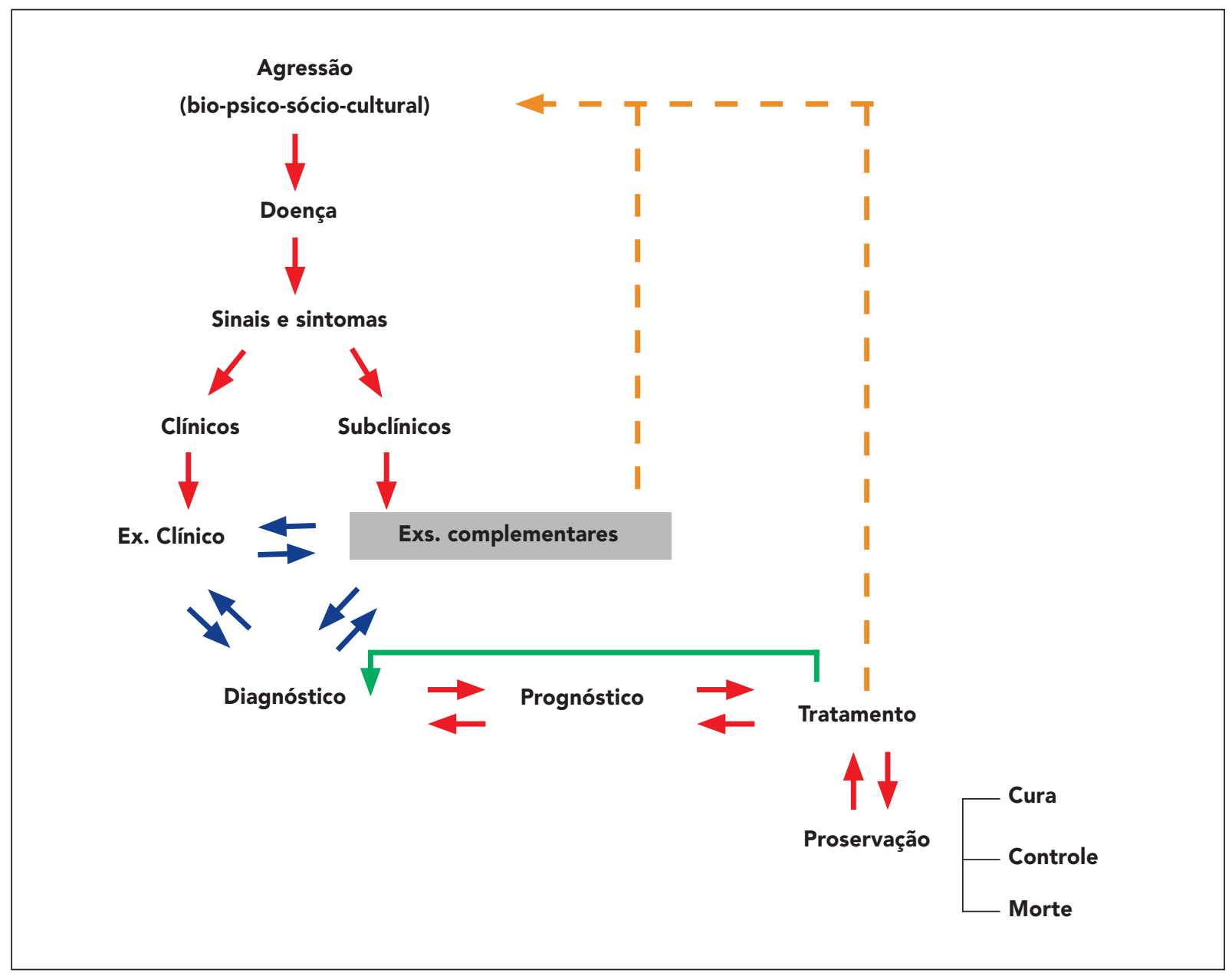

FIGURA 1 - Representação esquemática do processo diagnóstico (modificado de Tommasi, AF. Diagnóstico em Patologia Bucal. 3ed. São Paulo: Pancast, 2002. p.21)

O objetivo de um teste diagnóstico ou exame complementar, como aqueles por imagens, é o de adicionar informações não detectadas pelo paciente nem pelo profissional (condições subclínicas) a esta escala de probabilidades, para se chegar a um diagnóstico final (Fig. 1). Sendo assim, não se pode esquecer que as imagens, por mais que envolvam alta tecnologia, continuam sendo exames complementares, cuja indicação deve estar baseada em um criterioso exame clínico (anamnese/exame físico) e análise do seu custo/benefício.

Os avanços rápidos e substanciais da tecnologia e dos métodos de diagnóstico por imagens, o que evolve desde aspectos de sua terminologia até inovações relevantes para a prática clínica, nem sempre são informados de forma conveniente e adequada para o cirurgião-dentista, sendo ele generalista ou especialista. Além disso, a evolução destes métodos possui, historicamente, impactos diferentes em termos de aplicabilidade quando se compara a radiologia médica ou geral com a radiologia bucomaxilofacial ("radiologia odontológica"). Sendo assim, o objetivo desta revisão ilustrada por casos clínicos é fornecer ao profissional uma noção geral da importância e das principais aplicações das técnicas tomográficas no contexto da Ortodontia. 


\section{REVISÃO DE LITERATURA}

\section{Considerações gerais sobre o diagnóstico por imagem}

O diagnóstico por imagem, em um grande número de vezes, vem sendo usado muito mais como uma forma de "fazer alguma coisa" quando não se sabe por onde começar, do que como um teste diagnóstico complementar selecionado com base em uma anamnese e exame físico criteriosos, etapas as quais o profissional nem utiliza ou, quando o faz, as informações são arquivadas e não utilizadas. Este é um dos pontos em que reside o maior número de limitações na utilização/indicação de qualquer exame por imagem. Como prejuízos podemos listar: perdas na relação custo/benefício, super ou sub-diagnósticos, bem como tratamentos desnecessários ou omissão de uma contribuição precoce no diagnóstico de doenças/alterações, mesmo que o tratamento das mesmas não seja da competência do cirurgião-dentista.

Hoje, quando falamos em "Diagnóstico por imagem" estamos nos referindo a uma área que abrange não apenas os métodos que utilizam os raios $\mathrm{X}$, mas também outras fontes de energia, assim apresentadas:

- A Radiologia convencional = todas as técnicas que utilizam raios $\mathrm{X}$ e possuem um filme como receptor de imagem;

- A Radiologia digital = em Odontologia inclui as técnicas de exames intra e extrabucais que utilizam raios $\mathrm{X}$ e possuem sensores como receptores de imagens. Estas imagens podem ser apresentadas, armazenadas, processadas e transmitidas eletronicamente por um computador. A digitalização de imagens obtidas primariamente por métodos convencionais constitui a radiologia digital indireta;

- As Técnicas tomográficas = todas aquelas que obtêm imagens seccionais ou em planos de corte do corpo humano, independente da fonte de energia e do receptor de imagem utilizados.
Assim, elas também estão incluídas no contexto dos métodos convencional (tomografia convencional) e digital (tomografia computadorizada - TC, ressonância magnética - RM). A TC se diferencia da tomografia convencional por contar com o auxílio do computador e detectores de raios $\mathrm{X}$ na aquisição das imagens. As imagens por ressonância magnética (RM) e algumas técnicas da medicina nuclear (cintilografia) - Single-photon Emission Computed Tomography - SPECT, estão incluídas no conjunto dos exames tomográficos que utilizam outras fontes de energia;

- A Ultra-sonografia = utiliza cristais piezelétricos (transdutores) que emitem e recebem ondas sonoras, as quais atravessam as diferentes partes do corpo humano fornecendo imagens ecográficas, cujas principais aplicações são para a avaliação de tecidos moles, principalmente estruturas ocas ou de conteúdo líquido (exs: acompanhamento de gestações, lesões císticas e tumores de partes moles);

- A Radiologia vascular ou intervencionista $=$ estuda os vasos sanguíneos por meio da injeção de meio de contraste e realiza procedimentos clínicos guiados por imagens (exs: introdução de dispositivos e cateteres no interior de vasos sanguíneos; biópsias, punções e drenagens guiadas por diferentes métodos de imagem);

- A Termografia = método de diagnóstico por meio de registro fotográfico, feito por câmara de infravermelho, das temperaturas da superfície do corpo, com base na irradiação infravermelha dele emanada (exs: diagnóstico de dores craniofaciais crônicas e difusas; medicina esportiva).

O diagnóstico por imagem é uma das ferramentas mais tradicionais utilizadas pelos ortodontistas para medir e registrar tamanho e forma das estruturas craniofaciais (telerradiografia e panorâmica). Os princípios da modalidade ideal devem incluir a determinação de uma anatomia o mais próximo do real em termos de precisão da orientação espacial, tamanho, forma e relação com as estruturas anatômicas circunjacentes ${ }^{20,46}$. 
Isto requer uma avaliação da anatomia nos três planos espaciais, visto que a região craniofacial é definida tridimensionalmente. Informações importantes são perdidas quando a estrutura tridimensional é representada por um grupo de coordenadas bidimensionais.

No contexto das técnicas radiográficas convencionais, um variado número de técnicas (periapicais, panorâmica, cefalométricas, carpal, articulação temporomandibular - ATM, etc) estáticas e bidimensionais são empregadas para registrar a anatomia tridimensional da região bucomaxilofacial, o que resulta em uma das principais limitações das referidas técnicas, somado à deficiência das mesmas para a avaliação dos tecidos moles da região ${ }^{46}$.

$\mathrm{O}$ interesse pela imagem digital tem crescido por uma série de razões que incluem: possibilidade de aquisição quase instantânea da imagem sem a etapa do processamento químico; possibilidade de tratamento/processamento das imagens no computador, empregando-se algoritmos (realce, restauração, análises, compressão e síntese de imagens) que podem influenciar no resultado diagnóstico das imagens ${ }^{36}$; dose de exposição à radiação equivalente à dos filmes E-speed; redução do espaço físico para armazenamento das imagens; além da transmissão eletrônica das mesmas (teleradiologia) ${ }^{46,66}$.

O futuro das técnicas de imagens da região bucomaxilofacial reside na obtenção de imagens eficientes, de baixo custo, com riqueza de detalhes tridimensionais para o diagnóstico e plano de tratamento. O desenvolvimento de tecnologias que reúnam estas qualidades inclui, dentre outras, as técnicas tomográficas, especialmente a $\mathrm{TC}$ e a $\mathrm{RM}^{46}$.

\section{Tomografia Computadorizada}

\section{Aspectos técnicos básicos de aquisição das imagens}

O contraste da imagem tomográfica compu- tadorizada é basicamente determinado pelos diferentes níveis de atenuação do feixe de raios $\mathrm{X}$ (diminuição da intensidade do feixe ao atravessar o meio), gerado pela interação dos fótons de raios $\mathrm{X}$ com os elétrons orbitais dos objetos/tecidos atravessados por ele. $\mathrm{O}$ feixe atenuado é detectado por uma série de detectores de raios $\mathrm{X}$, gerando um sinal analógico (elétrico) o qual é convertido em dígitos (sinal digital), gerando uma imagem digital que pode ser apresentada, processada, armazenada e/ou transmitida eletronicamente pelo computador. Na maioria dos casos, as imagens obtidas diretamente do paciente são no plano axial, e a partir desse conjunto de imagens, diferentes softwares podem ser utilizados para realizar reconstruções ou reformatações nos diferentes planos anatômicos (reconstrução 2-D), bem como aquelas tridimensionais (3-D) $)^{35}$. Considerando o grande número de possibilidades de técnicas de processamento das imagens tomográficas, tornase importante investigar as vantagens e deficiências de cada uma delas para as aplicações clínicas específicas $^{52}$. Recentemente, alguns softwares para reconstruções tomográficas específicas para a região maxilo-mandibular tem sido desenvolvidos (ex. DentaScan, DentaCT) e contribuído de forma significante, especialmente para o planejamento em implantodontia, dentre várias outras aplicações ${ }^{2}$.

Quanto maior o número atômico do objeto/ tecido envolvido, maior a atenuação dos raios $\mathrm{X}$. Isto é o fundamento da escala numérica e empírica de Hounsfield, uma escala linear que estabelece valores (unidades Hounsfield $=\mathrm{UH}$ ) para os níveis de cinza em uma imagem digital obtida pela TC. Esta escala foi baseada em dois parâmetros: atenuação do ar seco (-1000 UH) e da água pura a $25^{\circ} \mathrm{C}$ (zero UH). Estruturas ósseas ou metálicas têm valores de atenuação tão elevados quanto 1000 a $3000 \mathrm{UH}$, enquanto a gordura possui valores negativos em torno de $-50 \mathrm{UH}$ (Fig. 2) ${ }^{46,59}$.

No que se refere à terminologia em TC, áreas osteolíticas que aparecem como tons mais 
escuros de cinza ou totalmente enegrecidas, tradicionalmente referidas como radiolúcidas/radiotransparentes na radiologia convencional, são aqui descritas como áreas de baixa densidade ou hipoatenuantes. Por outro lado, áreas osteoblásticas ou radiopacas, que aparecem em tons mais claros de cinza ou totalmente brancas, são aqui descritas com áreas de alta densidade ou hiperatenuantes.

\section{Vantagens e desvantagens}

A TC oferece um melhor delineamento das estruturas ósseas da base do crânio e esqueleto facial do que a radiografia convencional. A sua melhor resolução e ausência de sobreposições determinam significantes vantagens na avaliação de lesões neoplásicas e traumáticas, o que tem levado este método a suplantar a tomografia convencional da região de cabeça e pescoço. A TC é freqüentemente indicada, também, para evidenciar sítios de destruição óssea e linfoadenopatias (linfomas, metástases). Uma outra vantagem da TC é a caracterização de tecidos por meio da densitometria. Foi o primeiro exame que permitiu a obtenção de imagens diretas dos tecidos moles, ainda que deficientes.

Como desvantagens da TC, torna-se importante destacar os artefatos causados por estruturas ósseas compactas (especialmente na base do crânio) e estruturas metálicas (restaurações e dispositivos dentários), imagens dos tecidos moles com resolução deficiente e a exposição do paciente a altas doses de radiação. Jóias e bijuterias, bem como próteses removíveis devem ser retiradas antes de qualquer exame de cabeça e pescoço para prevenir e/ou minimizar artefatos, os quais poderão impedir a interpretação das imagens. Os aparelhos ortodônticos também são fontes de artefatos que podem ou não prejudicar ou até inviabilizar a interpretação das imagens ${ }^{68}$.

\section{Aplicações da TC em Ortodontia}

Apesar da TC ser um exame de alto custo e proporcionar altas doses de radiação para ser utilizado na rotina clínica da Ortodontia, em certas situações os benefícios são superiores aos riscos, dentre eles destacam-se:

\section{Assimetria Facial/Cirurgia Ortognática}

No tratamento de deformidades craniofaciais, em que as assimetrias apresentam registros inadequados quando técnicas radiográficas bidimensionais convencionais são utilizadas, a TC tem um importante papel, especialmente as reconstruções 3-D ${ }^{40}$.

A microssomia hemifacial é a segunda anomalia facial congênita mais comum, perdendo apenas para a fissura lábio palatina ${ }^{37}$. A relação entre ossos (Fig. 3) e músculos na microssomia hemifacial tem sido estudada utilizando-se a reconstrução 3-D volumétrica e técnicas de processamento de imagem. Estas técnicas permitem, de forma acurada, precisa e independente, a reconstrução 3-D e a realização de medidas volumétricas dos músculos e ossos. Os resultados têm mostrado que a determinação da extensão da hipoplasia de músculos específicos da mastigação permite a estimativa da extensão da displasia nas origens e inserções ósseas desses músculos. Contudo, a extensão da hipoplasia dos ossos faciais não estima, necessariamente, a extensão da hipoplasia nos músculos da mastigação neles inseridos ${ }^{26}$. O tratamento de pacientes com microssomia hemifacial é mais efetivo em centros multidisciplinares, e o sucesso do tratamento do crescimento facial assimétrico depende do grau de severidade da anormalidade primária, do desenvolvimento anormal secundário e da intervenção ortodôntica/ortopédica e cirúrgica ${ }^{37}$.

O diagnóstico, planejamento pré-operatório, simulação e o resultado de procedimentos cirúrgicos de desordens craniofaciais (tumores, traumatologia, disgnatia, atrofia alveolar, más formações congênitas e assimétricas) podem ser visualizados utilizando-se de métodos sofisticados de reconstrução 3-D (Fig. 4), sendo que as 

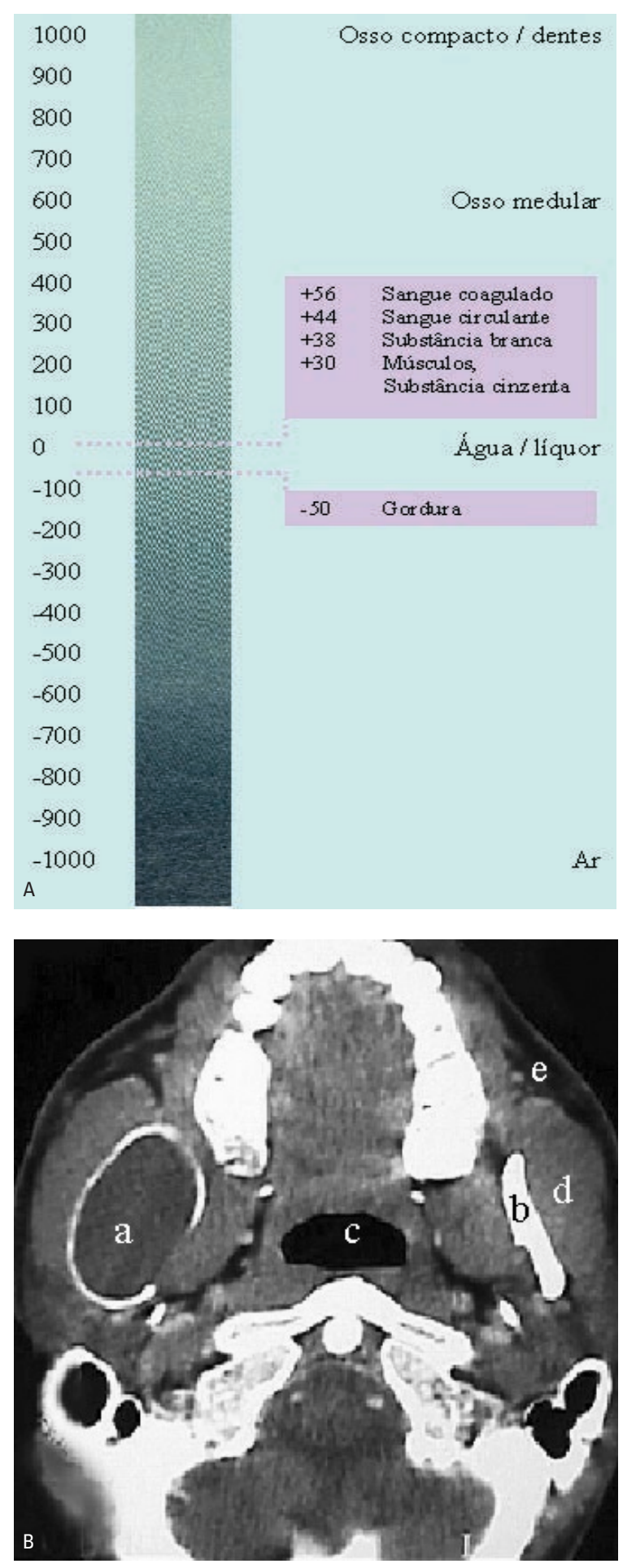

FIGURA 2 - (A) Escala Hounsfield; (B) TC em corte axial ao nível da maxila, em janela para tecidos moles, evidenciando lesão expansiva no ramo mandibular direito (a), com conteúdo de densidade cística (próximo ao zero). 0 ramo mandibular (b) tem densidade em torno de $+1000 \mathrm{UH}$, a bucofaringe (c) por ser um espaço aéreo, tem densidade em torno de $-1000 \mathrm{UH}$, o músculo masseter (d) em torno de $+30 \mathrm{a}+50 \mathrm{UH}$, e a gordura subcutânea (e) $-50 \mathrm{UH}$.
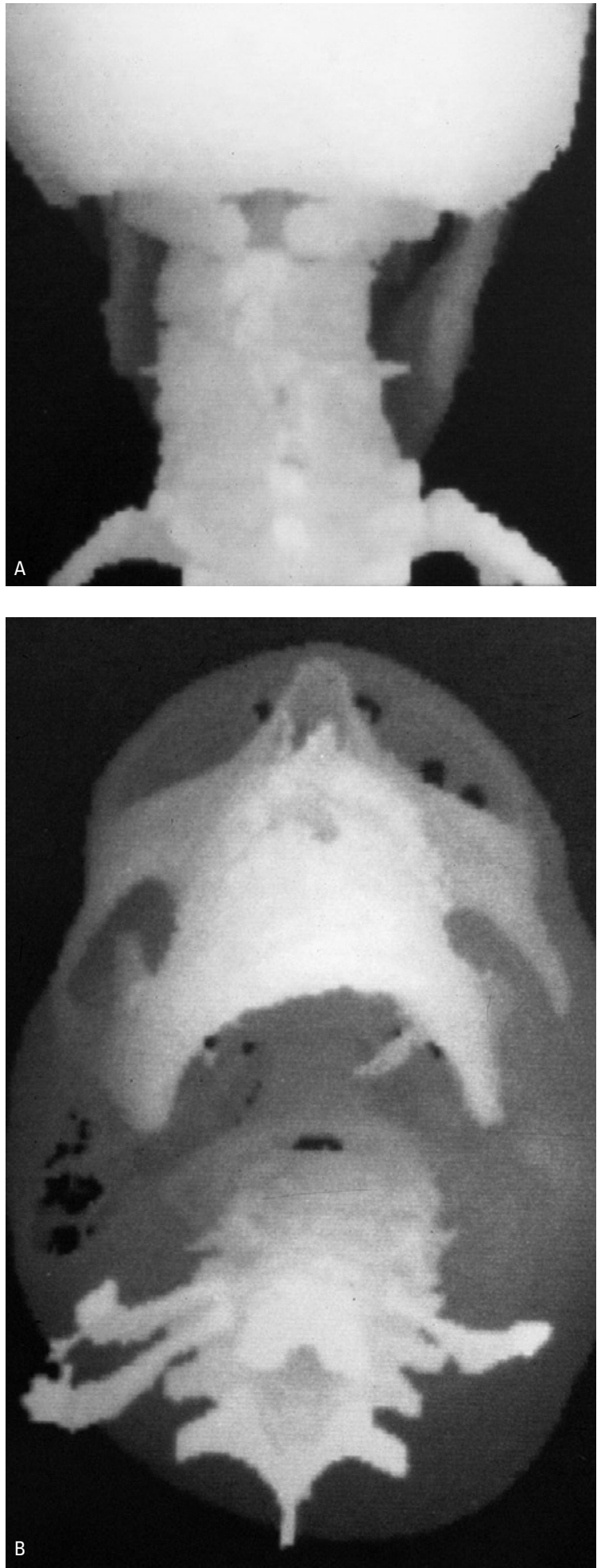

FIGURA 3 - Reconstruções tomográficas 3D de paciente com microssomia hemifacial. Assimetria dos ramos mandibulares numa vista posterior (A), alterações do desenvolvimento do arco zigomático, processos coronóide e condilar do lado esquerdo do paciente (B). 

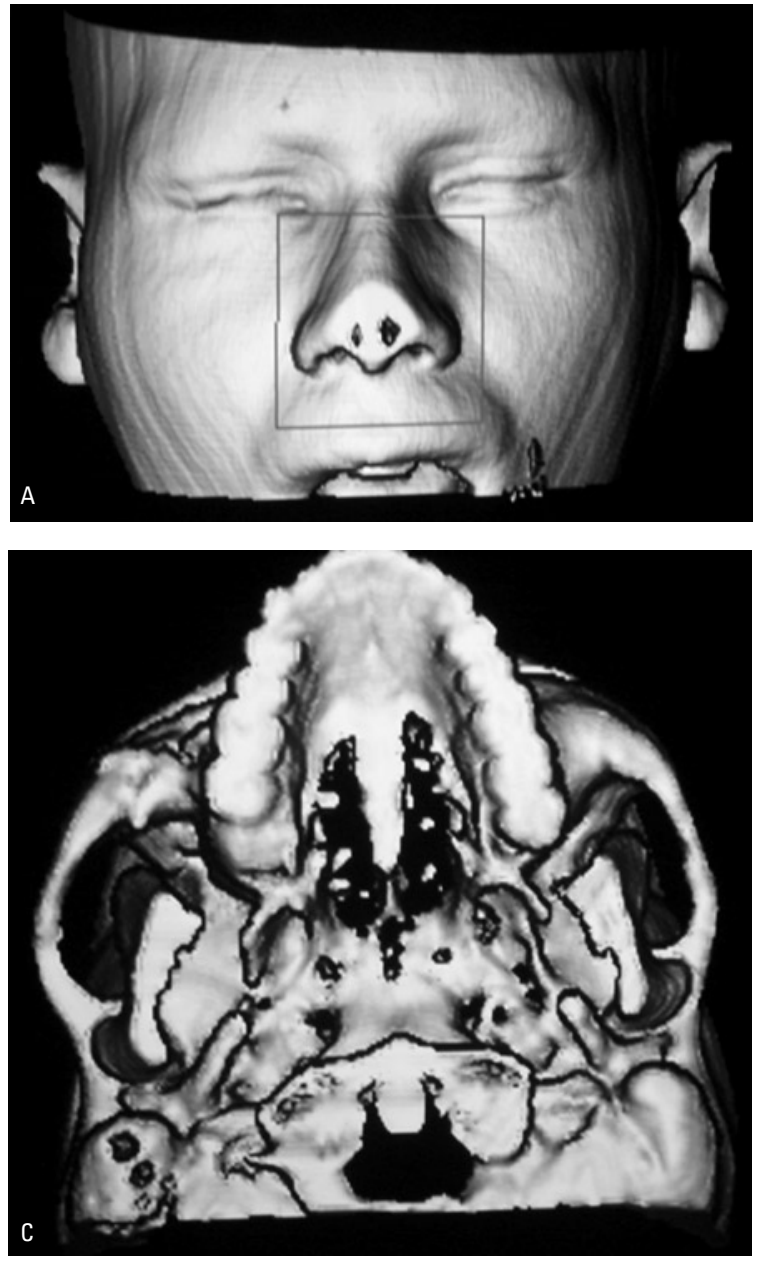

imagens podem ser visualizadas na tela de um computador, fotografadas em filmes radiográficos e/ou processadas para gerar modelos físicos (protótipos ou biomodelos) por prototipagem rápida (estereolitografia ou sinterização) ${ }^{40,53}$. As reconstruções 3-D permitem a seleção de quais os tecidos deverão estar incluídos na reformatação das imagens de uma determinada região, de forma que apenas um elemento, como a mandíbula ou um determinado grupo de vasos sanguíneos, pode ser visualizado isoladamente das outras estruturas anatômicas circunvizinhas e/ou transformado em protótipo (Fig. 5) ${ }^{14,53,56}$.

O plano de tratamento ortodôntico e cirúrgico em articulador pode ser comparado aquele que utiliza modelos estereolitográficos, nos quais o
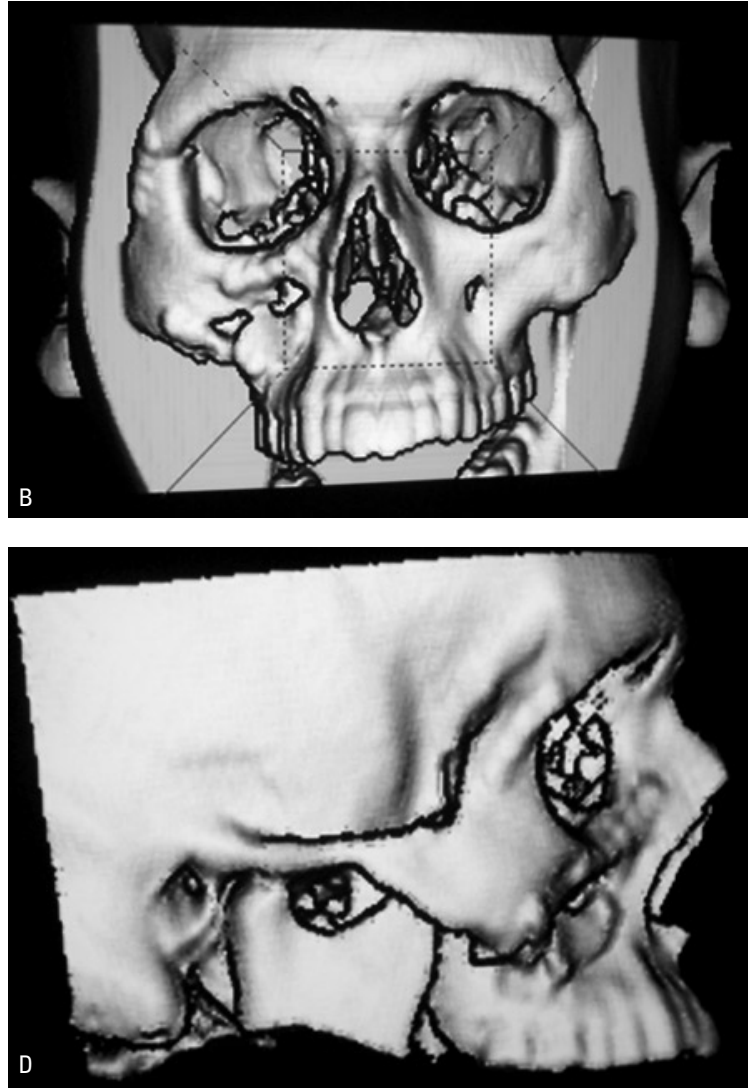

FIGURA 4 - Reconstruções tomográficas 3D de paciente com história de trauma de face. Afundamento da região orbital à direita (A), fraturas do assoalho de órbita e processo zigomático da maxila, à direita, vistas anterior (B), inferior (C) e lateralmente (D).

deslocamento esperado de um segmento, o melhor delineamento para a osteotomia e os resultados da simetria esquelética e dentária almejados podem ser analisados, além de poderem ser utilizados como guia-cirúrgicos nas reconstruções faciais. Entretanto, alguns autores ${ }^{14,56}$ têm chamado a atenção para o elevado tempo de trabalho e o alto custo dos protótipos, quando comparados à técnica do articulador, sugerindo que aqueles deveriam ser reservados apenas para os casos mais complexos de desarmonias dentofaciais, por permitirem planejamentos de maior precisão. Apesar de $80 \%$ dos valores das medidas obtidas dos modelos estereolitográficos apresentarem uma diferença de +/- $1 \mathrm{~mm}$ em relação às medidas reais do paciente, o valor máximo descrito dessa 

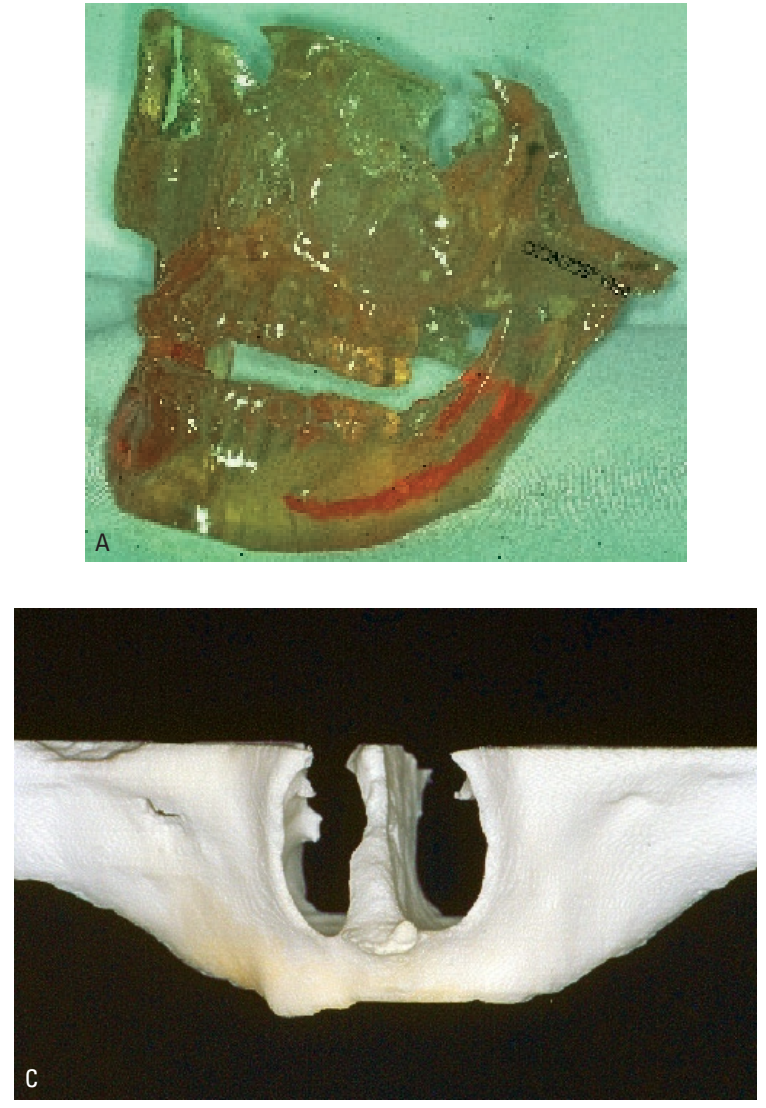

FIGURA 5 - Modelos construídos Oleskovicz e Hiron Andreazza).

diferença foi de $2 \mathrm{~mm}^{14,56}$.

Schultes e colaboradores ${ }^{56}$ demonstraram, por meio da utilização de protótipos pré e pós-operatórios em cirurgia ortognática, que pacientes prognatas e retrognatas, após serem submetidos à osteotomia sagital bilateral da mandíbula, apresentaram acentuadas alterações na anatomia e posição condilar.

As deformidades faciais têm sido corrigidas por numerosos procedimentos cirúrgicos, sendo que durantes estes procedimentos, alterações na posição condilar podem ocorrer por várias razões: a posição do paciente sob anestesia geral, o tipo de osteotomia, o tipo de contenção empregada, a técnica cirúrgica, a presença de interferências ósseas entre os segmentos proximal e distal e a mo-
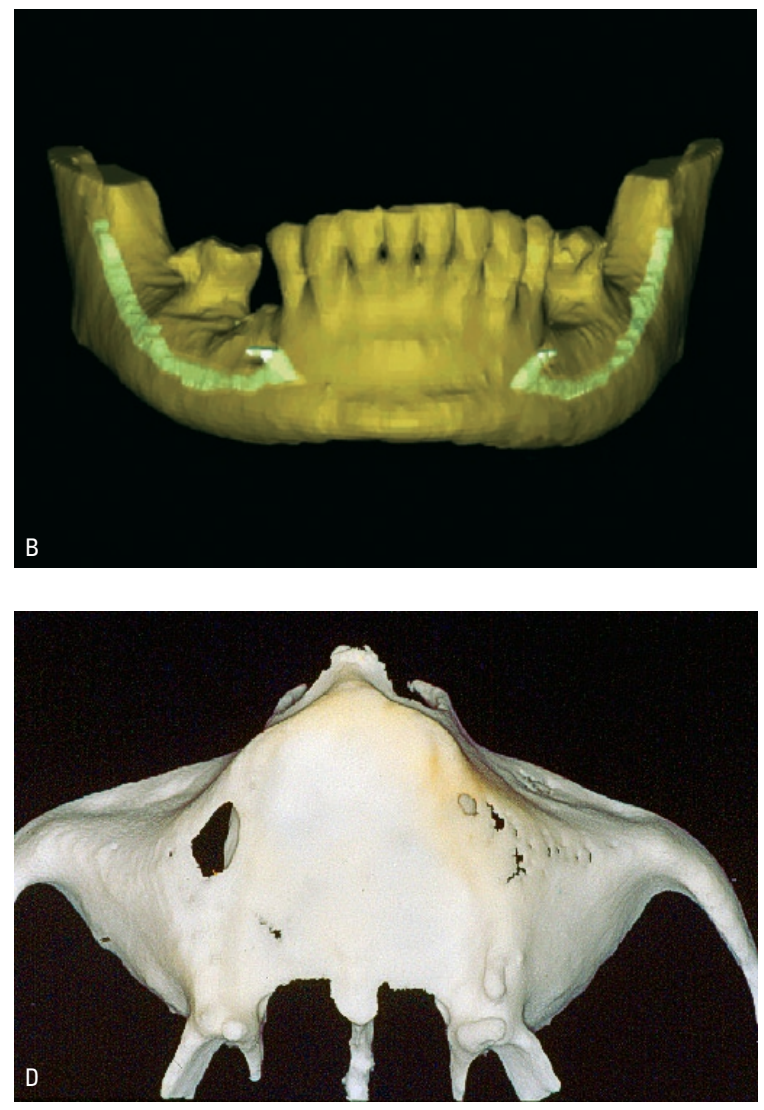

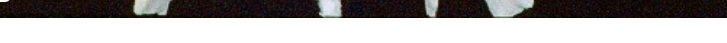


condilar foram observadas, enquanto as alterações de posicionamento do côndilo no interior da articulação foram mínimas ${ }^{27}$.

\section{Articulação Temporomandibular (ATM)}

O diagnóstico por imagens da ATM é um campo vasto e determina um capítulo separado da radiologia bucomaxilofacial. A Academia Americana de Radiologia Dentomaxilofacial (AAOMR) publicou um consenso em termos de critérios de seleção e indicação de exames por imagens disponíveis para o estudo da $\mathrm{ATM}^{3}$, em que as vantagens e limitações dos vários métodos são discutidas. Torna-se importante ressaltar que, considerando o grande número de técnicas, os detalhes do que se investiga deverão determinar qual das técnicas é a mais apropriada para cada caso individualmente, baseados em exame clínico minucioso. Nenhuma única modalidade pode oferecer imagens de todos os componentes da articulação. TC e RM são usadas, freqüentemente, como exames complementares.

A TC fornece excelentes imagens dos componentes ósseos da ATM, porém inadequadas para visualização do disco articular. Ela pode ser utilizada, principalmente, na avaliação de tumores (Fig. 6), hiperplasia condilar, anquiloses, processos traumáticos e ósseo degenerativos da articulação (Figs. 7-8) ${ }^{41}$. Ou seja, nas alterações morfológicas, de maneira geral, dos componentes ósseo articulares.

Yamada e colaboradores ${ }^{71}$ sugeriram que alterações ósseas condilares podem estar relacionadas a um desvio lateral da mandíbula e à retrognatia mandibular, em pacientes com sintomas de desordens da ATM encaminhados para tratamento ortodôntico.

\section{Apnéia do sono}

Estudos $^{57,58}$ têm sugerido que muitas alterações fisiológicas e histológicas dos músculos da bucofaringe estão associadas a distúrbios do sono, especialmente a apnéia obstrutiva do sono. Esta alteração é caracterizada por vários sinais e sintomas, mais especificamente a ocorrência de episódios de colapso parcial ou total das vias aéreas superiores, impedindo a respiração e geralmente acompanhado de ronco acentuado, sonolência durante o dia e redução da saturação do oxigênio no sangue do paciente. Técnicas dinâmicas e estáticas de imagem têm proporcionado avanços no entendimento da patogênese da apnéia obstrutiva do sono e os mecanismos biomecânicos exercidos pelas intervenções terapêuticas. As técnicas de imagem, especialmente as tomográficas, têm evidenciado a importância da parede lateral da faringe, juntamente com a língua e o palato mole na modulação das alterações do calibre do espaço das vias aéreas superiores. A utilização destas técnicas de imagem pode determinar opções de tratamento mais efetivas para esses pacientes, o que inclui dispositivos de reposicionamento mandibular ${ }^{4,11,57,58}$. A TC apresenta várias vantagens no estudo das vias aéreas superiores, como as que se seguem: técnica realizada na posição supina, avaliação acurada da área e volume do espaço aéreo, excelente resolução óssea e do referido espaço, reconstrução tridimensional das estruturas craniofaciais e do espaço aéreo propriamente dito. Entretanto, devido à exposição do paciente à radiação ionizante e à baixa resolução dos tecidos moles, especialmente o tecido adiposo, a TC deixa a desejar se comparada às imagens por $\mathrm{RM}^{57,58}$.

\section{Implantes $x$ Ortodontia}

A ausência dentária, especialmente na região anterior, determina um importante impacto nos pacientes pelas conseqüências na aparência facial, no desenvolvimento da auto-estima e da identidade. $\mathrm{O}$ tratamento multidisciplinar tem aumentado as chances de reabilitação de pacientes com anodontia parcial ou perda dentária precoce decorrente de trauma. Os implantes unitários têm sido uma das principais indicações como alternativa de tratamento para esses casos, juntamente 

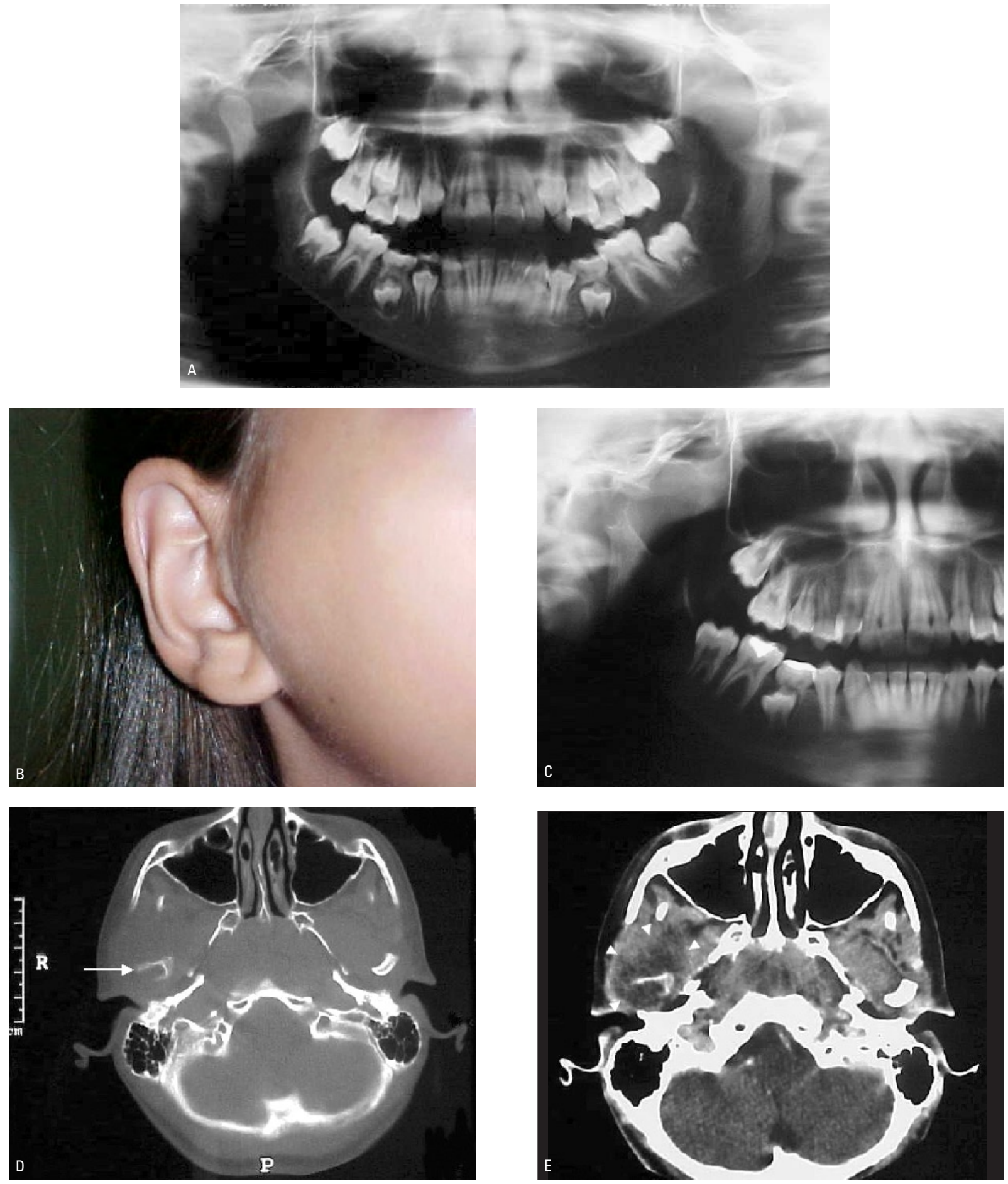

FIGURA 6 - Condrossarcoma da ATM direita em criança de 9 anos - Radiografia panorâmica realizada um ano anterior ao aparecimento da lesão, obtida dos arquivos do ortodontista, mostrando aspectos de normalidade do côndilo direito (A). Aumento de volume pré-auricular à direita (B), percebido há aproximadamente 2 meses da data da primeira consulta, assintomático e sem comprometimento otológico. Radiografia panorâmica evidenciando reabsorção irregular do côndilo direito (C). TC em cortes axiais em janela para tecidos duros (D) e com injeção de contraste em janela para tecidos moles (E). Cortes coronais com injeção de contraste em janela para partes moles ao nível do côndilo (F) e posterior a ele (G). As imagens $\mathbf{D}, \mathbf{E}, \mathbf{F}$ e $\mathbf{G}$ mostram detalhes da destruição condilar (seta) e o comprometimento dos tecidos sinoviais e musculares adjacentes (cabeças de setas), causada pelo tumor. c-côndilo; rm - ramo mandibular. (Créditos do caso clínico: Equipe do Centro Goiano de Doenças da Boca da FO/UFG e Equipe de cabeça e pescoço do Hospital Araújo Jorge da Associação de combate ao câncer em Goiás). 

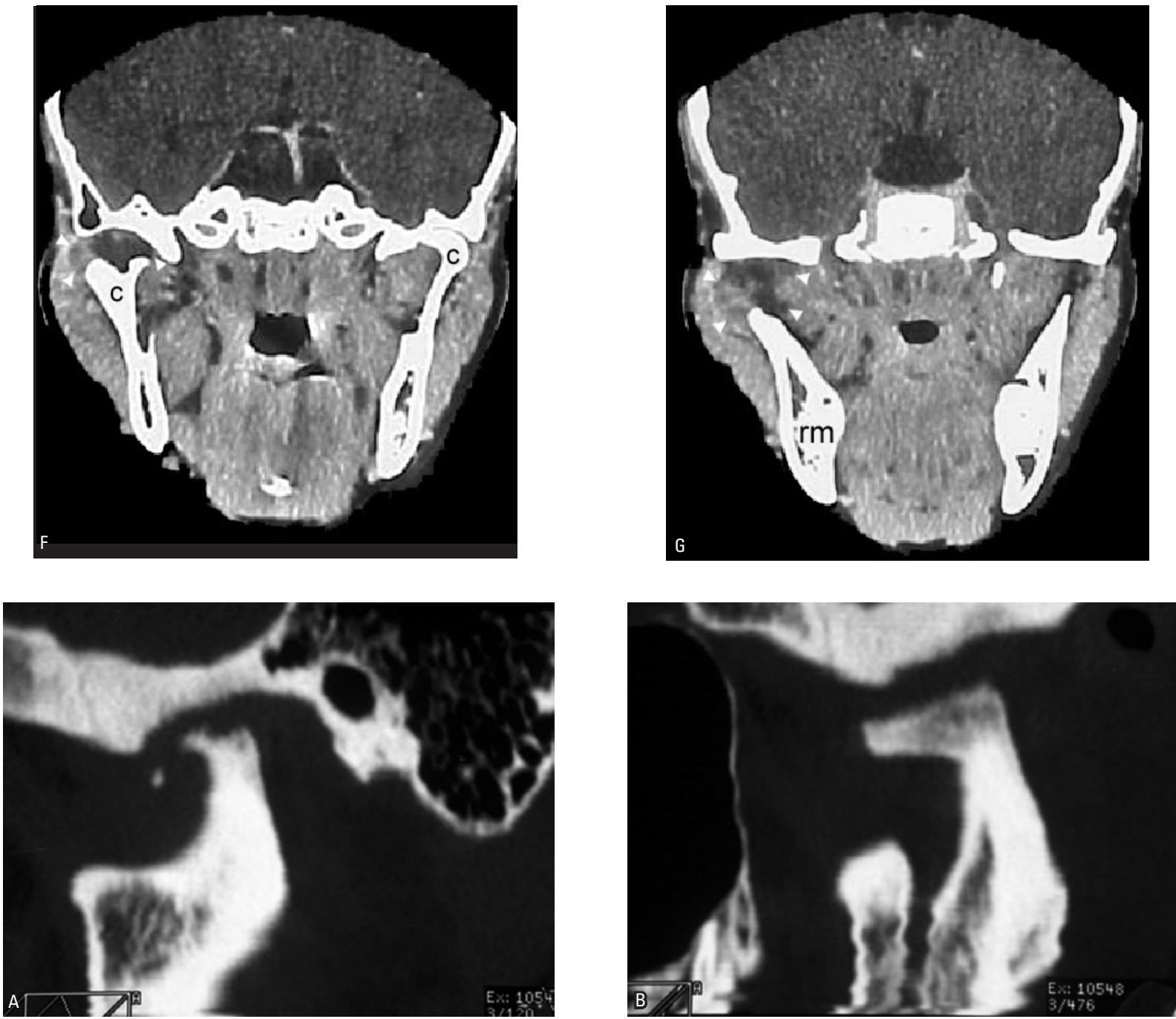

FIGURA 7 - Processo ósseo degenerativo da ATM. Reconstruções tomográficas sagitais na posição de boca fechada, evidenciando erosão no côndilo direito (A) ، reabsorção e extenso osteófito no côndilo esquerdo (B).
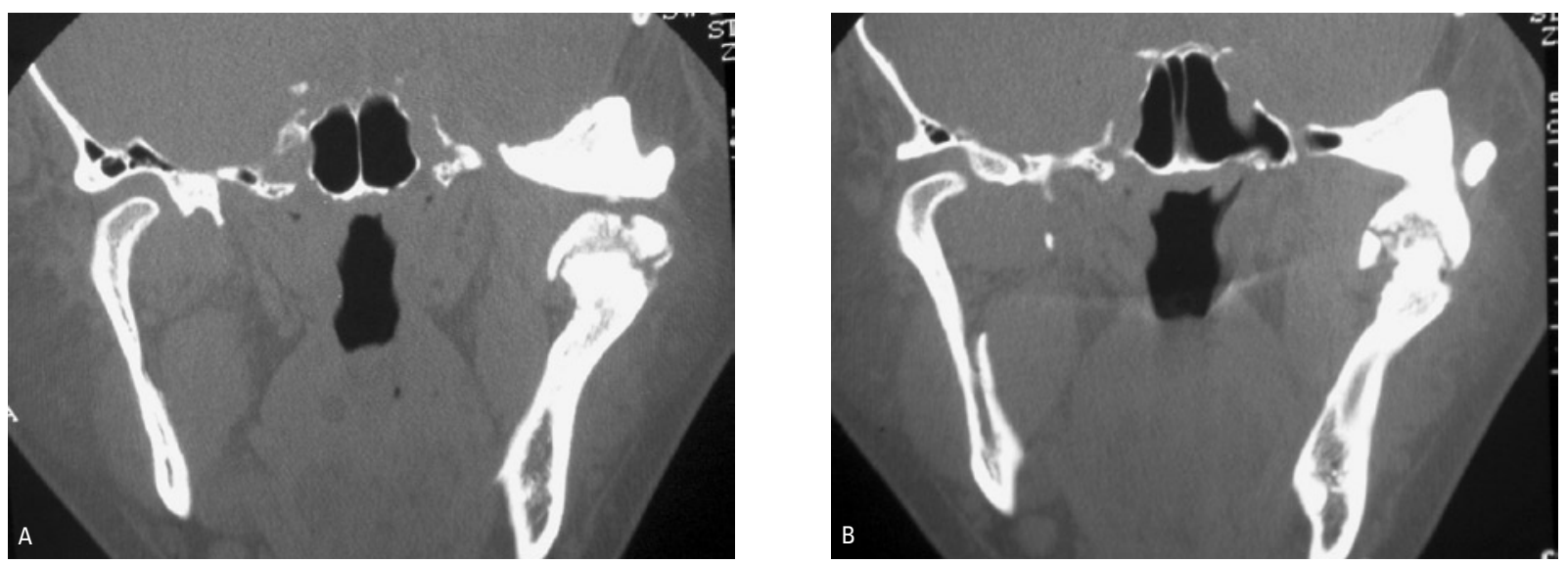

FIGURA 8 - Anquilose da ATM / osso temporal à esquerda. Reconstruções tomográficas coronais, mais anterior (A) e mais posterior (B) em relação à ATM, evidenciam côndilo esquerdo de aspecto irregular, onde observa-se formação tecidual de alta densidade unindo este côndilo à fossa mandibular do osso temporal, o qual apresenta-se esclerótico. Articulação direita dentro dos padrões de normalidade. 
com as próteses fixas, a Ortodontia e a Odontologia Estética ${ }^{13}$. É muito importante obter espaço suficiente no sítio do implante e a verticalização dos dentes adjacentes, reduzindo o risco de perda óssea marginal nos dentes contíguos ao implante e na superfície vestibular do mesmo (Fig. 9) ${ }^{64}$.

Implantes com a finalidade de ancoragem têm sido utilizados como um complemento ao tratamento ortodôntico, como por exemplo, no tratamento da mordida aberta anterior ${ }^{62}$. Estes pequenos implantes são colocados temporariamente em áreas que possuam osso cortical (ex. palato), e sua estabilidade permite a obtenção de uma ancoragem ortodôntica sem influências recíprocas negativas na posição dentária ${ }^{5,55}$.

O diagnóstico por imagem é um dos exames complementares mais utilizados para o monitoramento de todas as etapas da terapêutica com implantes. Dentre as várias modalidades disponíveis, as técnicas tomográficas tem um papel de destaque, especialmente por permitirem uma avaliação da espessura óssea vestíbulo-lingual ou vestíbulo-palatina, o que não é viável com técnicas radiográficas convencionais. Os sítios implantáveis precisam ser visualizados em um plano perpendicular ao plano curvo dos arcos dentários superior (maxila) ou inferior (mandíbula).

Neste contexto, a TC tem se sobressaído tanto para avaliação óssea quantitativa quanto para a qualitativa (densitometria óssea), especialmente em casos de maior complexidade, oferecendo ao cirurgião segurança para uma boa intervenção. É uma técnica capaz de fornecer essas informações sobre o osso cortical e trabecular de forma separada (Figs. 9, 10, 16), diferentemente das técnicas convencionais, em que a cortical externa pode mascarar a qualidade óssea de partes internas do osso.

Consensos de associações norte-americanas e européias de radiologia bucomaxilofacial e de osseointegração têm sido publicados, com o objetivo de nortear os critérios de indicação de exames por imagem em implantodontia, especialmente na etapa de planejamento ${ }^{19,65}$.
Apesar da tomografia convencional ser o método seccional recomendado para o planejamento em casos de implantes unitários ${ }^{65}$, a TC permite a utilização de softwares de reconstrução de imagens específicos para a maxila e mandíbula, os quais conferem informações mais precisas e maior segurança para o profissional (Fig. 9) ${ }^{17}$.

\section{Dentes impactados, reabsorção radicular e fra- turas dentárias}

Os primeiros estudos utilizando a TC aplicada especificamente aos tecidos dentários datam de 1990, visto que até então as atenções para o uso desta técnica no campo da Odontologia eram voltadas apenas para a ATM e implantodontia. A maioria desses estudos está relacionada a dentes impactados: seu posicionamento (especialmente a inclinação vestíbulo-lingual) e diagnóstico de reabsorções dos dentes adjacentes (Fig. 10) ${ }^{42}$.

Alguns autores evidenciam a superioridade da TC na detecção de reabsorções dentárias associadas a dentes impactados, quando essa técnica foi comparada à radiografia panorâmica ${ }^{23} \mathrm{e}$ à tomografia convencional ${ }^{29}$. A TC facilita o tratamento de caninos impactados, especialmente quando os dentes estão muito oblíquos no arco, reduzindo o tempo dedicado aos exames complementares, pois fornece informações precisas quanto à localização e posicionamento dos referidos dentes. E ainda, as reabsorções dos incisivos adjacentes, em particular aquelas localizadas nas superfícies vestibular e palatina, são mais bem visualizadas ${ }^{45}$. Alguns autores sugerem que a TC aumenta em $50 \%$ a detecção de reabsorções radiculares em incisivos adjacentes a caninos superiores com erupção ectópica. A presença de artefatos adjacentes à reabsorção radicular nas imagens tomográficas tem sido discutida ${ }^{8,9}$.

As reabsorções externas associadas à inflamação dos tecidos marginais determinam uma condição clínica de difícil diagnóstico. Estas lesões, freqüentemente, determinam erros de diagnóstico e são confundidas com cáries e reabsorções 

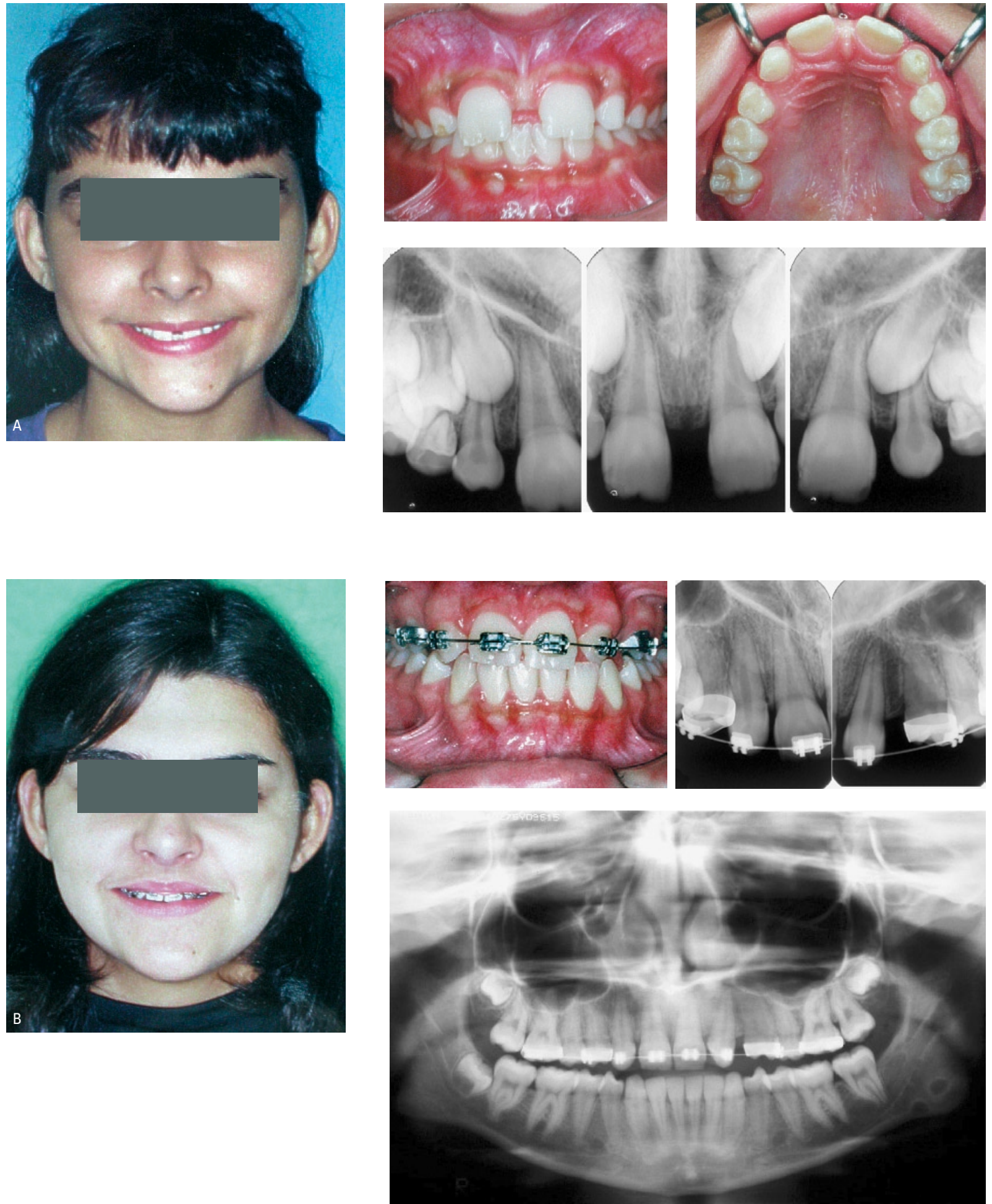

FIGURA 9 - Agenesia dos incisivos laterais superiores reabilitada com implantes. Aspectos clínico e radiográfico da paciente do gênero feminino aos 9 anos de idade (A) e aos dezoito anos, quando já estava em tratamento ortodôntico (B). As radiografias panorâmica e periapicais aos 21 anos de idade (C, D) mostram a obtenção do espaço e paralelismo entre os dentes 21 e 23, aspectos estes duvidosos do lado direito (C, D). Imagens tomográficas computadorizadas foram solicitadas (E, F, G, H, I, J) para melhor avaliação da região do 12.0 planejamento (E) e as reconstruções transversais $(\mathbf{F}, \mathbf{G}, \mathbf{H})$ utilizando o software DENTACT evidenciam a inclinação do processo alveolar, bem como detalhes do osso disponível no sentido vestíbulo-palatino da região do 11 (H) e 21 (G), este último já com o implante instalado. 

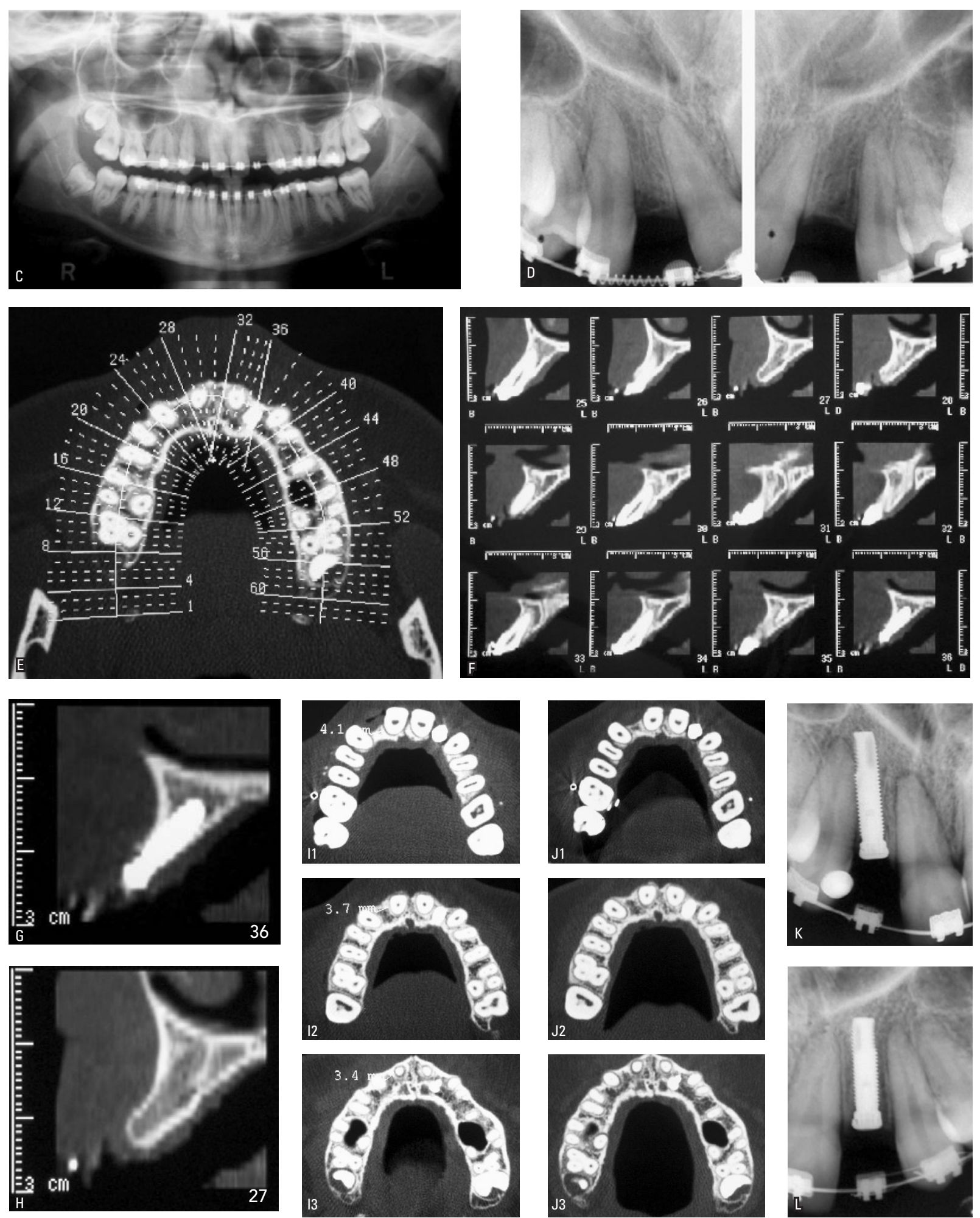

FIGURA 9 - (continuação) A análise das imagens axiais em janela para tecido ósseo (I, J) desde a mais coronal (I1) a mais apical (I3), permite a verificação da falta de paralelismo e insuficiência de espaço entre 011 e 13, especialmente na região apical (3,4mm). As imagens $\mathbf{J 1}$ a J3, após 6 meses de nova intervenção ortodôntica, mostram ganho médio de $1 \mathrm{~mm}$ em toda a extensão corono-apical da região do 12. As radiografias periapicais da paciente aos 22 anos de idade com os implantes instalados bilateralmente (K,L), num pós-operatório imediato (Créditos do caso clínico: Drs. Heraldo Gouveia de Alvarenga e Leandro Antônio de Oliveira). 

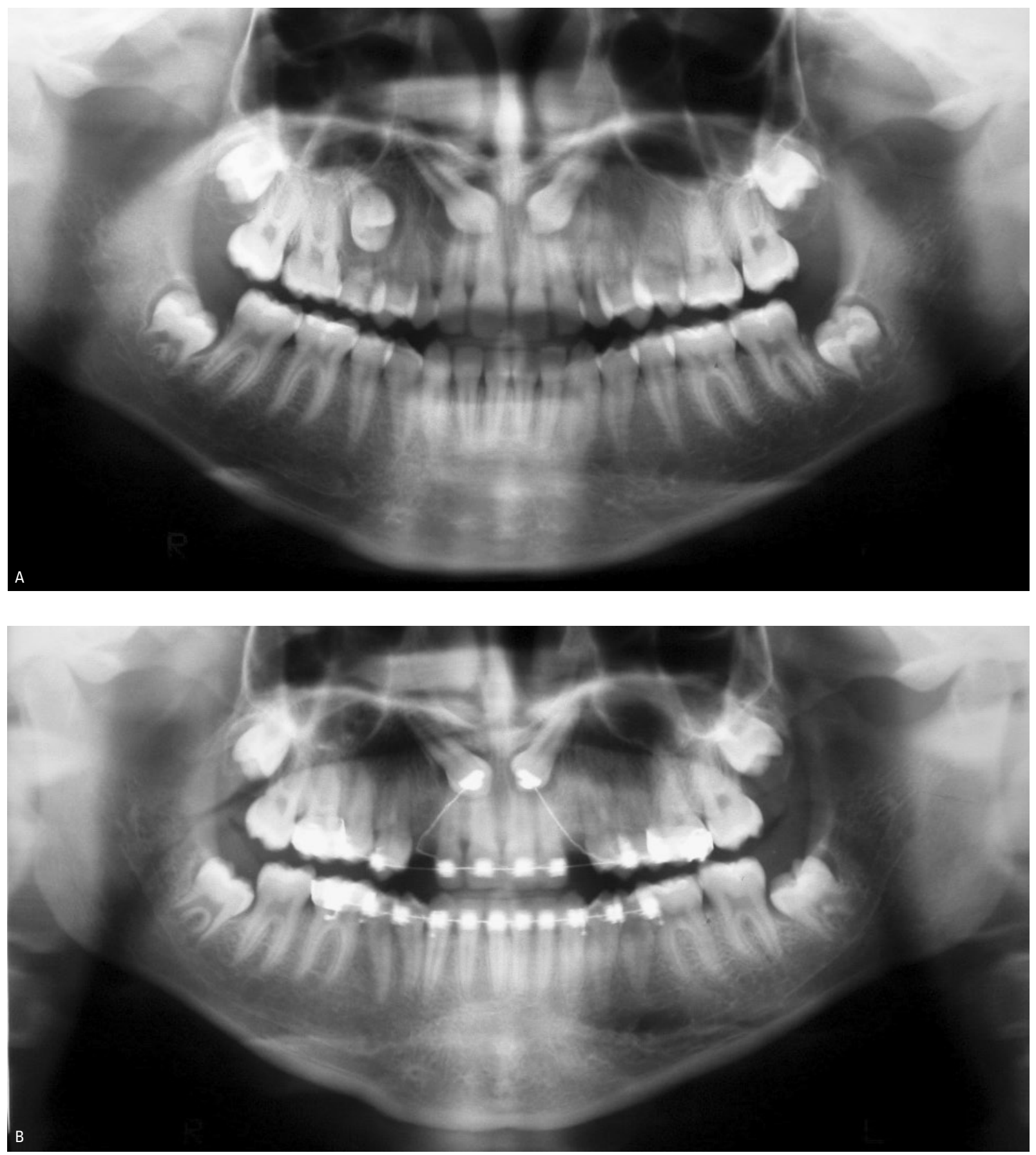

FIGURA 10 - Reabsorção radicular provocada por impacção dentária. Paciente do gênero feminino, leucoderma, 13 anos de idade, em que a radiografia panorâmica (A) mostra os caninos superiores inclusos e impactados nas raízes dos dentes anteriores. Após tentativa, sem sucesso, de tracionamento dos caninos, radiografia panorâmica e periapicais da paciente aos 14 anos (B,C), evidencia sinais de reabsorção radicular dos incisivos laterais e a dificuldade da obtenção de detalhes tridimensionais da relação dos dentes inclusos com incisivos, para um novo planejamento da terapêutica de tração. 

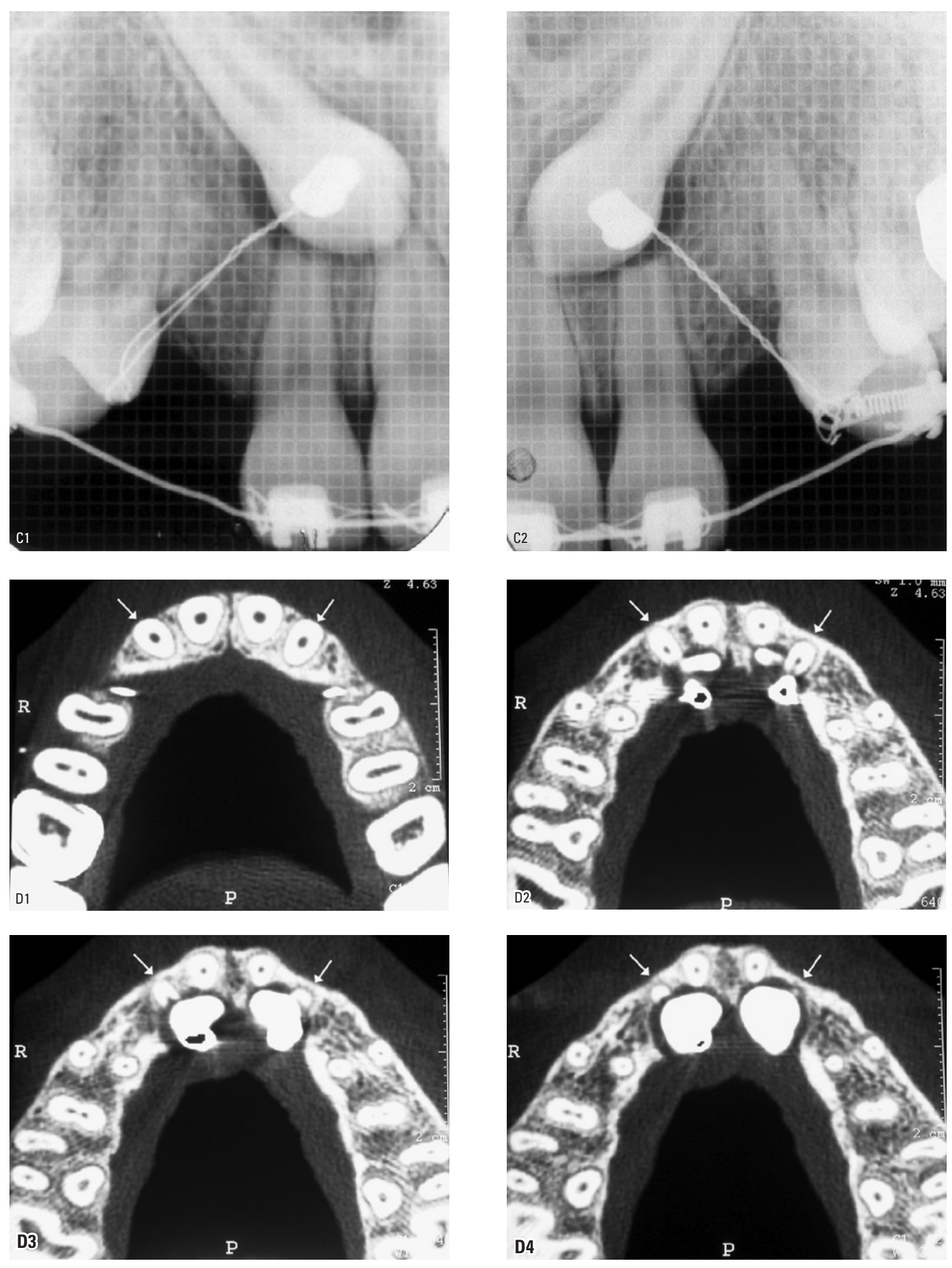

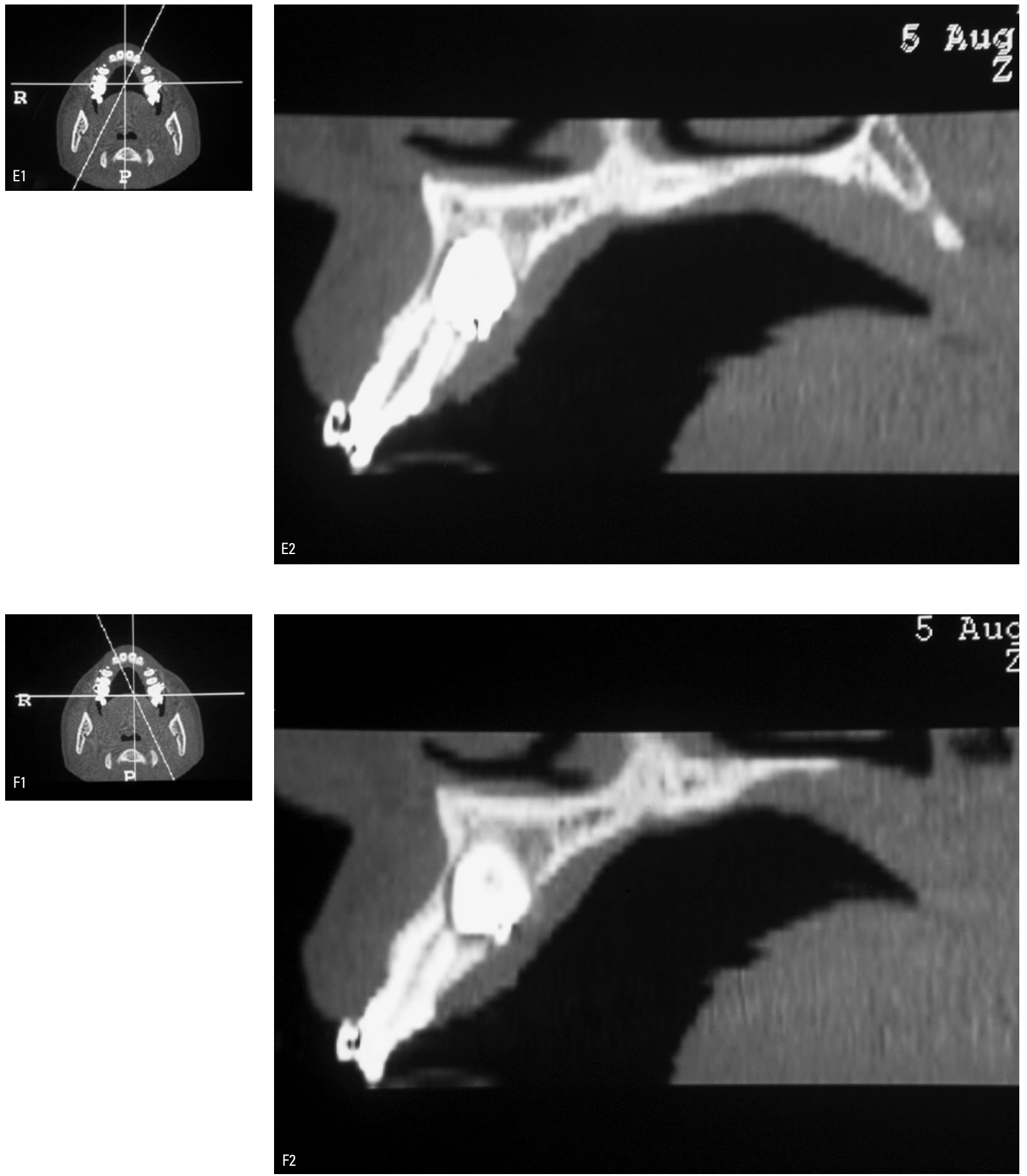

FIGURA 10 - (continuação) Após mudança de profissional e solicitação de tomografia computadorizada, imagens axiais em janela para osso no sentido corono- (D1) apical (D4) em relação aos incisivos, mostraram detalhes da reabsorção radicular por palatino dos dentes 12 e 22 (setas) e a integridade preservada do 11 e 21 . As reconstruções sagitais nas regiões do 22 (E) e 12 (F) permitem a visualização da inclinação dos caninos impactados em relação aos dentes irrompidos e ao processo alveolar. As forças ortodônticas foram redirecionadas e o caso está em proservação (Créditos do caso clínico: Dr. José Valladares Neto). 
internas. Como resultado, tratamentos inadequados são freqüentemente iniciados. A TC permite uma exata determinação da extensão da lesão pela diferenciação entre a reabsorção superficial (cemento/dentina) e a que se estende para a polpa (Figs. 11, 12, 13). A utilização da TC e de protótipos esteriolitográficos no diagnóstico da localização exata da área reabsorvida tem sido discutida $^{28}$. Entretanto, devido às suas doses de radiação, a TC deve ser reservada para os casos não esclarecidos pela radiologia convencional e/ ou aqueles em que os possiveis achados na TC podem mudar o plano de tratamento. Existe ainda, um número limitado de estudos na literatura radiológica que trata do diagnóstico das reabsorções radiculares externas, internas ou a combinação de ambas, utilizando a TC. A necessidade de maiores pesquisas para redução da dose de radiação e melhora do custo benefício dessa técnica para a esta finalidade é eminente.

As fraturas dentárias que não estão situadas paralelamente à incidência do feixe de raios $\mathrm{X}$ também são de difícil diagnóstico com técnicas convencionais. Enquanto as fraturas radiculares horizontais são tipicamente de origem traumática e de fácil diagnóstico, as fraturas radiculares verticais tendem a possuir uma origem iatrogênica e diagnóstico clínico complexo. As fraturas verticais podem ocorrer em dentes vitais como resultado de restaurações conservadoras (ex. com preenchimento de amálgama) ou naqueles tratados endodônticamente, como resultados de pressão excessiva durante a obturação do canal ou colocação de pino. Considerando-se que o tratamento para estas fraturas é a extração dentária, e que os seus sinais e sintomas podem simular outras condições dentárias que necessitam de terapêutica totalmente diferente, torna-se fundamental a identificação de uma técnica mais eficiente para o diagnóstico precoce das mesmas. A TC em cortes axiais é ideal para o diagnóstico das fraturas verticais, uma vez que o plano é perpendicular à linha de fratura (Fig. 13, 14, 15). Assim como nas reabsorções dentárias, existem poucos estudos, disponíveis na literatura, que investigam este tema. Um dos poucos pesquisadores que investigou o valor da TC na detecção de fraturas verticais, encontrou uma sensibilidade de $70 \%$ e uma especificidade de $100 \%$ do método. Os autores também enfatizam a questão da exposição à radiação ionizante e sugerem que a TC deve ser indicada apenas para os casos em que exista uma suspeita clínica significante, não esclarecida pelos métodos convencionais de imagem ${ }^{73}$.

\section{Avaliação de condições patológicas na maxila e mandíbula}

A região bucomaxilofacial, que se estende da base do crânio ao osso hióide, é uma das regiões anatômicas mais complexas do corpo humano. Ela contém estruturas e órgãos que pertencem a um número diferente de sistemas, os quais podem ser afetados por uma variedade de processos patológicos locais e sistêmicos.

Um número considerável delesões odontogênicasenão-odontogênicasqueacometem a regiãobucomaxilofacialpodeminiciar-sesemquesinaise/ou sintomas sejam percebidos pelo paciente. Assim, muitas delas podem ser detectadas em exames de rotina na clínica odontológica, em especial no consultório do ortodontista, por meio das documentações radiográficas. Neste contexto, a radiografia panorâmica tem um importante papel de triagem, inclusive para a indicação de outros métodos complementares de imagem como a TC e a RM.

A TC, além de identificar e delimitar a lesão, permite ao radiologista a possibilidade de reconstruções de imagens que auxiliam o cirurgião no plano de tratamento (Fig. 16). A capacidade desta técnica em detectar a imagem de estruturas de baixa densidade pode ajudar na determinação do conteúdo de lesões (ex. sangue X massa tecidual; cisto $\mathrm{X}$ tumor), antes da realização de qualquer procedimento invasivo, auxiliando inclusive no estabelecimento do melhor sítio para realização 


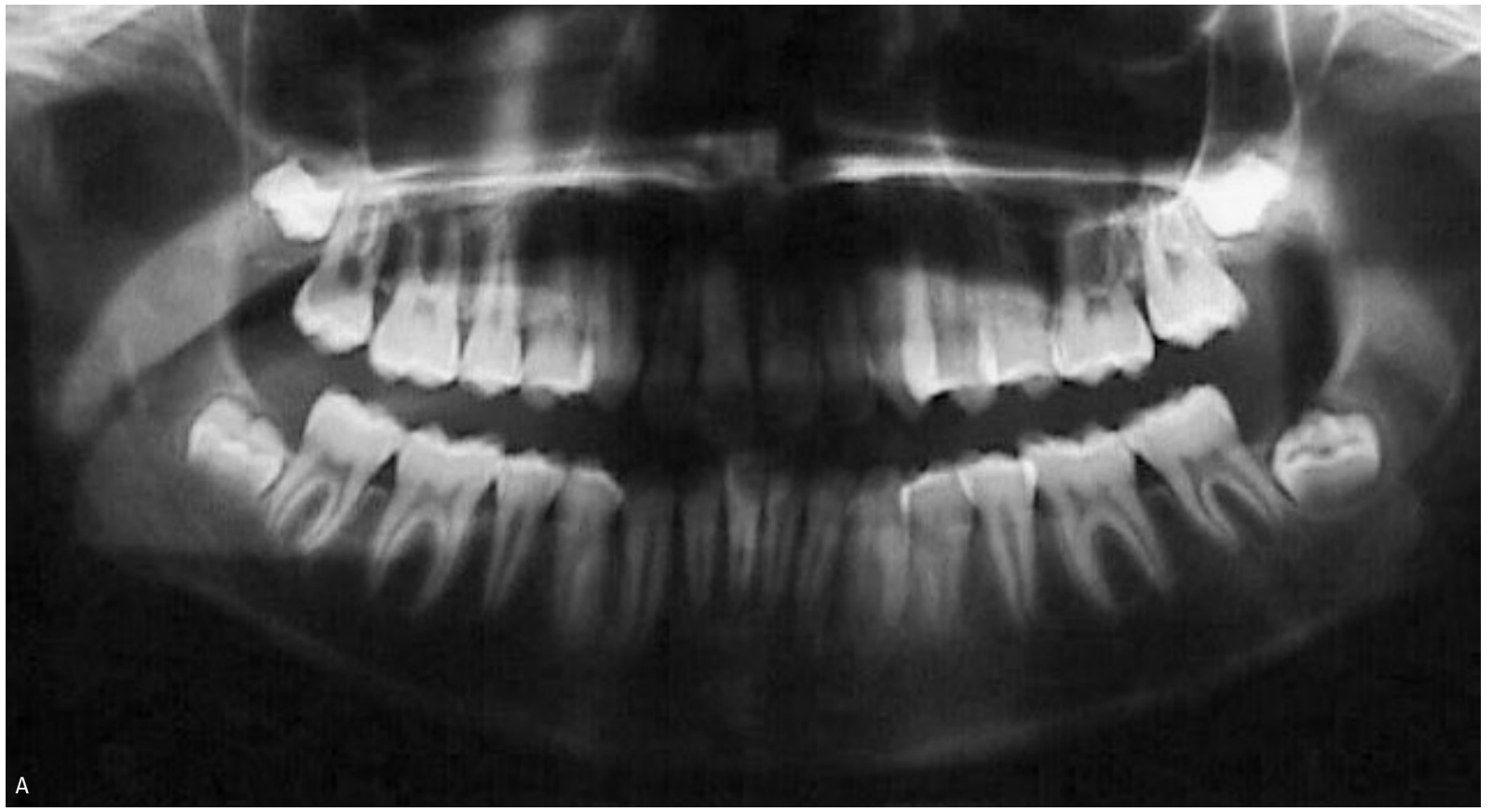

FIGURA 11 - Reabsorção externa mais extensa do que o sugerido pela radiografia periapical. Paciente do gênero feminino, leucoderma, 14 anos. Após insucesso na movimentação ortodôntica do 21, radiografia periapical (B) evidencia áreas radiotransparentes irregulares no terço cervical distal da raiz do referido dente. A radiografia panorâmica prévia ao tratamento (A), apesar da baixa qualidade da imagem, já apresentava suspeitas na região mencionada do 21, numa reavaliação. 0 tratamento foi interrompido e a paciente encaminhada à endodontista, que confirmou a vitalidade do dente e solicitou TC para detalhamento da extensão da reabsorção e da sua relação com o conduto radicular e espaço periodontal. Os cortes axiais em janela para osso (C1, C2, C3, C4) confirmaram tratar-se de reabsorção externa por substituição (C3) e as reconstruções panorâmicas, sem (D1) e com (D2) inversão da imagem, revelaram que a reabsorção não comprometia apenas o terço cervical da raiz, mas a região médio-cervical da mesma. Sendo assim, houve uma mudança no plano de tratamento que previa o tratamento endodôntico e tração ortodôntica do dente para expor e eliminar a área reabsorvida da raiz. Optou-se pela proservação, considerado os pontos de anquilose, além da reabsorção ser maior do que aquela mostrada nas radiografias convencionais. Em exame de reavaliação após 2 anos a condição mantinha-se estável, tendo a mesma sido acompanhada por técnica radiográfica por subtração digital. (Créditos do caso clínico: Dra. Maria Inês Pinheiro Costa e Dr. Ronaldo da Veiga Jardim)

da biópsia. A TC pode registrar soluções de continuidade das corticais ósseas ou a invasividade de lesões nos tecidos adjacentes (Figs. 6 e 17). E ainda, identificar o comprometimento de linfonodos regionais, importante no estadiamento de tumores malignos. O ajuste das janelas de contraste auxilia no delineamento da extensão da lesão (Figs. 6, 16, 17) ${ }^{41}$.

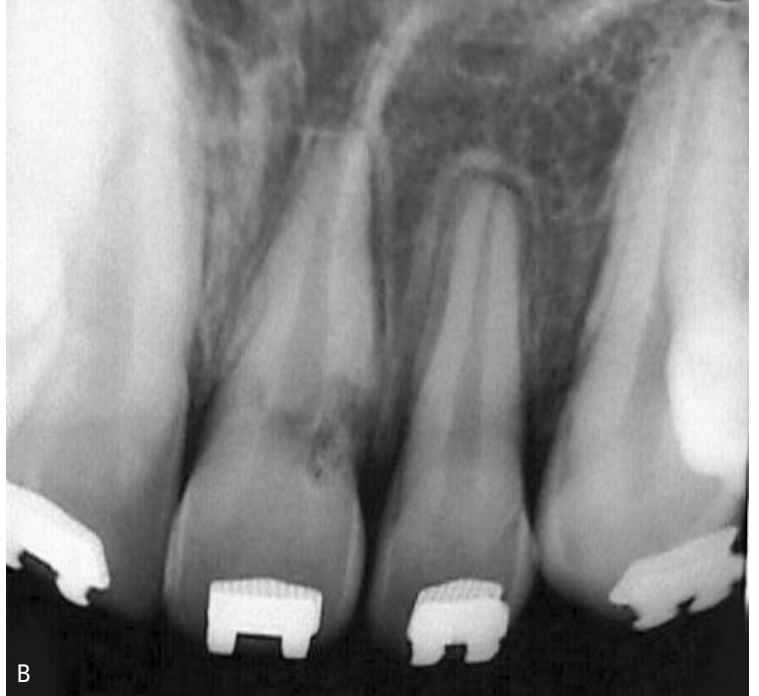

Ressonância Magnética

Aspectos técnicos básicos de aquisição das imagens

A obtenção de imagens por RM é determinada por um conjunto de princípios físicos totalmente diferentes daqueles que definem as técnicas radiográficas, como a radiologia convencional ou a TC. Ao contrário das imagens por raios X, que 

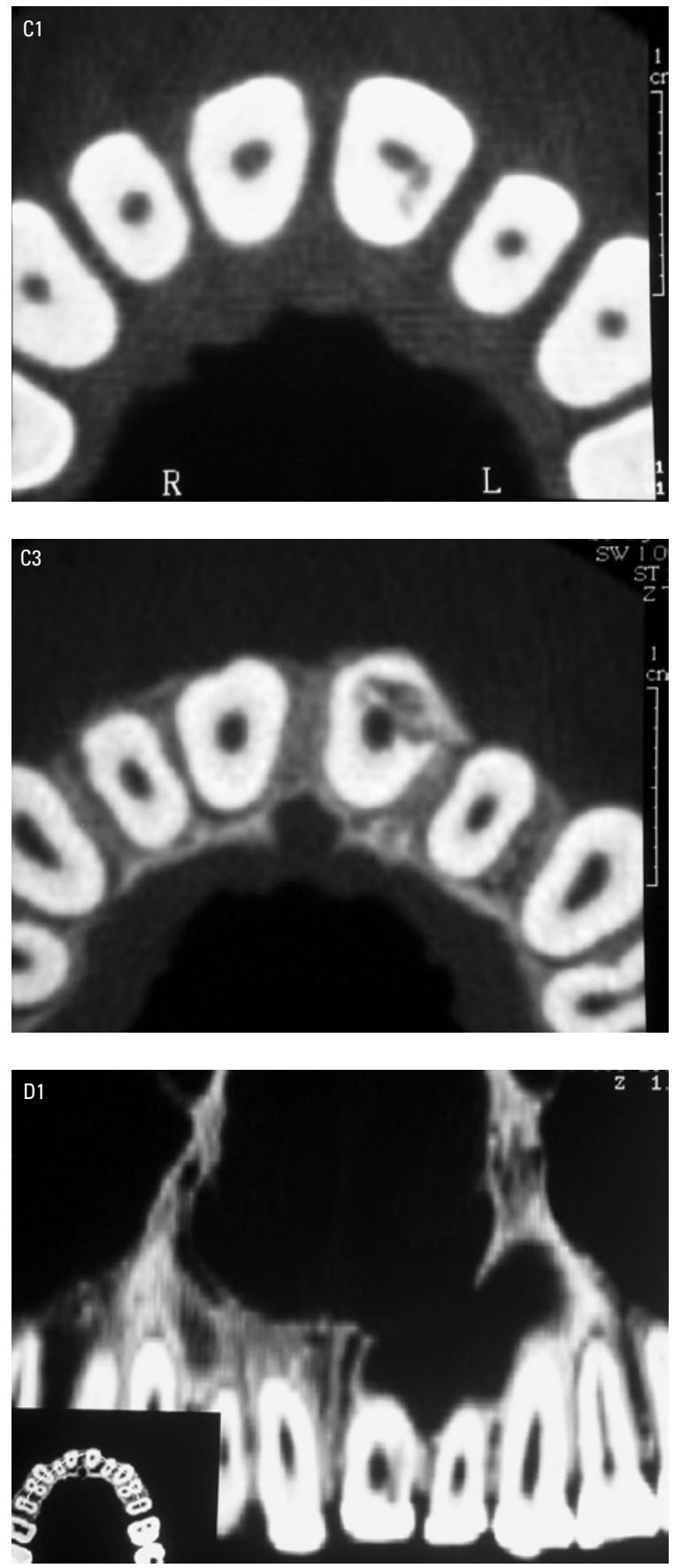

são produzidas através da atenuação dos fótons na eletrosfera dos átomos da matéria, o sinal de $\mathrm{RM}$ origina-se exclusivamente dos prótons existentes nos núcleos dos átomos ${ }^{47}$.

De forma simplista, a aquisição de imagens por RM poderia ser resumida em 5 etapas (Fig. 19):
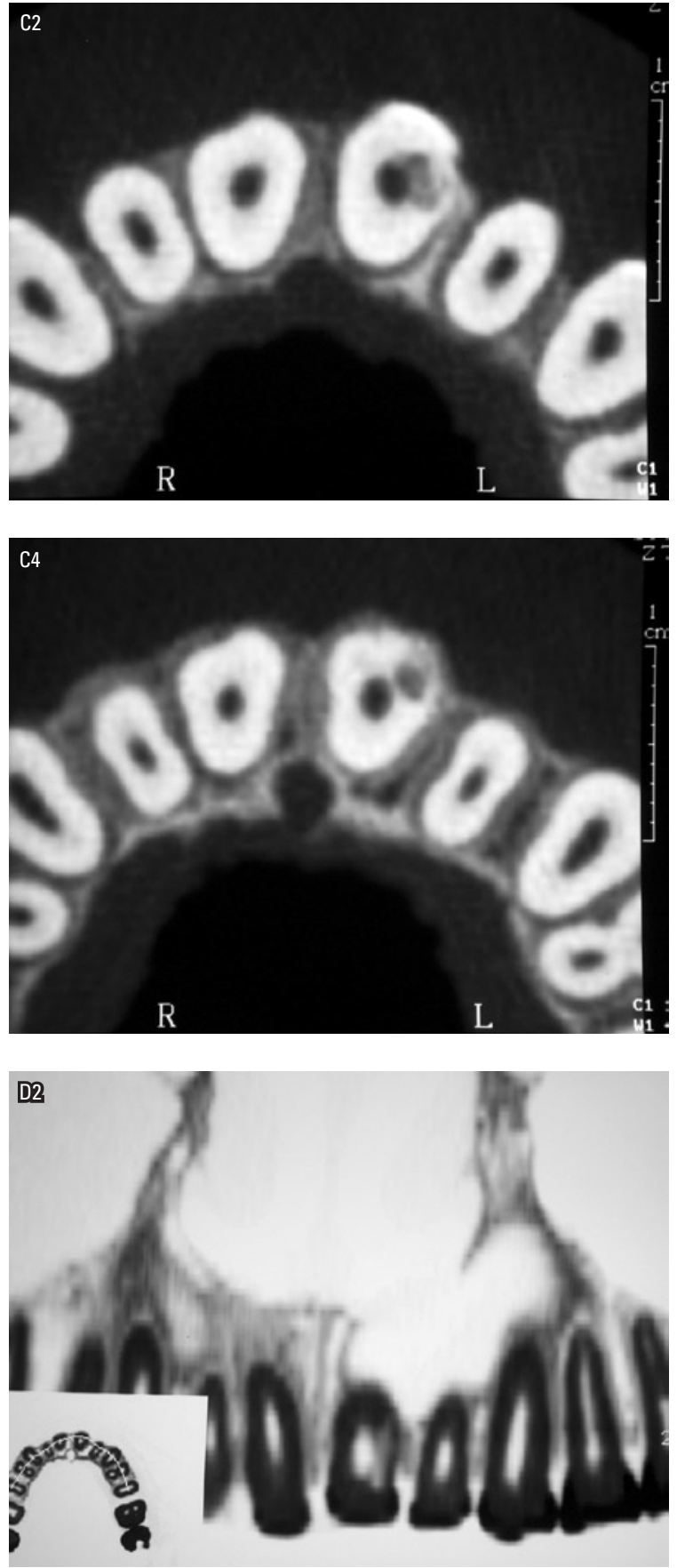

a) O paciente é colocado em um forte campo magnético (gantry), e essencialmente se torna um magneto. Isto porque, as partículas atômicas (prótons) de alguns elementos químicos que compõem os tecidos orgânicos (o mais abundante é o hidrogênio) têm a propriedade de gi- 

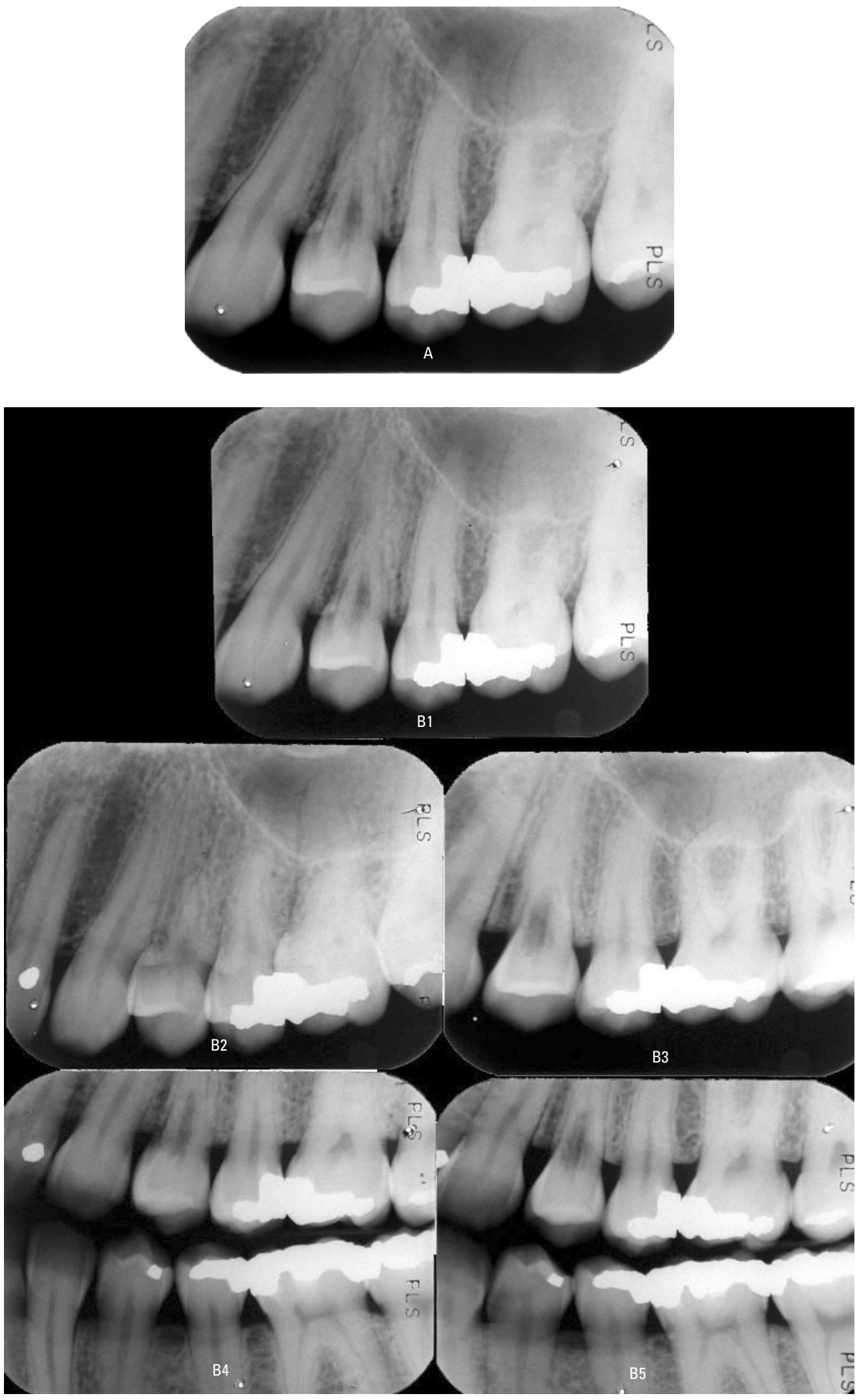

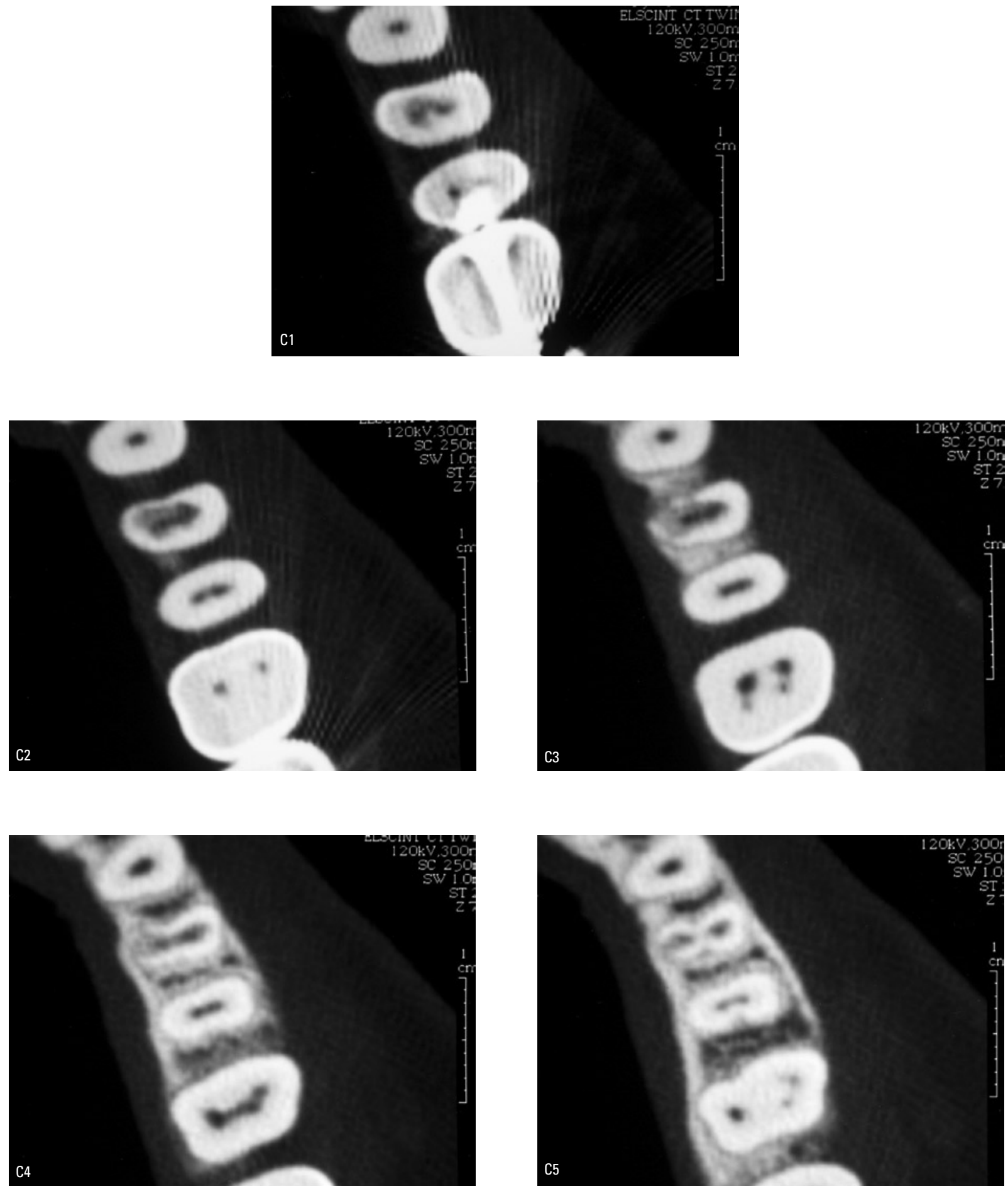

FIGURA 12 - Confirmação de reabsorção externa. Paciente do gênero feminino, leucoderma, 27 anos, encaminhada ao endodontista devido à suspeita de "perda de substância pulpar" do dente 24 (A), identificada durante exame odontológico de rotina. Paciente já havia sido submetida a tratamento ortodôntico para fechamento de diastema anterior. Técnicas radiográficas com diferentes angulações foram solicitadas (periapical ortogonal = B1; periapical distalizada = B2; periapical mesializada = B3; bitewing distalizada = B4; bitewing mesializada = B5), as quais não foram esclarecedoras quanto à possível reabsorção externa, apesar do exame por percussão ter sugerido anquilose dentária. A TC foi solicitada para o detalhamento da relação entre reabsorção, conduto radicular e ligamento periodontal. 0s cortes axiais em janela para osso, mostram de coronal (C1) para apical (C5) a reabsorção por substituição comprometendo a região mésio-palatina do 24 , na extensão do seu terço médio-cervical (D1, D2). 

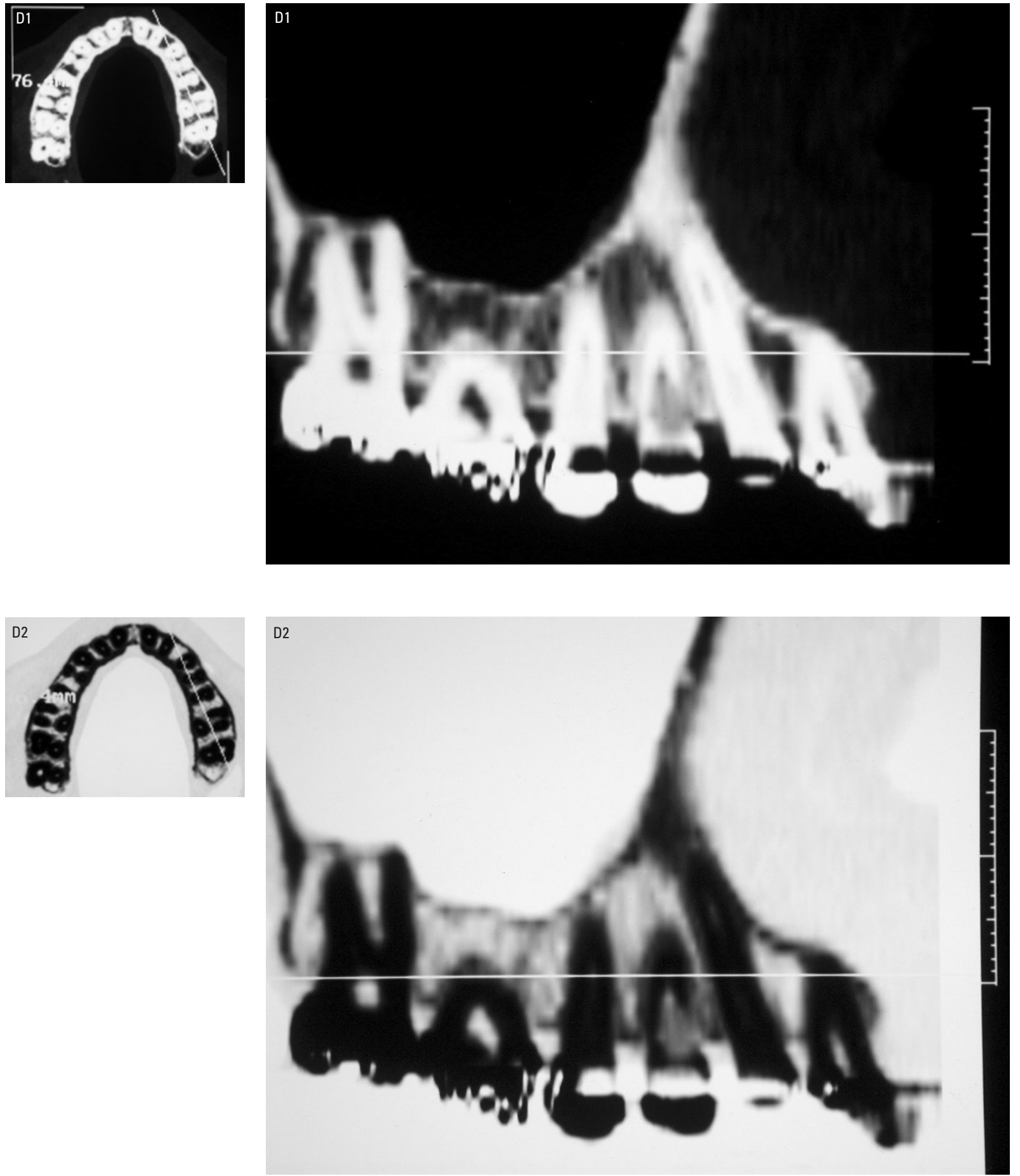

FIGURA 12 - (continuação) As reconstruções panorâmicas sem (D1) e com (D2) inversão de imagem evidenciam o detaIhamento da reabsorção. 0 tratamento endodôntico foi descartado e optou-se pela proservação (Créditos do caso clínico: Dr. Heraldo Gouveia de Alvarenga). 

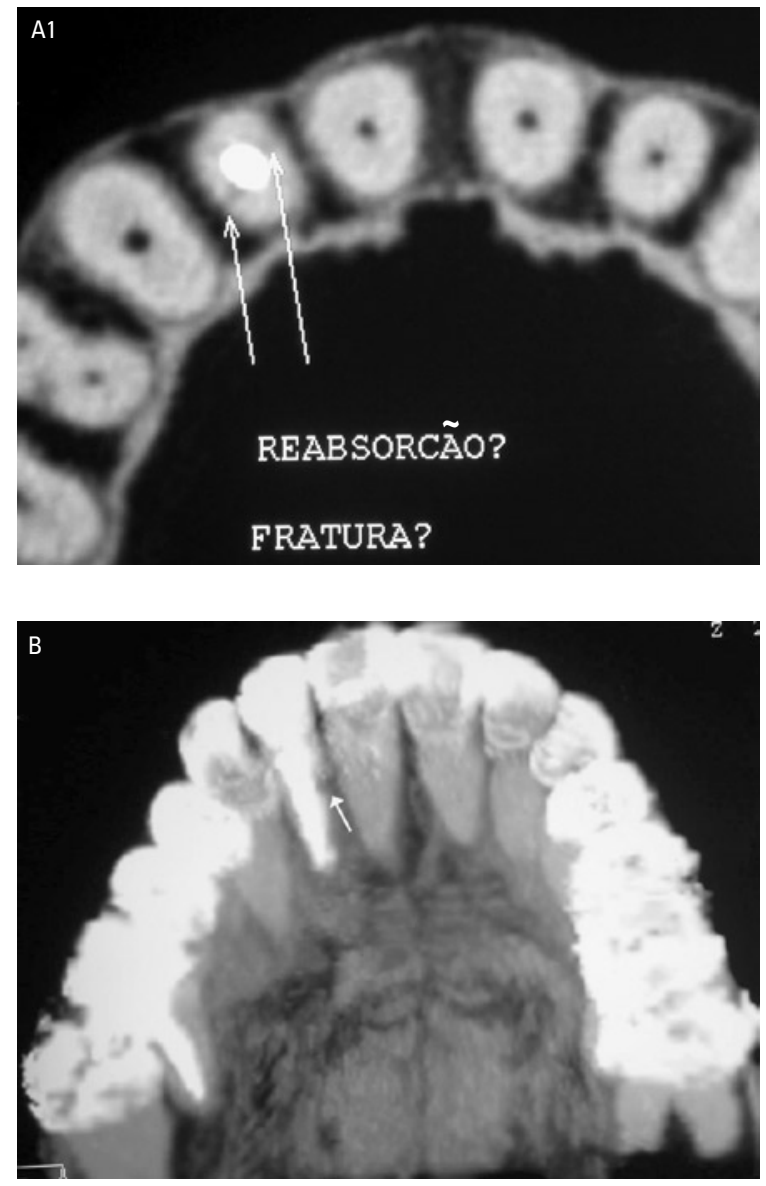

rar em torno do seu próprio eixo (spin), e por serem cargas elétricas em movimento (definição de corrente elétrica), geram um campo magnético ao seu redor, o qual pode ser alterado por um campo magnético externo; b) um sistema de bobinas, posicionadas em uma região anatômica de interesse, emite ondas de rádio freqüência; c) as ondas de rádio freqüência são desligadas; d) o paciente emite um sinal (sinal de RM), liberando a energia recebida de forma semelhante às ondas de rádio freqüência; e) o sinal é recebido pelo mesmo sistema de bobinas que emitiu as ondas de rádio freqüência, e é utilizado para a formação das imagens digitais nos diferentes planos anatômicos, que serão apresentadas no monitor do computador ${ }^{32}$.

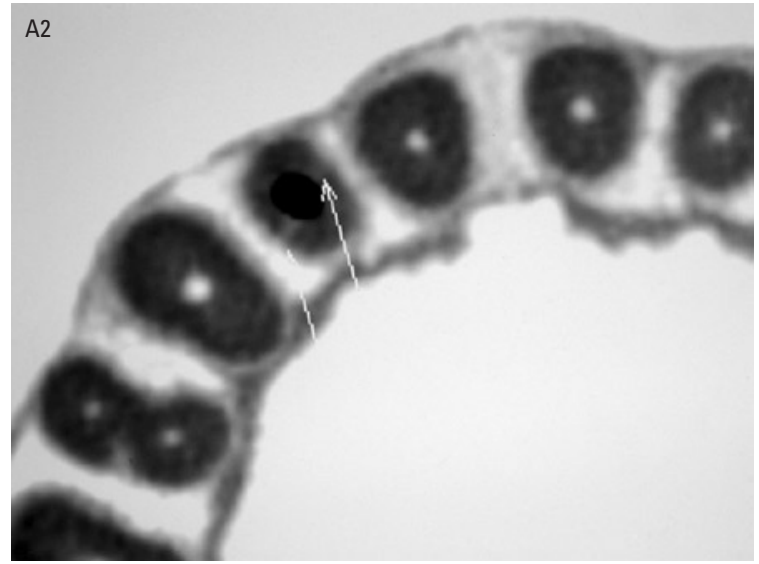

FIGURA 13 - Reabsorção/Fratura radicular. Paciente do gênero feminino, leucoderma, 45 anos de idade, que procurou a endodontista para retratamento endodôntico do dente 12 , visto que a obturação do canal não estava a contento e a paciente iria submeter o referido dente a um tratamento estético. $\mathrm{Na}$ análise minuciosa da radiografia periapical, a endodontista observou uma área radiotransparente discreta no terço médio radicular e solicitou a TC. As imagens axiais ampliadas sem (A1) e com inversão (A2) evidenciaram duas áreas lineares de baixa densidade nas paredes mesial e distal do terço médio radicular (setas). As características linear e de obliqüidade do comprometimento radicular somavam para o diagnóstico de uma fratura, entretanto a análise da reconstrução tridimensional (B - seta ) sugeria aspectos de reabsorção externa. Como plano de tratamento optou-se pela não realização do retratamento do conduto radicular e pela proservação. 0 tratamento estético foi realizado e num pós-operatório de 2 anos o caso permanece estável. (Créditos do caso clínico: Dra. Maria Inês Pinheiro Costa).

A imagem por RM representa a distribuição dos núcleos/prótons livres de hidrogênio de uma região específica do corpo, suas propriedades magnéticas e como esses prótons voltam ao equilíbrio, após terem sido excitados pelas ondas de rádio freqüência, sob um forte campo magnético. Dentre as razões pelas quais o próton de hidrogênio é escolhido para este mapeamento está o fato de ser ele o átomo mais abundante do corpo, que possui uma propriedade física específica - momento magnético dipolo. Esta propriedade faz com que esses átomos se assemelhem a pequenas barras magnéticas. Eles são especialmente abundantes na água e nos lipídeos ${ }^{32,47}$.

As alterações nos tons de cinzas da imagem por RM são descritas em termos de intensidade 

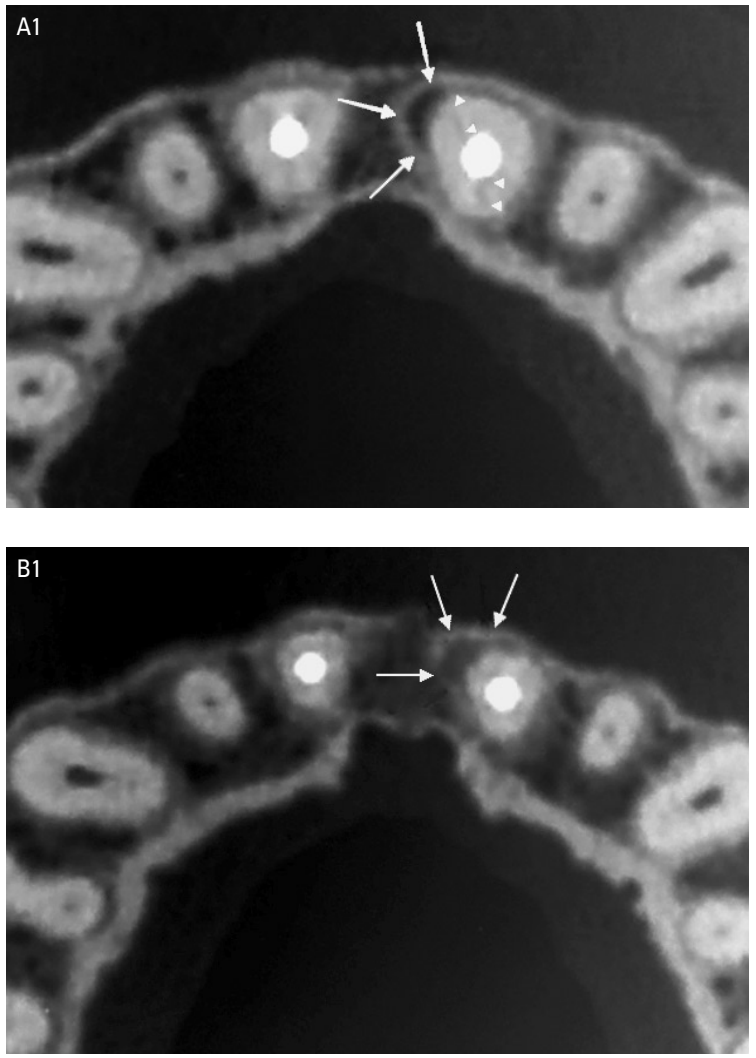
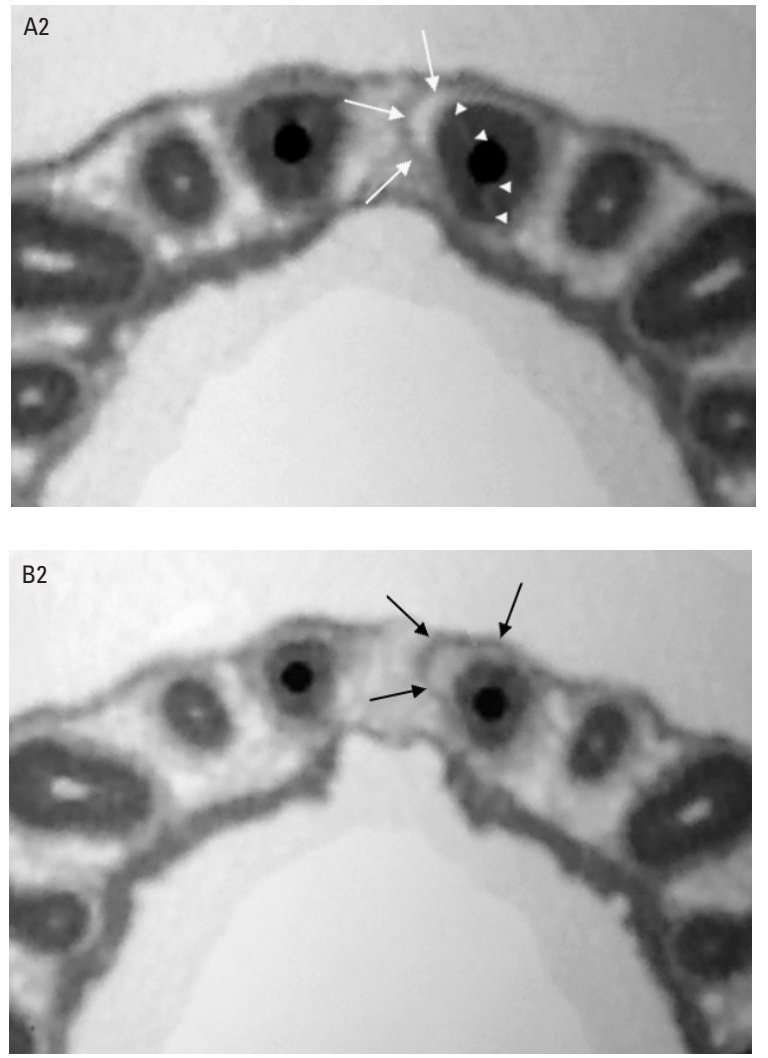

FIGURA 14 - Fratura radicular. Paciente do gênero feminino, leucoderma, 40 anos de idade, com história de trauma na região de incisivos centrais superiores, procurou a profissional para refazer coroas do 11 e 21 por questões estéticas. Após exame clínico minucioso, decidiu-se pela troca dos pinos pré-existentes por outros mais adequados. Durante a análise da radiografia periapical foi observado um discreto espessamento do espaço do ligamento periodontal no terço médio da parede mesial da raiz do 21, o qual poderia passar desapercebido por olhos menos experientes. A TC foi então solicitada. As imagens axiais ao nível do terço médio radicular sem (A1) e com inversão (A2) mostraram um traço de fratura que se estendia desde a parede mésio-vestibular até a parede palatina do referido dente (cabeças de setas). 0 espessamento do espaço do ligamento periodontal na região mésio-vestibular (setas), desde o terço médio (A1, A2) ao terço apical (B1 = sem inversão, B2 = com inversão da imagem), também foi observado. 0 retratamento endodôntico do 21 foi realizado, instalado um pino fibroresinoso e a coroa refeita. Em proservação após 6 meses do tratamento o caso apresentava-se sem evidências clínicas de alteração. (Créditos do caso clínico: Dra. Maria Inês Pinheiro Costa, Dra. Fernanda Maria de Castro).

de sinal. Tecidos que possuem um pequeno conteúdo de água e/ou gordura, aparecerão como áreas mais escuras ou hipointensas ou com baixa intensidade de sinal (ex. cortical óssea). Tecidos ricos em água e/ou gordura (ex. medula óssea) aparecerão com um sinal intenso ou hipersinal, ou seja, mais esbranquiçados ou brilhantes (Fig. 20) ${ }^{32,47}$.

A intensidade de sinal característica de cada tecido pode ser alterada por processos patológicos, e dependendo da natureza dessas alterações os tecidos moles podem ser mais bem visualizados nas imagens obtidas (ponderadas) em $\mathrm{Tl}$ ou
T2. T1 e T2 são os dois principais mecanismos envolvidos nas medidas de energia das imagens por RM, o que resulta da interação entre as características intrínsecas do tecido com os parâmetros técnicos estabelecidos pelo operador do equipamento ${ }^{32}$.

Nas imagens ponderadas em $\mathrm{Tl}$, as fontes mais comuns de hipersinal são: gordura, cristais de colesterol, secreções hiperprotéicas, melanina, hemorragia. Essas imagens documentam de forma acurada o realce das características de sinal de estruturas normais e patológicas, sendo uma 


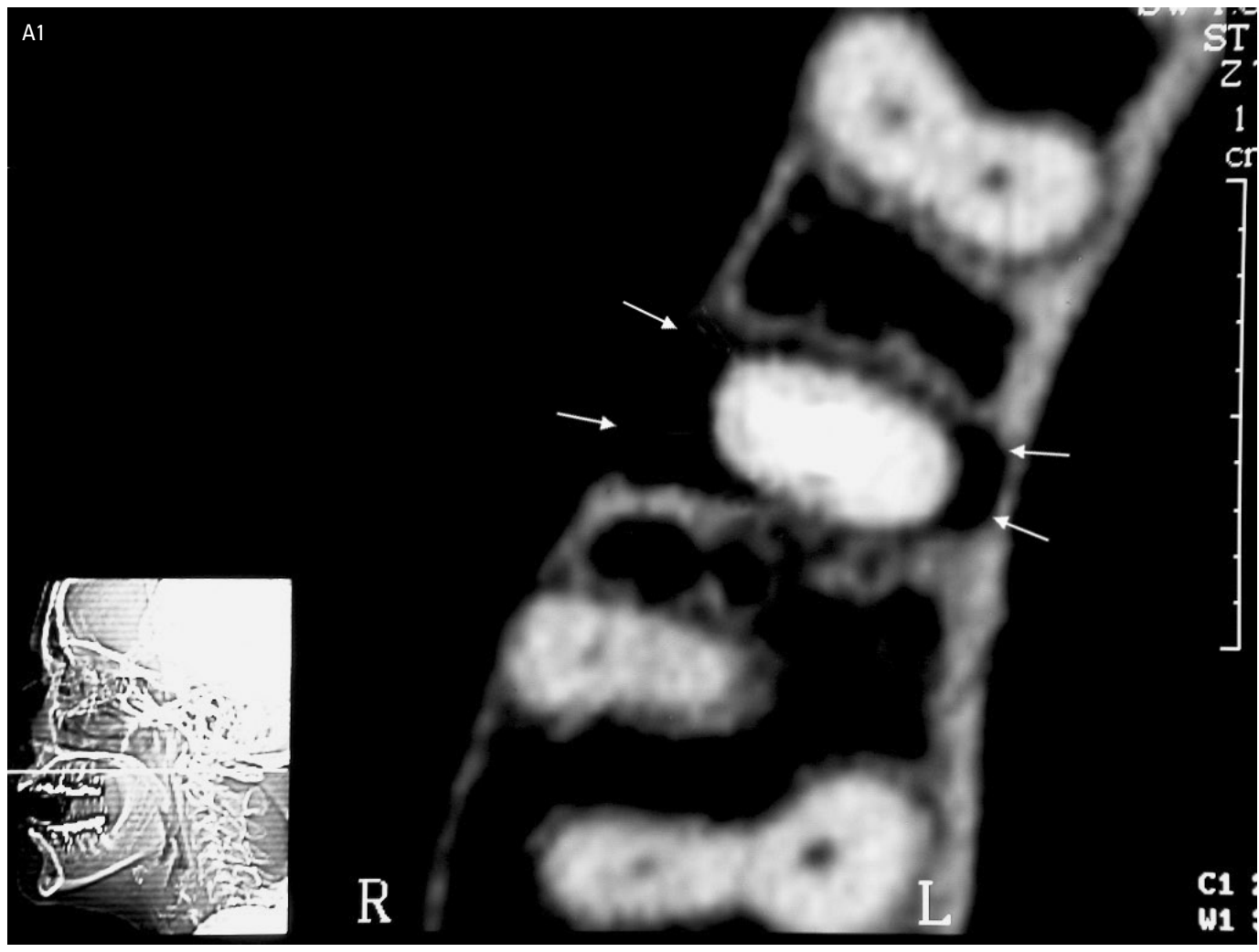

A2
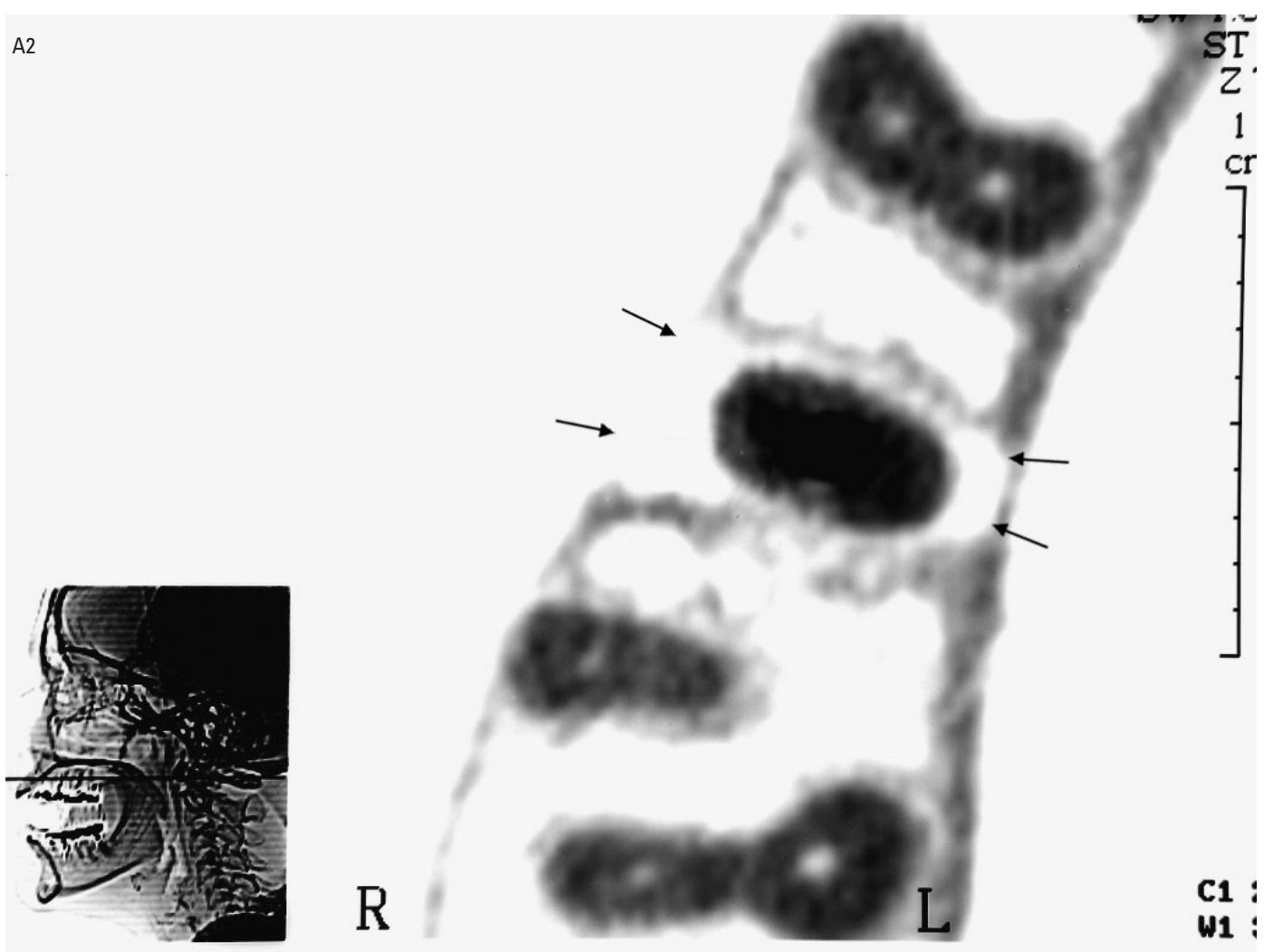

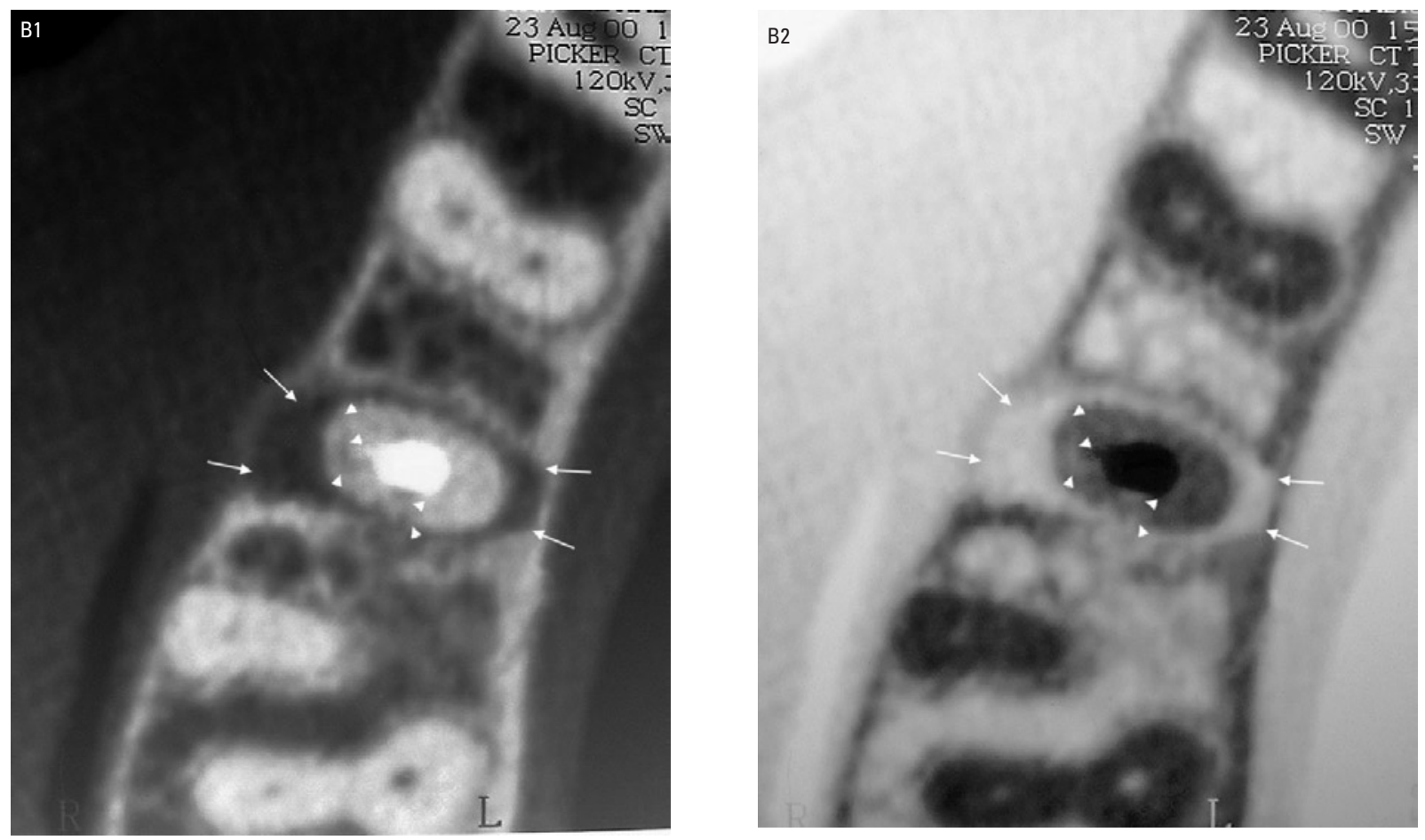

FIGURA 15 - Fratura radicular. Paciente do gênero feminino, leucoderma, 53 anos de idade, com um quadro de diabetes descompensado, foi encaminhada ao cirurgião-dentista para pesquisa de foco infeccioso de origem dentária. 0 exame radiográfico periapical evidenciou lesão periapical e uma trinca no dente 25 . 0 tratamento endodôntico foi realizado e o provisório instalado. Na proservação de seis meses observou-se que a lesão periapical havia regredido e a coroa definitiva foi confeccionada. Dois anos após a instalação da coroa a paciente apresentou um edema na região vestibular do 25 , próximo à coroa, observado clinicamente pela cirurgiã-dentista, determinando a suspeita de que a trinca inicialmente detectada poderia ter se aberto em uma fratura. A TC foi solicitada e a fratura da parede vestíbulo-distal (cabeças de setas), associada a um aumento do espaço do ligamento periodontal (setas) pode ser identificado desde o terço médio (A1 = sem inversão, A2 = com inversão da imagem) até o terço apical (B1 = sem inversão, B2 = com inversão da imagem) (Créditos do caso clínico: Dra. Maria Inês Pinheiro Costa, Dra. Elaine Gomes Andrade Rosa, Dr. Alfeu da Veiga Jardim Filho).

etapa essencial na formulação de um bom diagnóstico diferencial por este método (Figs. 18, 20, $21,23,24,25,26,27,30)^{72}$

Em T2, as fontes mais comuns de hipersinal são: fluidos corpóreos (ex. humor vítreo, edema); conteúdo cístico, adenoma pleomórfico, pólipos, linfonodos, hemangiomas. Pelo fato da maioria dos processos patológicos resultarem em um aumento da quantidade de água livre, as imagens em T2 são mais comumente usadas para detectar lesões (Figs. 18, 28, 29, 30) ) $^{72}$.

\section{Vantagens e desvantagens}

A imagem por RM é superior à TC na diferenciação dos tecidos moles e por fornecer não apenas informações anatômicas, mas também fisiológicas (Figs. 18, 26, 28, 29, 30). Imagens de qualquer plano anatômico podem ser obtidas sem o reposicionamento do paciente, sem a utilização de radiação ionizante. É a única modalidade de imagem que permite a detecção precoce de alterações da medular (Fig. 21), devido ao hipersinal da referida estrutura. Além disso, permite a aquisição de imagens arteriográficas sem a necessidade de injeção de meio de contraste ${ }^{69}$. A espectroscopia por RM permite a visualização anatômica do tecidos e também a quantificação de substâncias que os caracterizam ${ }^{57,58}$.

As duas principais desvantagens da RM estão relacionadas à técnica e a interpretação das mesmas. A primeira refere-se aos artefatos associados aos metais (ex. aparelho ortodôntico) (Fig. 22), os quais promovem um desvio do campo magnético ou aqueles causados pelo movimento do 

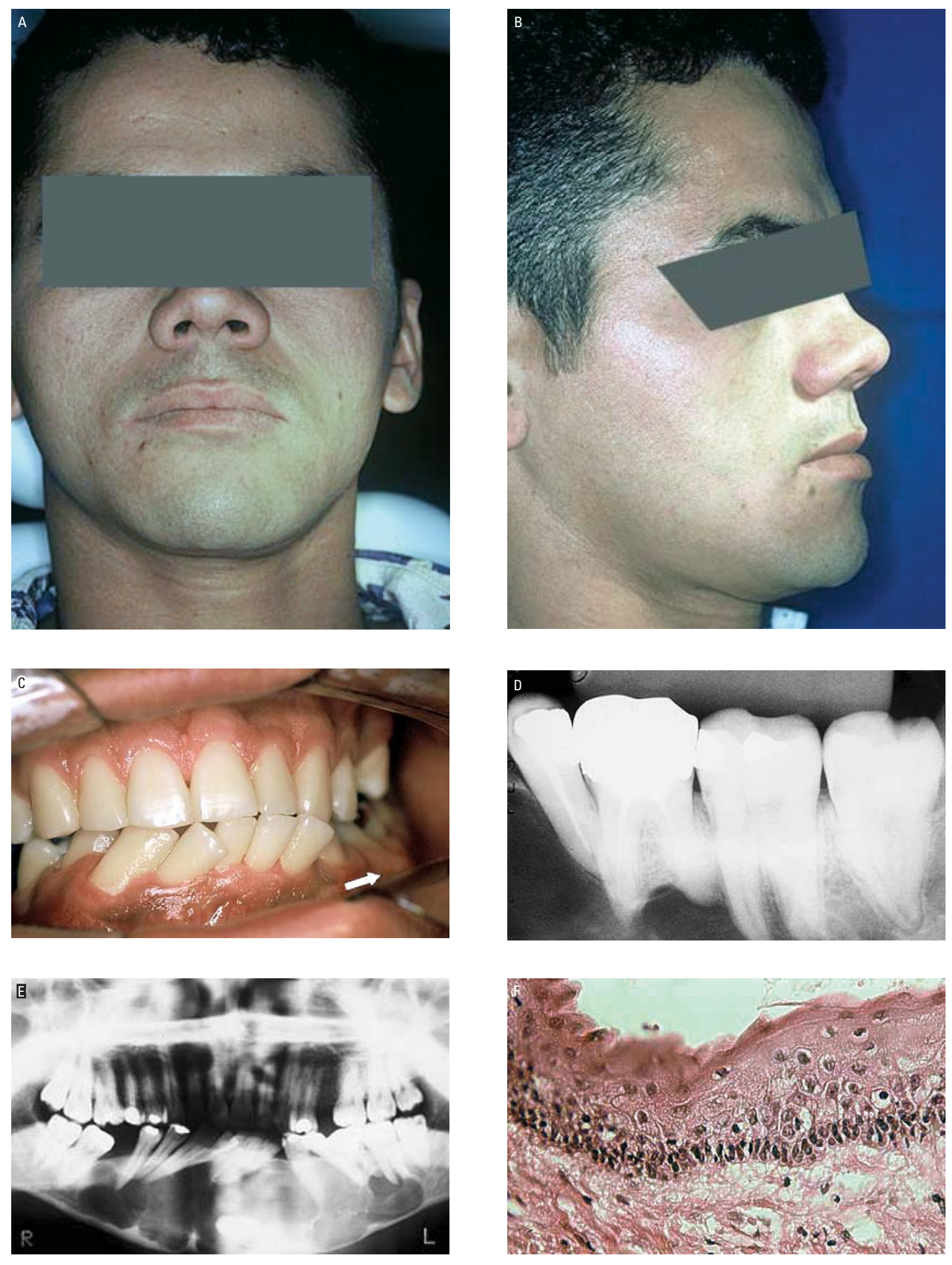

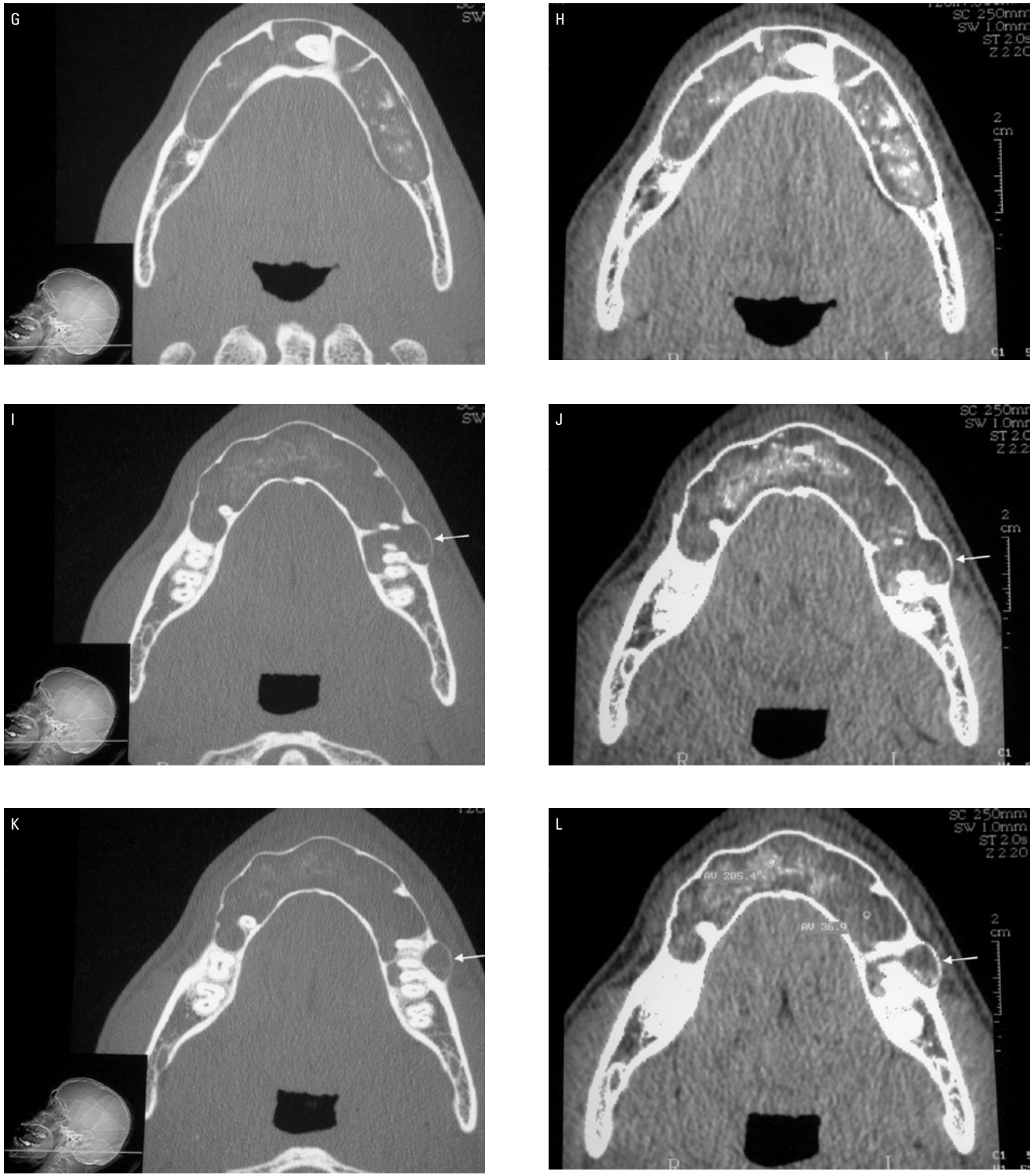

FIGURA 16 - Queratocisto odontogênico. Paciente gênero masculino, leucoderma, 23 anos, com queixa de dentes tortos (A, B, C) procurou um cirurgião-dentista para tratamento ortodôntico. Durante exame clínico intrabucal foi observado aumento de volume na região vestibular do 36 , 0 que motivou o encaminhamento do mesmo para a FO/UFG. A hipótese diagnóstica do profissional foi de lesão periapical com evolução de aproximadamente 3 meses. 0 paciente estava assintomático, e trazia radiografia periapical da região do 36 (D), juntamente com solicitação de tratamento endodôntico do mesmo dente. A história pregressa não registrava nada digno de nota. Ao exame físico extrabucal não havia assimetria facial (A, B). Ao exame intrabucal constatou-se abaulamento vestibular na região do 36 (seta em C), medindo $\pm 2 \mathrm{~cm}$ no seu maior diâmetro recoberto por mucosa de aspectos normais, com apagamento do fundo de vestíbulo, sendo consistente à palpação e com drenagem sulcular de líquido amarelado. Por meio da radiografia panorâmica maxilo-mandibular (E) observou-se extensa lesão radiotransparente multilocular, com pequenas áreas radiopacas dispersas, estendendo-se da mesial do 47 à distal do 37. Uma loja com radiotransparência mais acentuada sugeria lesão periapical relacionada ao 35 e/ou 36, cujos condutos radiculares apresentavam tratamento endodôntico deficiente. Presença de canino incluso em íntima relação com a basilar na região anterior da mandíbula. Paciente foi submetido à punção aspirativa, 

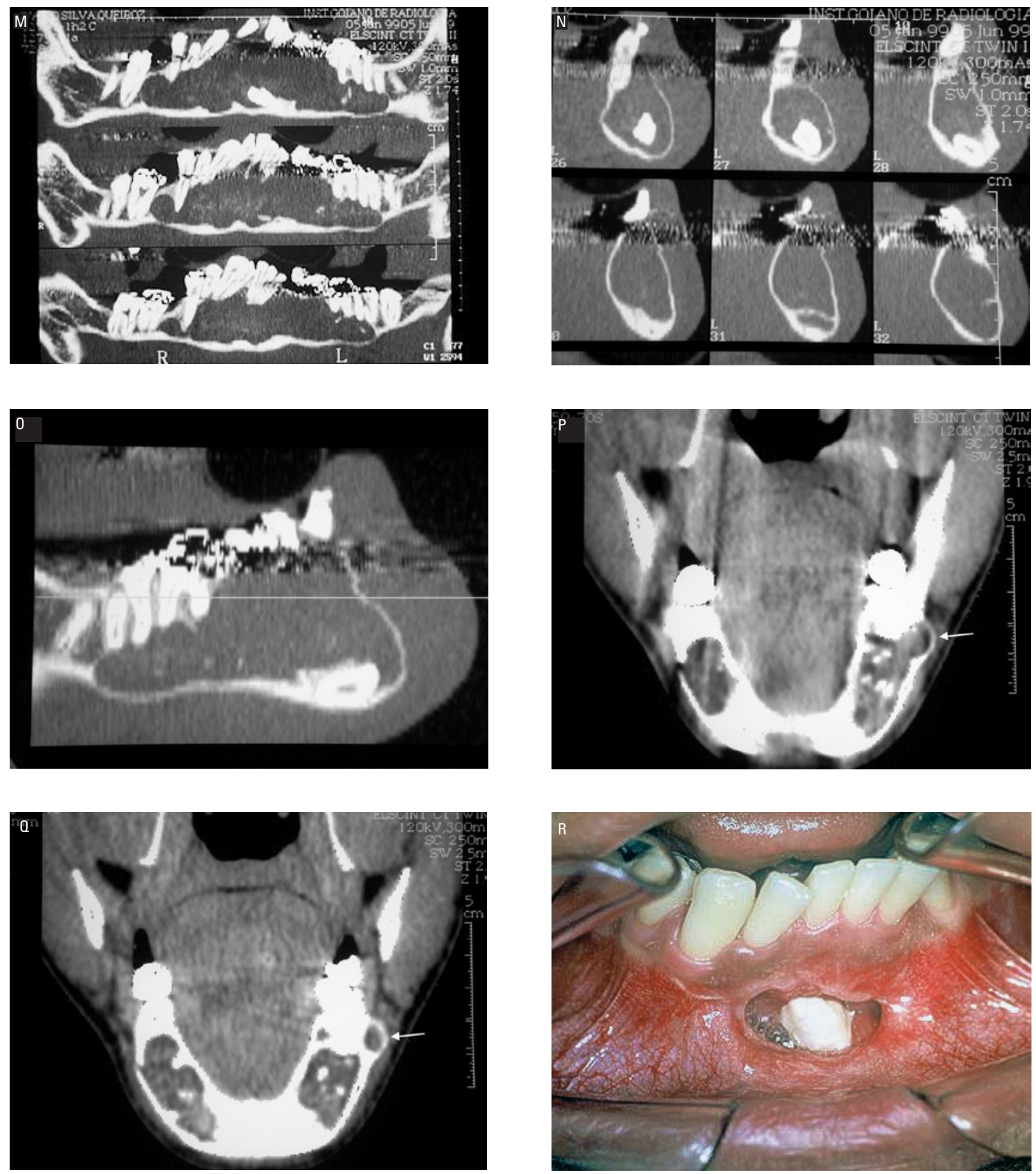

a qual foi negativa para líquido. No orifício da punção observou-se extravasamento de pequena quantidade de secreção serosa. 0 material foi insuficiente para citologia. 0 material colhido através de biópsia incisional teve sua análise anátomo-patológica descrita como uma lesão com cavidade cística, revestida por epitélio estratificado pavimentoso paraqueratinizado, com 5 a 8 camadas de células, estando as células da camada basal dispostas em paliçada e com núcleos hipercromáticos (F). Subjacente, na cápsula conjuntiva fibrosa, observou-se intenso infiltrado inflamatório mononuclear e na cavidade cística, grande quantidade de queratina e células inflamatórias, compatível com queratocisto odontogênico. A TC confirmou a densidade heterogênea da lesão, o que pode ser melhor visualizado comparando-se os cortes axiais em janela para osso (G, I, K) com aqueles em janela para partes moles (H, J, L). 0 deslocamento dos dentes sem reabsorção radicular ( $\mathbf{M}$ - reconstruções panorâmicas), o deslocamento inferior do canal mandibular e a relação do canino incluso com a base da mandíbular ( $\mathbf{N}$ - reconstruções tranversais e $\mathbf{0}$ - sagital), bem como a expansão acentuada da cortical vestibular na região periapical do 36 em comunicação com a lesão maior (I, J, K, L- setas e P, $\mathbf{Q}$ - reconstruções coronais em janela para partes moles - setas) foram observados no exame tomográfico. 0 tratamento de escolha foi a marsupialização. 

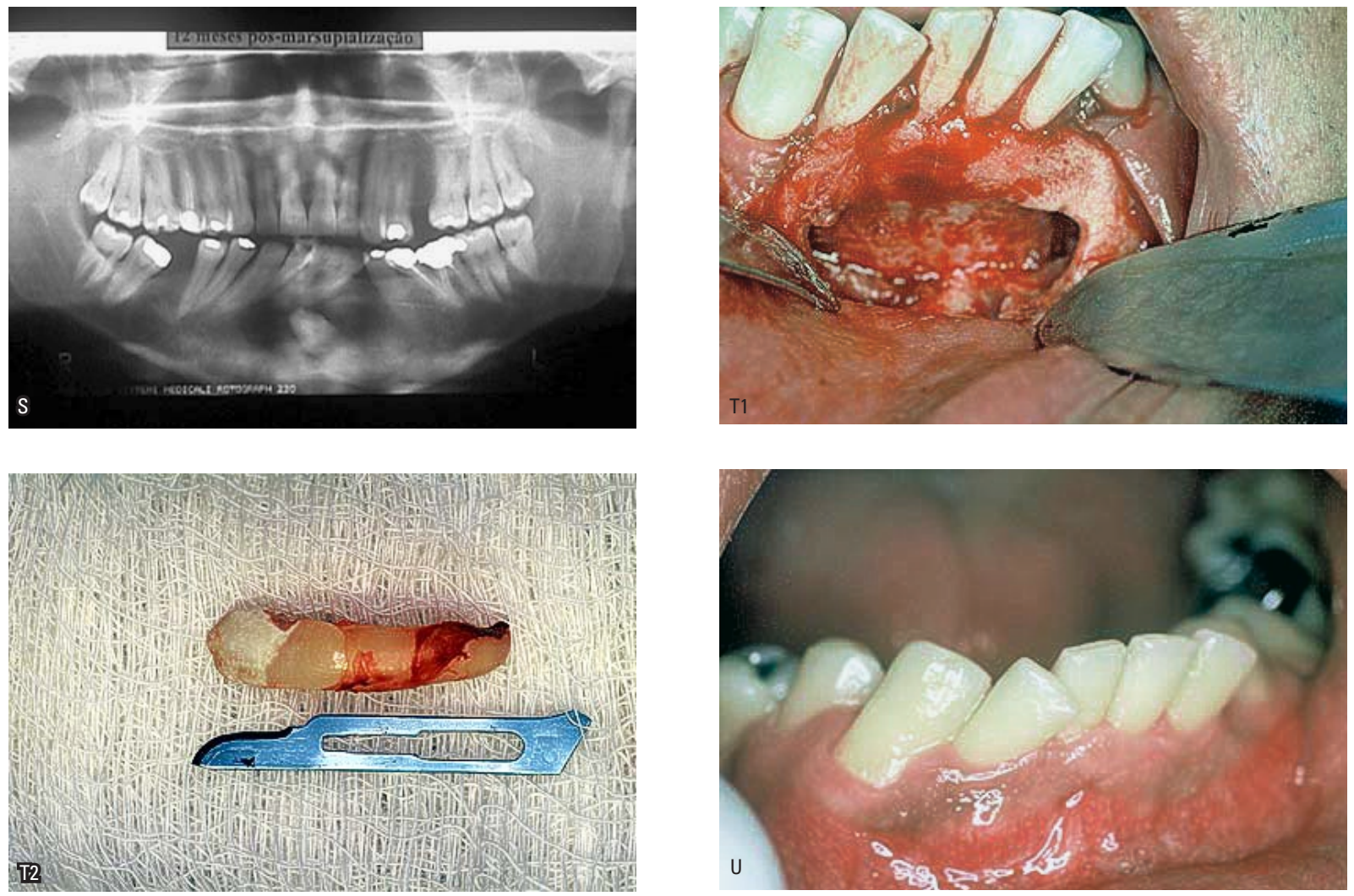

FIGURA 16 - (continuação) Após 12 meses de acompanhamento clínico e radiográfico, com evidência de extensa neoformação óssea, mudança de posição do dente incluso (S), o qual podia ser visualizado através da região marsupializada (R), foi realizada a cirurgia para enucleação da lesão remanescente e remoção do dente incluso (T). Aspecto clínico do pós-operatório de 3 meses (U). Paciente continua em proservação, especialmente devido ao comportamento altamente recidivante dessa lesão (Créditos do caso clínico: Equipe do Centro Goiano de Doenças da Boca da F0/UFG).

fluxo sanguíneo do paciente, especialmente nas longas seqüências de exame. A segunda é devido ao baixo sinal das corticais ósseas (Fig. 21, 24 a 30) que reduz a capacidade deste método, se comparado à TC, para a identificação de sítios de destruição óssea precoce ${ }^{69}$.

Apesar de não haver risco biológico conhecido associado à RM, este exame possui duas principais contra-indicações absolutas: para pacientes que possuam implantes de ativação elétrica, magnética ou mecânica, como os marcapassos cardíacos e para aqueles com dispositivos ou implantes metálicos ferromagnetizáveis (que possam ser movimentados/deslocados pela ação do campo magnético) localizados em áreas nobres (ex. clips metálicos de aneurismas cerebrais).

Considerando o importante instrumento de diagnóstico que hoje as imagens por RM representam, torna-se importante o conhecimento da influência do forte campo magnético sobre as restaurações e dispositivos metálicos, e os materiais de implantodontia utilizados em Odontologia, bem como destes materiais no resultado final da imagem. Apesar das propriedades ferromagnéticas desses materiais raramente serem descritas pelos fabricantes, o profissional que solicita um exame por RM deve conhecê-las. Ele deve saber também, o tamanho, forma e localização do objeto metálico implantado ou que o paciente está usando. Alguns estudos, ainda escassos, têm testado diferentes tipos de metais odontológicos, utilizando análises variadas. Das conclusões desses estudos destacam-se:

- Os materiais metálicos mais comumente 

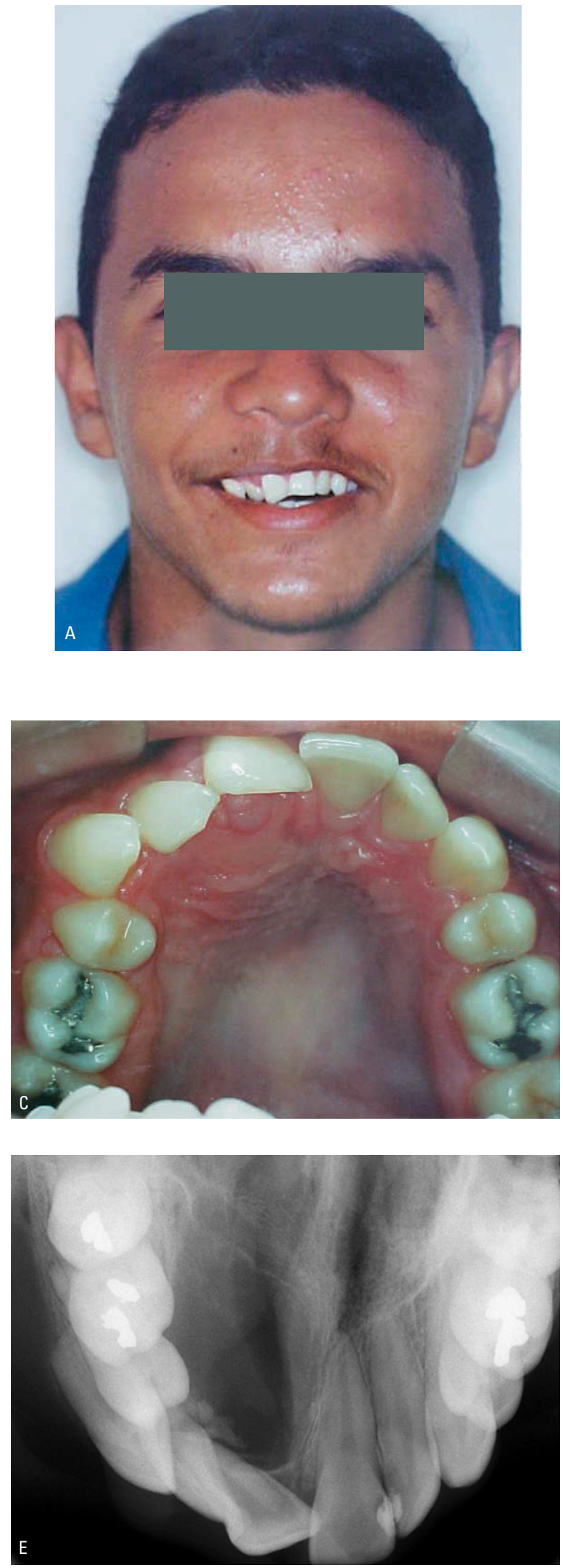

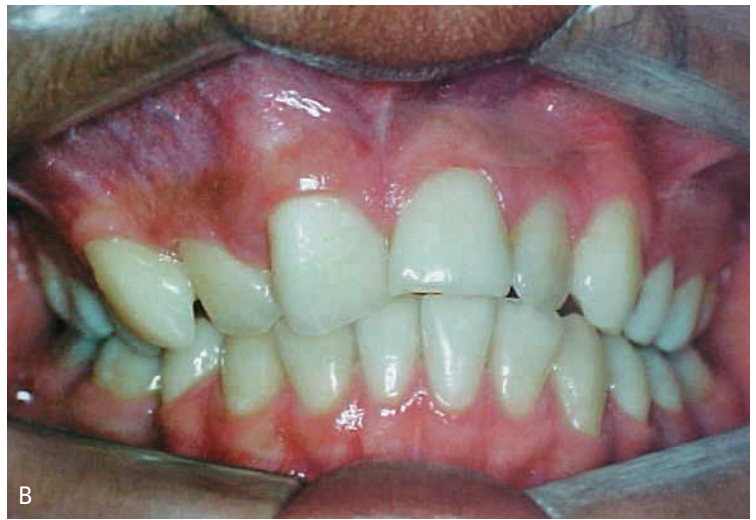

FIGURA 17 - Cisto odontogênico calcificante tipo formador de odontoma. Paciente do gênero masculino, leucoderma, 16 anos de idade, apresentou aumento de volume no terço médio da face à direita $(\mathbf{A})$, assintomático, identificado ao acaso pelo ortodontista, o qual o encaminhou ao cirurgião bucomaxilofacial. 0 tempo de evolução era impreciso ( $\pm 1,5$ anos) e não havia história de trauma. Não havia nada digno de nota na história médico-odontológica, nem na história familiar. Ao exame físico intrabucal apresentava apinhamento dentário, apagamento do fundo de vestíbulo na região anterior superior direita, bem como aumento de volume na região de rafe palatina ipsilateral (B, C). Ao exame radiográfico convencional (D, E, F, G) observou-se lesão óssea radiotransparente estendendo-se desde o dente 11 ao 17, com
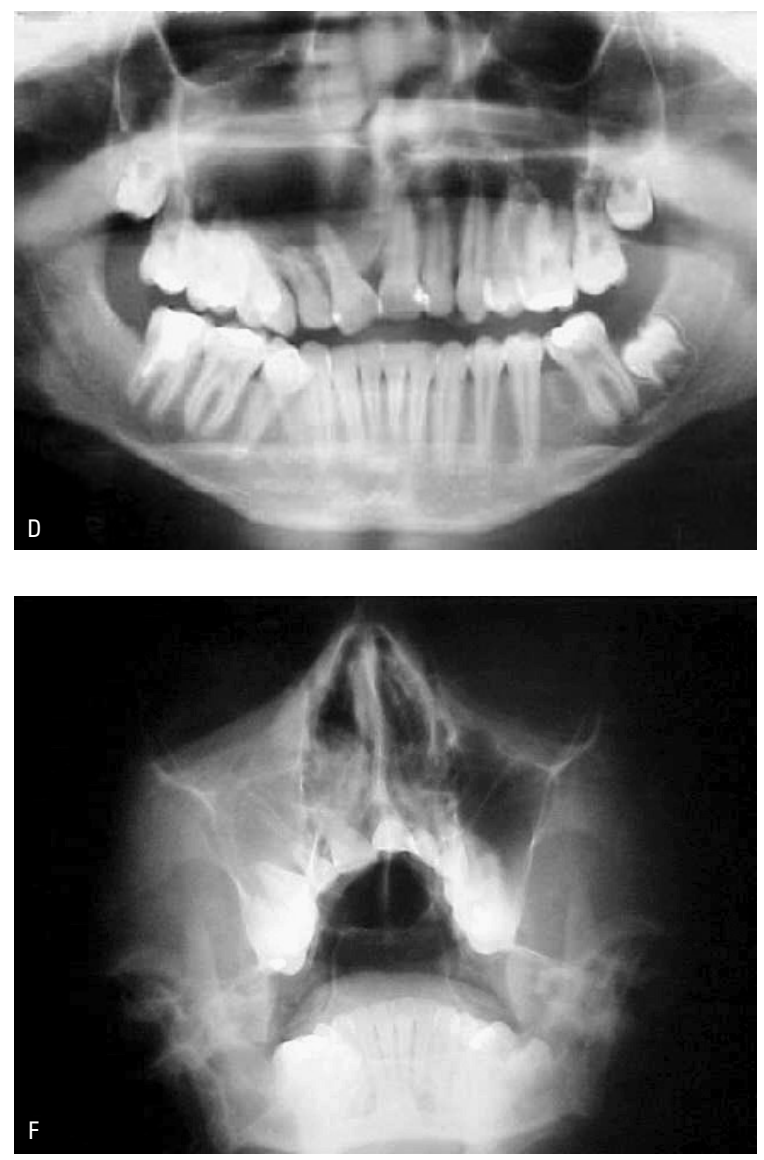

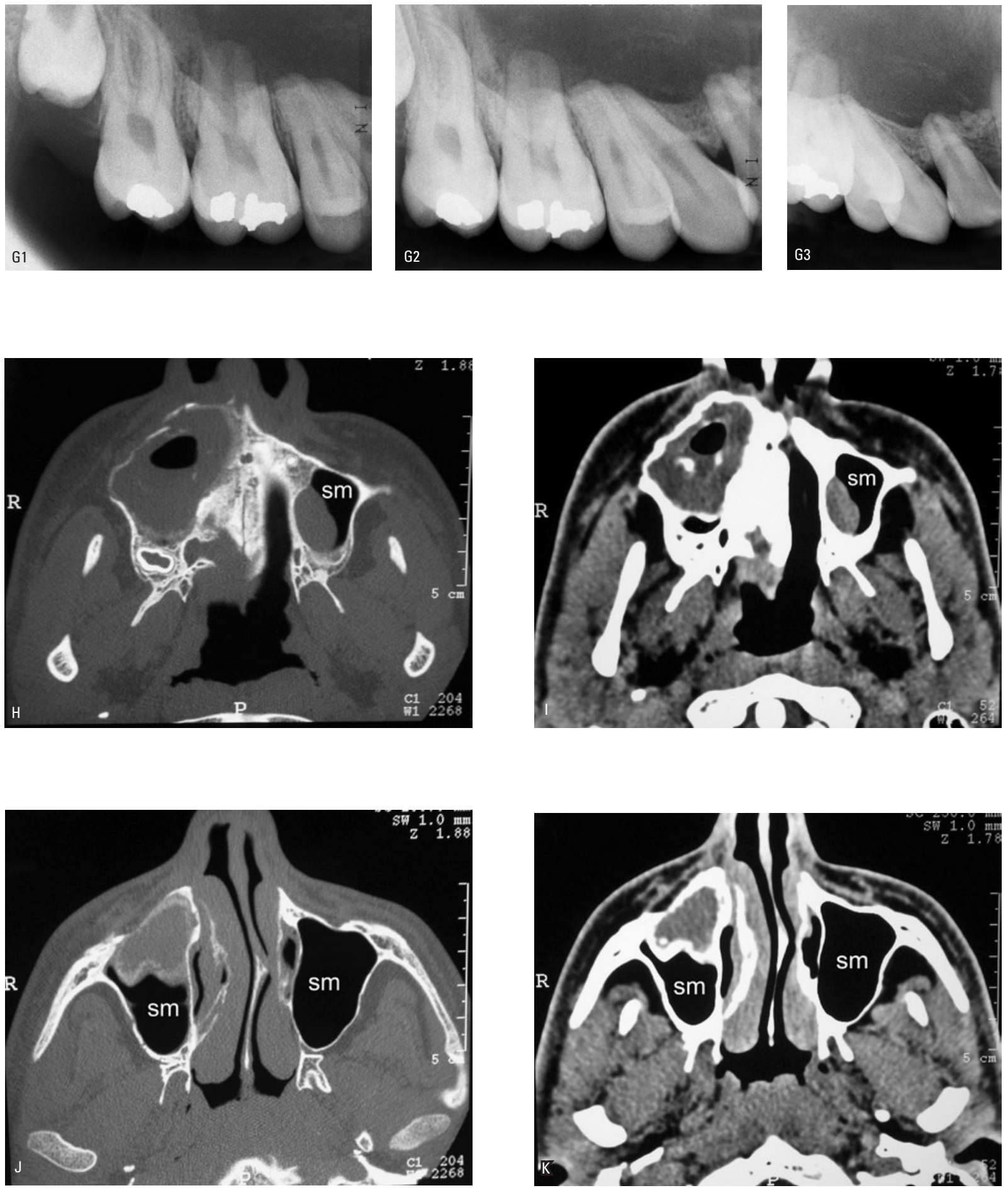

deslocamento e reabsorção dentária (D, G). Pequenas áreas mineralizadas são observadas no seu interior (E, G). Velamento total do seio maxilar direito e hipertrofia de cornetos à direita (F). A TC foi solicitada para melhor avaliação da relação da lesão com seio maxilar. Os cortes axiais em janela para osso (H, J) e para partes moles (I, K) evidenciaram lesão óssea expansiva heterogênea a direita na maxila, com calcificações no interior, sem invasão da linha média, com expansão acentuada por palatino $(\mathbf{H}, \mathbf{I}, \mathbf{L})$. Evidência de área com densidade gasosa no interior da lesão $(\mathbf{H}, \mathbf{I}, \mathbf{N})$, associada à região de biópsia incisional. Elevação do assoalho do seio maxilar (sm) ipsilateral, sem sinais de invasão (J, K, M, N). Discreto realce heterogêneo após injeção de meio de contraste (I, K, N). As reconstruções tridimensio- 

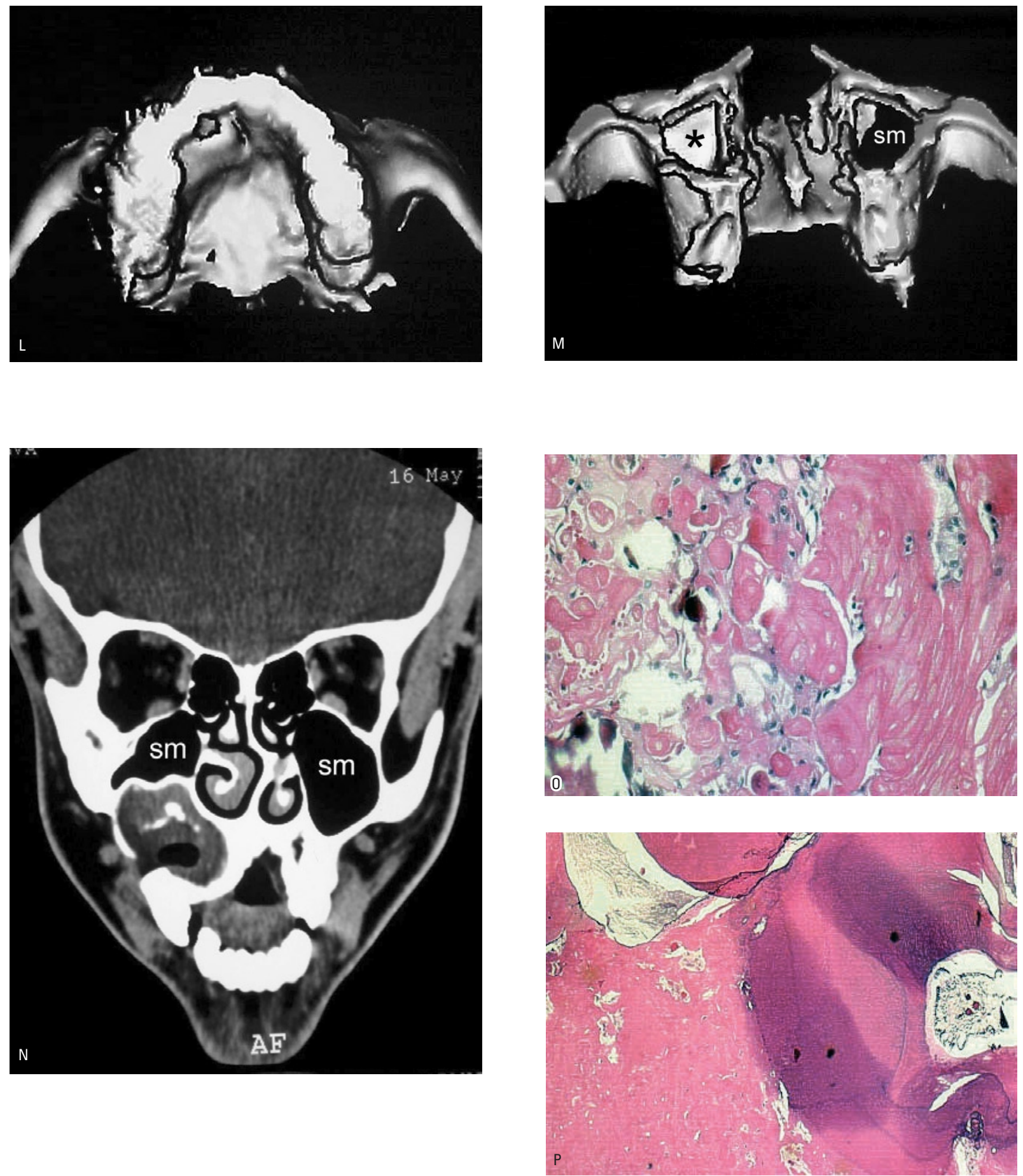

nais permitem uma visão da expansão palatina com solução de continuidade da cortical na região da biópsia incisional (L) e da elevação do seio maxilar direito (M - asterisco, N). 0 anátomopatologico descreveu uma lesão cística revestida por cápsula fibrosa e epitélio odontogênico espesso, com camada externa de células basais colunares dispostas em paliçada e a camada interna semelhante ao retículo estrelado (órgão do esmalte). Presença de grande quantidade de corpos eosinofílicos (células fantasmas) (0), conglomerados amorfos com início de calcificação e estruturas calcificadas semelhantes aos tecidos dentários (odontoma) (P). 0 tratamento de escolha foi a enucleação da lesão. Paciente em proservação (Créditos do caso clínico: Dr. Túlio Humberto Spini, Dra. Dorcely Rodrigues, Dra. Renata Tucci e Equipe do Centro Goiano de Doenças da Boca da FO/UFG). 

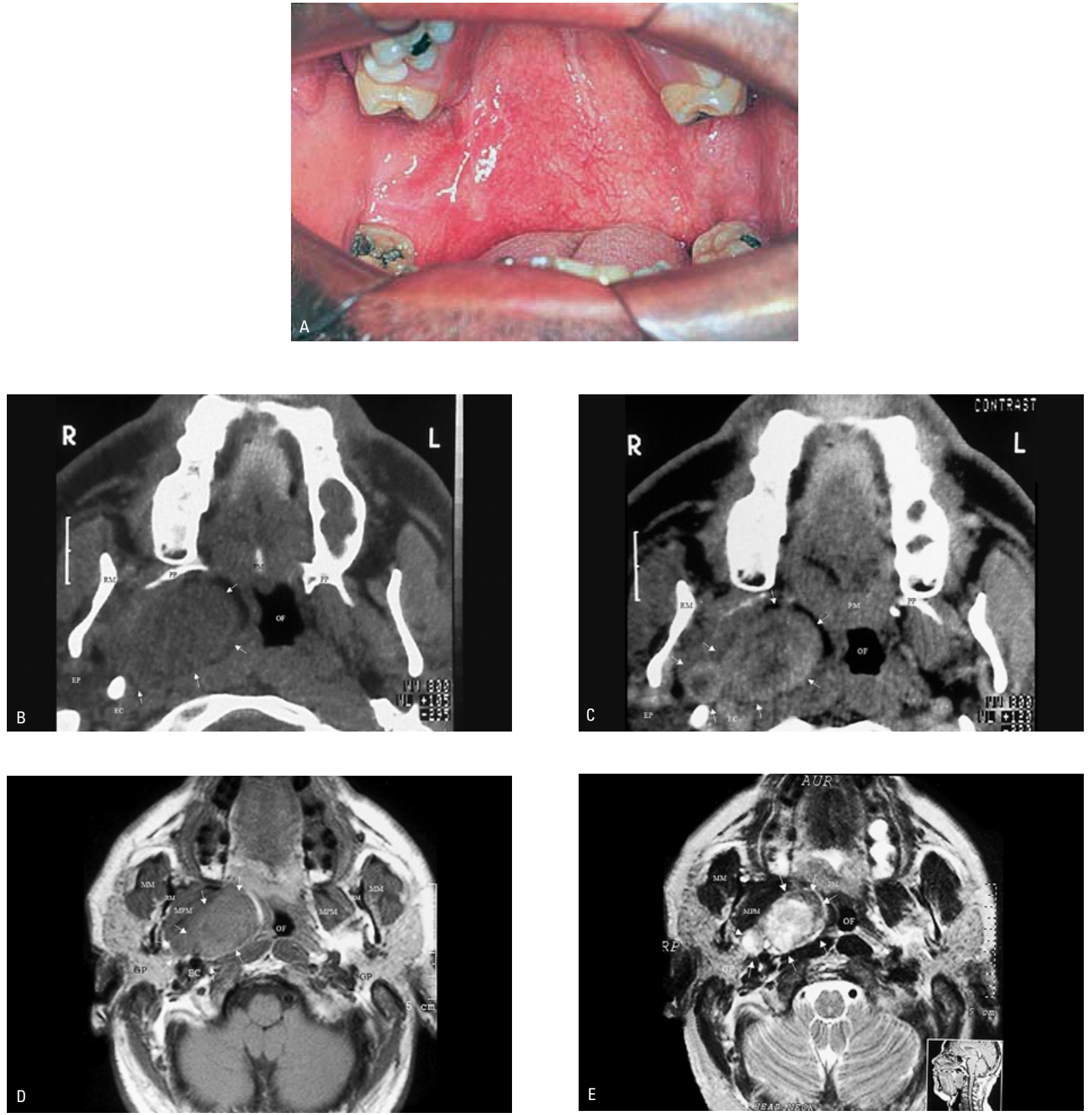

FIGURA 18 - Tumor de glândulas salivares menores do espaço parafaríngeo simulando neoplasia de palato mole. Paciente gênero masculino, 42 anos, leucoderma, foi encaminhado ao Centro Goiano de Doenças da Boca - CGDB/FO/UFG (Goiânia-G0), com hipótese diagnóstica de neoplasia de bucofaringe com expansão do palato mole (A). 0 paciente já havia sido submetido a exame de TC e à biópsias prévias da região de palato mole, cujo laudo anatomopatológico foi compatível com tecido glandular normal ou hiperplasia adenomatóide de origem medicamentosa, sujeito à confirmação clínica. Ao exame clínico a queixa principal do paciente era de "carne crescendo na boca" há aproximadamente 10 anos, tendo percebido o aumento na região de bucofaringe acentuar-se nos últimos 3 meses. Ele associava a alteração da anatomia da bucofaringe com o aparecimento de ronco durante o sono. A história médica pregressa revelou cirurgia de remoção da vesícula biliar e que o paciente não fazia uso regular de qualquer medicação. Na história odontológica pregressa, bem como na história familiar, não foi encontrado nada digno de nota. Paciente foi fumante durante 17 anos (12 cigarros/dia), tendo parado há um ano. Ao exame físico intrabucal, observou-se aumento de volume bem delimitado, localizado na região de palato mole à direita, estendendo-se para bucofaringe, recoberto por mucosa discretamente avermelhada, medindo aproximadamente 3,5 cm no seu maior diâmetro, assintomático, apresentando superfície irregular com cicatriz cirúrgica e resiliência à palpação (A). Na TC encaminhada com o paciente, observou-se lesão ovalada, com densidade de partes moles, contorno nítido, sem calcificações no seu interior, provocando deslocamento medial da gordura do espaço parafaríngeo e da parede lateral da bucofaringe (B -setas), com discreto realce após injeção de contraste (C - setas). Observou-se ainda, rechaçamento e abertura das lâminas do processo pterigóideo direito do osso esfenóide (B), sugerindo crescimento lento com remodelação óssea, compatível com o comportamento biológico de lesões benignas. Entretanto, este exame não foi esclarecedor quanto aos limites da lesão em relação à glândula parótida, ao espaço carotídeo e mús- 
culos do espaço mastigatório (B, C). Para o diagnóstico diferencial e melhor visualização do conteúdo desses espaços anatômicos, foi indicada uma RM da região. As imagens obtidas em um campo magnético de 2.0 Teslas, utilizando as seqüências Spin Echo T1 sagital, axial, coronal e Fast Spin Echo T2 axial, revelaram lesão expansiva ovalar, com sinal isointenso em T1, em relação à musculatura (D, F - setas), sinal hiperintenso heterogêneo em T2 (E), localizada predominantemente no espaço parafaríngeo direito, sem plano de clivagem nítido com o espaço parotídeo (D, E). A lesão com aproximadamente 5,5X 4,1 cm de diâmetro, apresentou realce moderado e heterogêneo em T1, após infusão de meio de contraste paramagnético (F). Observou-se ainda, compressão e rechaçamento das estruturas anatômicas circunjacentes, sem sinais de invasividade e ausência de adenomegalia regional (D, E, F). 0 tratamento de escolha foi a exérese da lesão. Após biópsia transcirúrgica por congelação, a qual não revelou sinais de neoplasia maligna, procedeuse a exérese da neoplasia, utilizando-se acesso cirúrgico intrabucal. 0 laudo anatomopatológico da peça cirúrgica revelou ausência de atipias celulares, presença de proliferação de células mioepiteliais, estruturas ductiformes, componentes mesenquimais lembrando áreas condróides, circundados por uma tênue cápsula fibrosa, compatível com adenoma pleomórfico do espaço parafaríngeo. No pós-operatório de 40 dias, o paciente evoluiu bem, sem intercorrências, com cicatrização normal, estando o mesmo, ainda, em proservação. $\mathbf{P M}$ - palato mole; $\mathbf{P P}$ - processo pterigóideo; $\mathbf{R M}$ - ramo mandibular; OF - bucofaringe; EP - espaço parotídeo; EC - espaço carotídeo; MM - músculo masseter; MPM - músculo pterigóideo medial; GP - glândula parótida; SM - seio maxilar (Créditos do caso clínico: Dr. Túlio Humberto Spini, Equipe do Centro Goiano de Doenças da Boca da FO/UFG e do Serviço de Cabeça e Pescoço do Hospital Araújo Jorge da Associação de combate ao câncer em Goiás).

utilizados em restaurações, próteses, implantes, dispositivos ortodônticos e cirúrgicos são seguros para os pacientes submetidos ao exame por RM, ou seja, não existe risco de movimentação dos mesmos pela atração do campo magnético. Porém, eles podem gerar artefatos os quais podem alterar substancialmente o resultado das imagens. Os artefatos gerados se caracterizam por uma ausência de sinal (área escura) circundada por uma linha brilhante e distorções da imagem (Fig. 22) ${ }^{24}$;

- O ouro foi o metal que produziu os maiores artefatos e o amálgama os menores ${ }^{1,34}$;

- Ao contrário dos metais utilizados em próteses fixas, os fios e bandas ortodônticas de aço inoxidável (Ni-Cr 18/8) podem gerar artefatos que influenciam não apenas na qualidade, mas também no diagnóstico das imagens da $\mathrm{ATM}^{10}$;

- Imagens de boa qualidade da ATM podem ser obtidas de pacientes que estejam utilizando aparelhos ortodônticos, preferencialmente aqueles com braquetes de cerâmica nos dentes anteriores e tubos colados diretamente nos molares, sem a colocação dos arcos estabilizadores ${ }^{38}$;

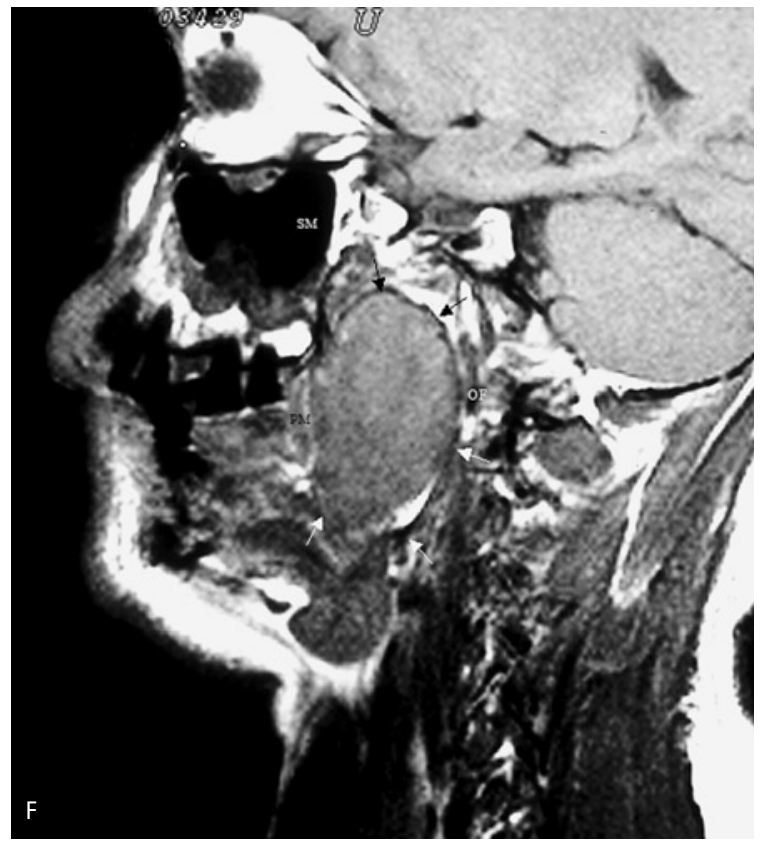

- Os implantes de titânio, além de não serem influenciados pelo campo magnético, produzem artefatos de pequenas dimensões. Entretanto, as retenções tipo magneto, conectadas aos implantes que suportam próteses do tipo "over denture", foram uma das grandes causas de artefatos e devem ser removidas quando o paciente for submetido à $\mathrm{RM}^{6}$;

\section{Aplicações em Ortodontia}

\section{Articulação Temporomandibular (ATM)}

A primeira aplicação clínica das imagens por RM na clínica odontológica foi para o estudo da ATM no início dos anos 80 . Foi o primeiro exame que permitiu a visualização direta dos tecidos moles articulares, com imagens de alta resolução. Esses tecidos, até então, eram visualizados apenas indiretamente por meio da injeção de contraste nos espaços articulares (artrografia ou artrotomografia) ou diretamente pela TC, mas com uma resolução deficiente ${ }^{47}$.

A RM contribuiu para mudança de muitos conceitos da etiopatogenia e diagnóstico das de- 

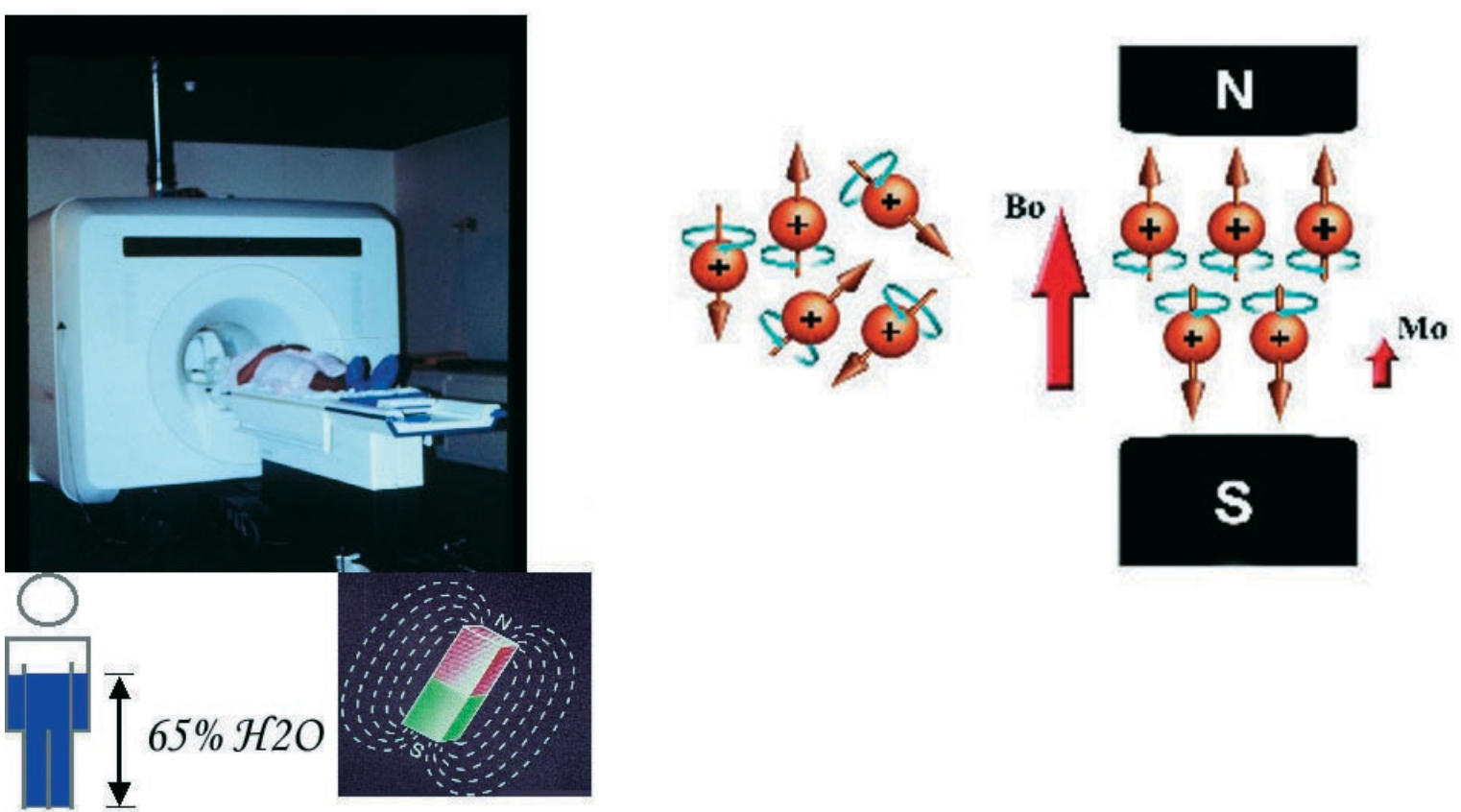

A

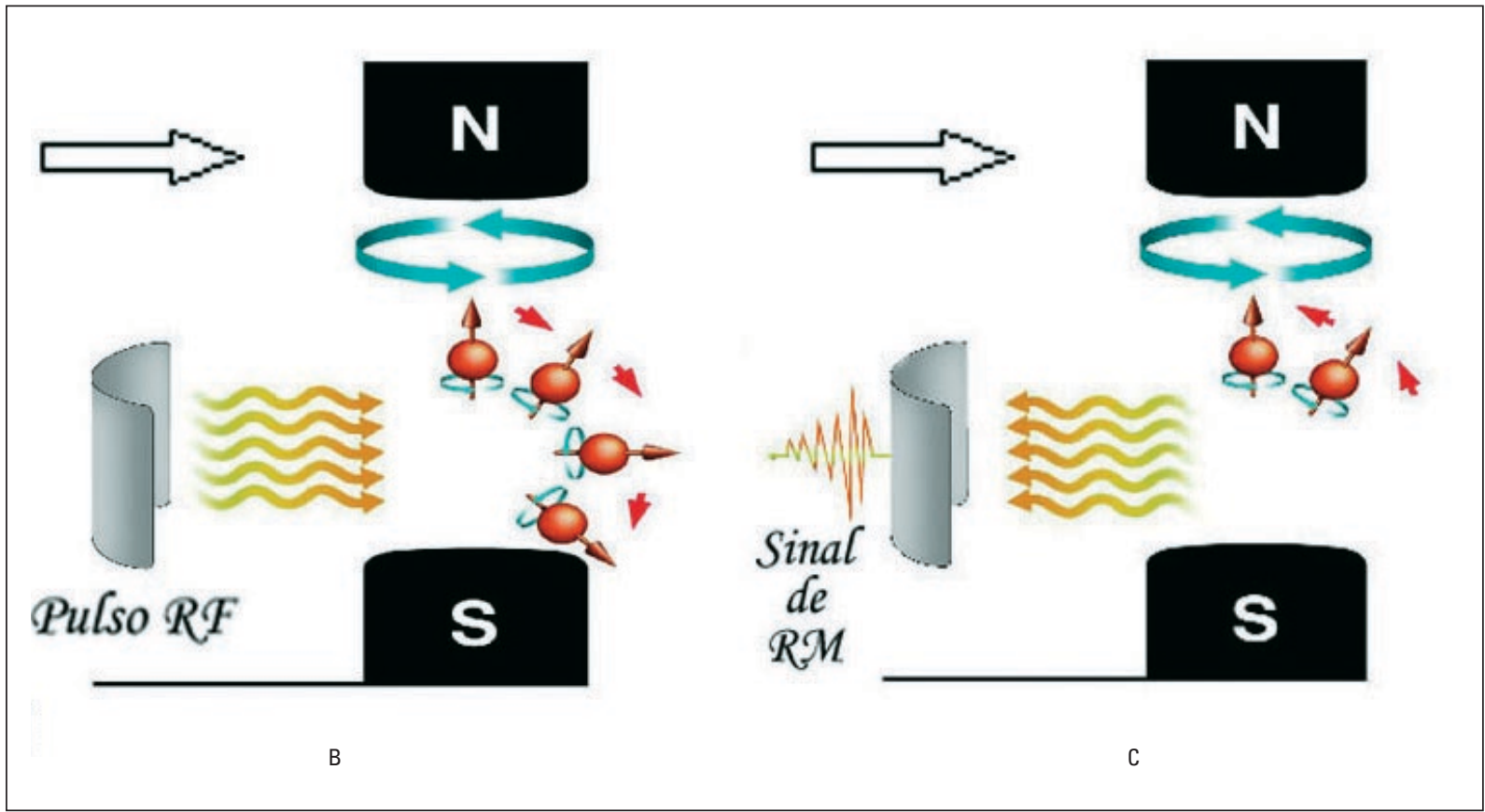



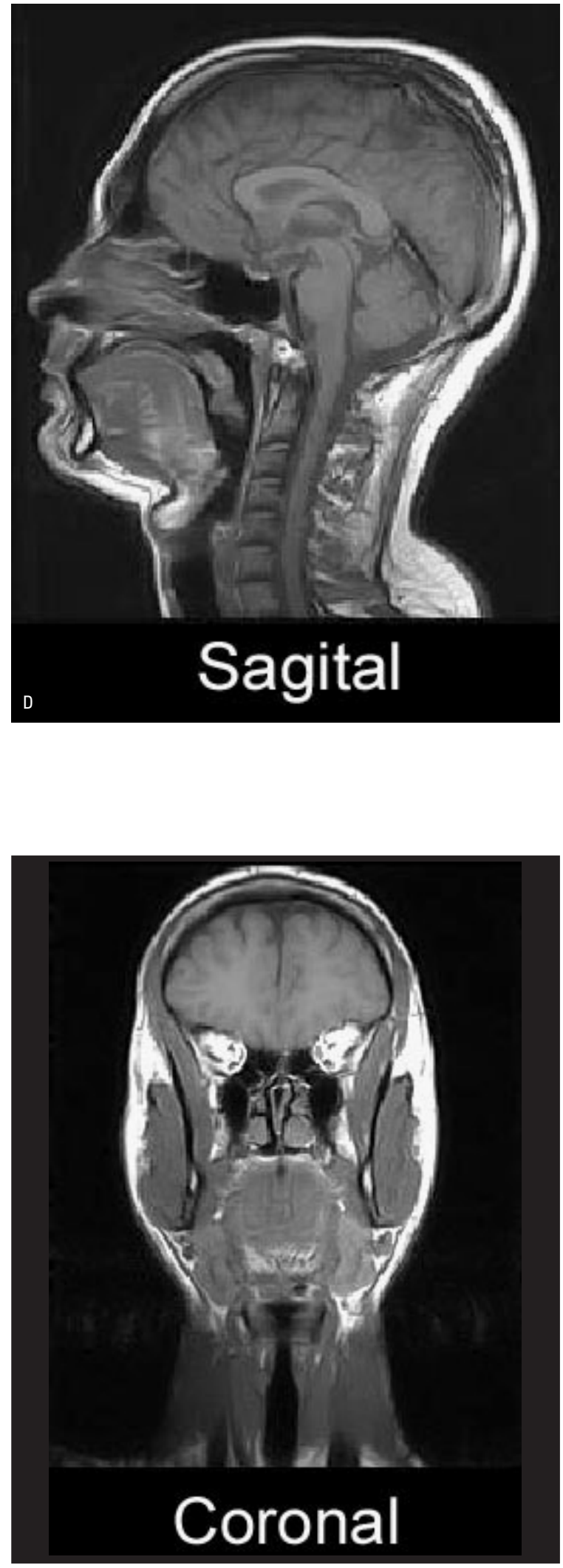

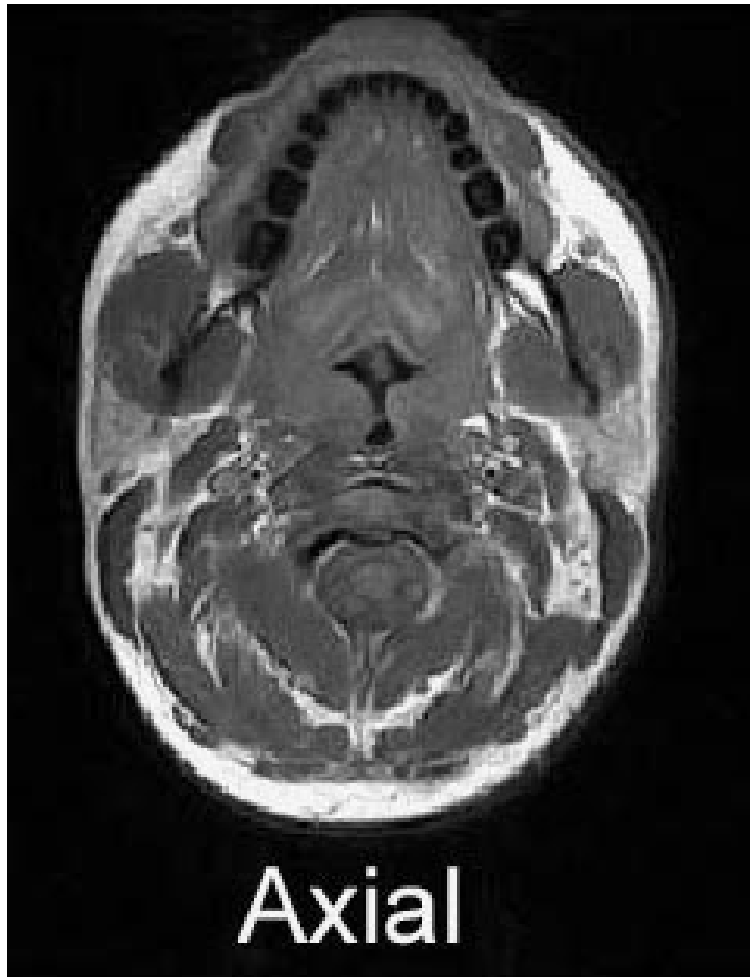

FIGURA 19 - Princípios técnicos de aquisição das imagens por RM. (A) 0 paciente é colocado em um forte campo magnético (gantry - grande tubo) e os prótons de hidrogênio (cargas elétricas positivas), que são os mais abundantes dos tecidos orgânicos (65\%) e com a propriedade de girar em torno dos seus próprios eixos (spin) em orientação aleatória (setas), são alinhados pela ação do forte campo magnético (Bo / dipolos Norte [N] e Sul [S]), gerando uma magnetização no interior dos tecidos (Mo); (B) um sistema de bobinas (antenas) emite ondas de rádio freqüência (pulso RF) que são absorvidas pelas partículas atômicas alinhadas pelo campo magnético externo, alterando o estado de energia das mesmas. A seguir (C), as ondas de rádio freqüência são desligadas e o paciente emite um sinal, liberando a energia recebida de forma semelhante às ondas de rádio freqüência, e o sinal (sinal de RM) é recebido pelo mesmo sistema de bobinas que emitiu as ondas de rádio freqüência, sendo utilizado para a formação das imagens digitais nos diferentes planos anatômicos (D). 


Gordura
Medula óssea
Cérebro
Órgãos abdominais
Músculos
Fluidos corpóreos
Cartilagem
Osso cortical
Ar
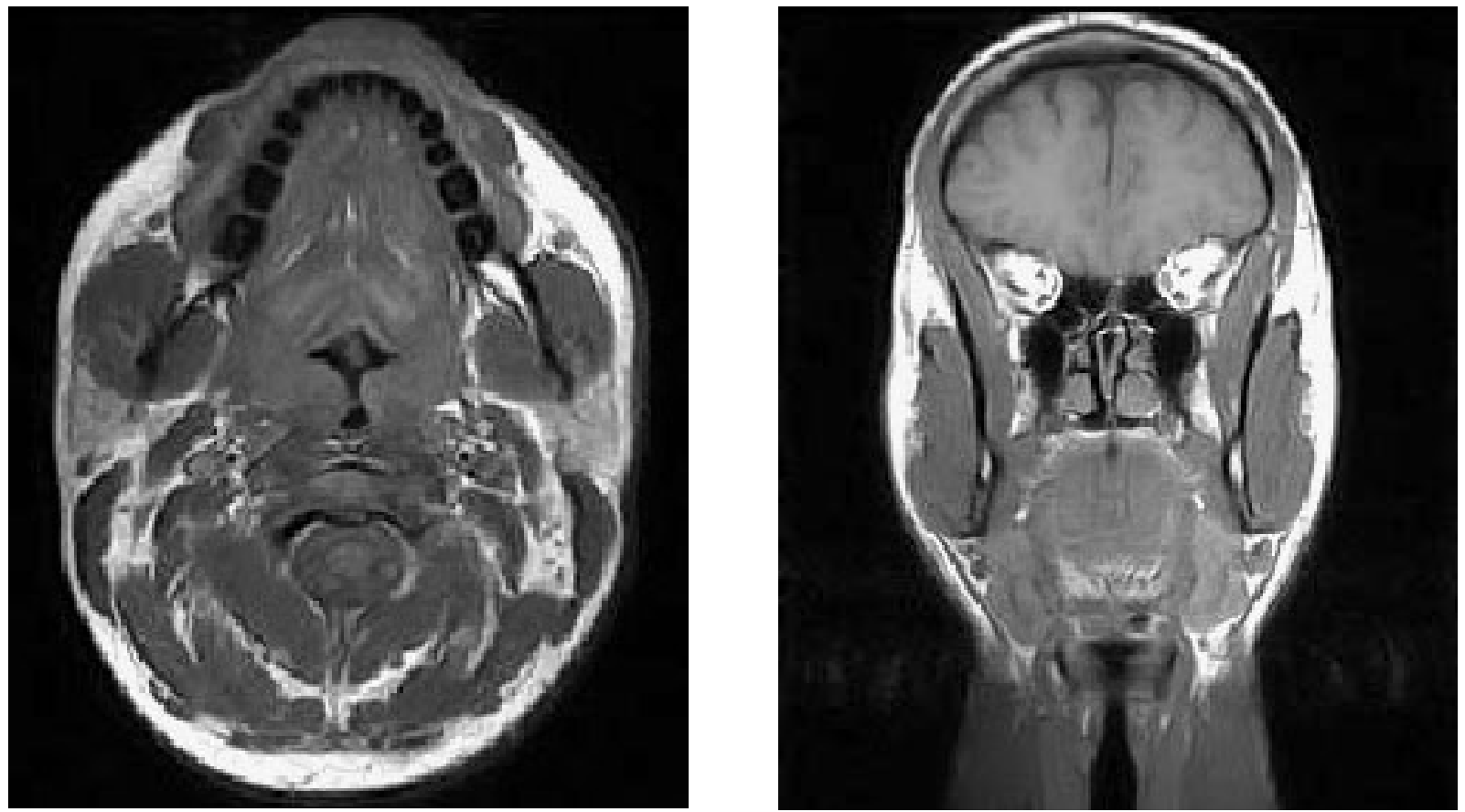

FIGURA 20 - Escala da intensidade de sinal em RM (seqüência spin-eco, T1, aparelho 2Tesla). As alterações nos tons de cinzas da imagem por RM são descritas em termos de intensidade de sinal. Tecidos que possuem um pequeno conteúdo de água e/ou gordura, aparecerão como áreas mais escuras ou hipointensas ou com baixa intensidade de sinal (ex. cortical óssea). Tecidos ricos em água e/ou gordura (ex. medula óssea) aparecerão com um sinal intenso ou hipersinal, ou seja, mais esbranquiçados ou brilhantes. Os parâmetros técnicos utilizados (T1, T2, seqüências...), bem como a intensidade do campo magnético, influenciam nas características do sinal de RM dos tecidos. 


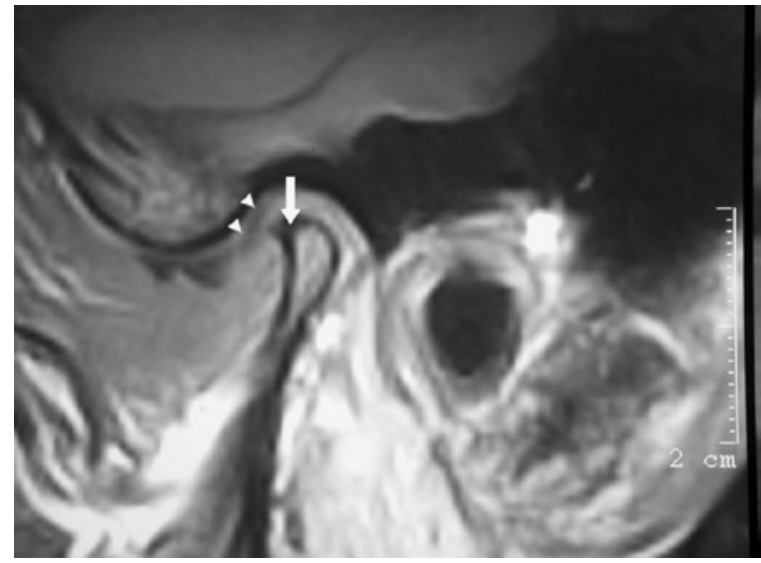

FIGURA 21 - Deslocamento anterior do disco articular da ATM, fibrose do ligamento posterior do disco e necrose avascular/esclerose do côndilo. Corte parasagital ponderado em T1, na posição de boca fechada, em que se observa o deslocamento anterior do disco articular, redução do sinal de parte do ligamento posterior do disco (cabeças de setas) sugestivo de fibrose, e redução do sinal da medula óssea condilar (seta), o que poderia ser compatível com esclerose e/ou necrose avascular.

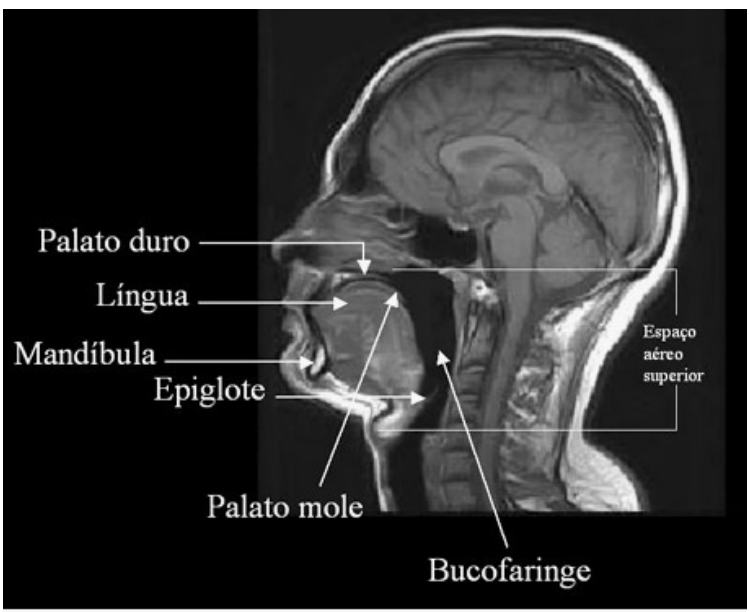

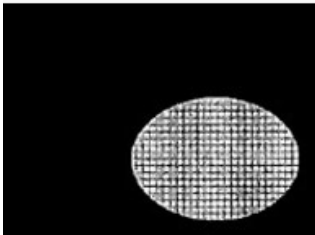

A

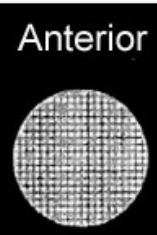

B

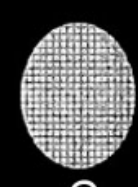

C

\section{Posterior}

FIGURA 23 - Diferenças na geometria do espaço aéreo superior em um indivíduo normal (A), naquele que ronca (B) e no apnêico (C). No indivíduo normal o eixo mais longo do espaço aéreo é no sentido lateral enquanto que no apnêico é no sentido ântero-posterior. 0 corte sagital em T1 mostra a excelente resolução do espaço aéreo e tecidos moles adjacentes, importante para 0 diagnóstico, plano de tratamento e proservação dos pacientes com apnéia obstrutiva do sono.
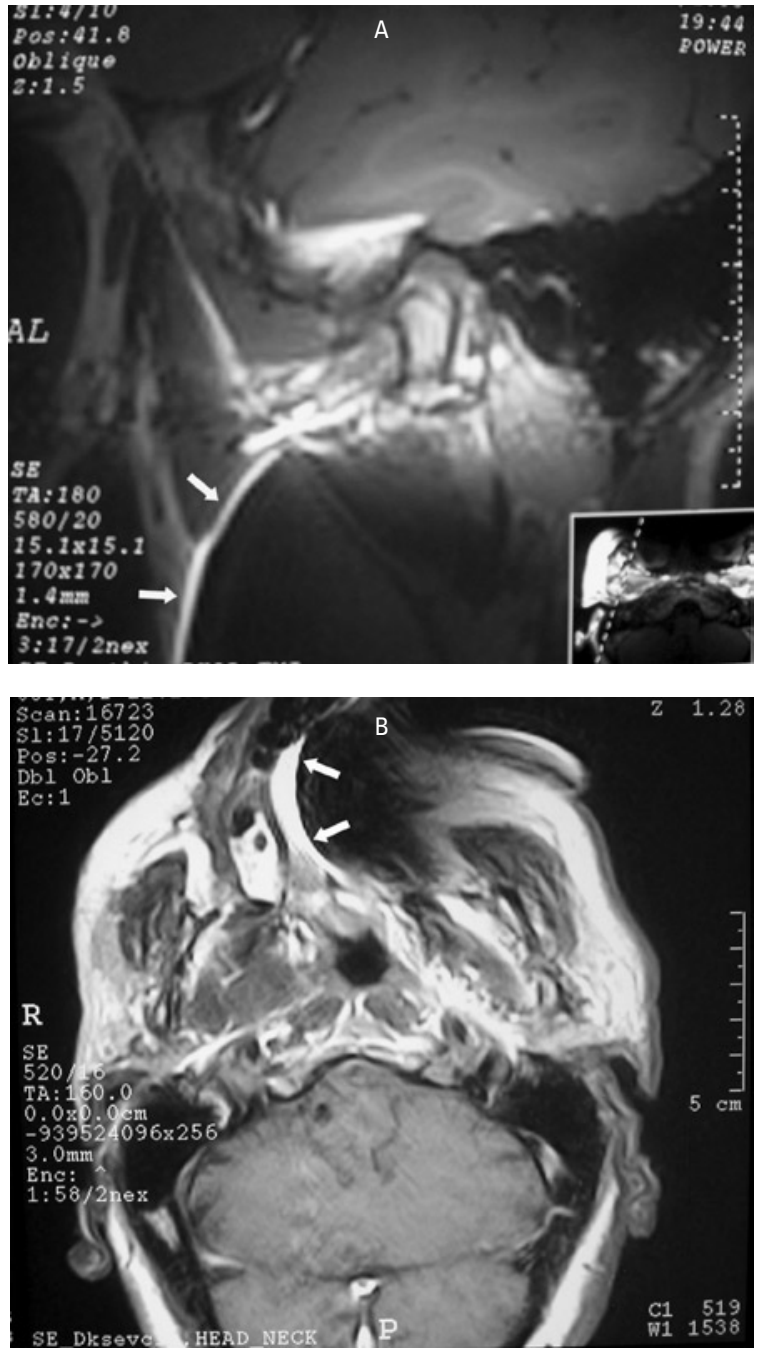

FIGURA 22 - Artefatos metálicos gerados por dispositivos odontológicos em imagens por RM da região bucomaxilofacial. Os artefatos gerados se caracterizam por uma ausência de sinal (área escura) circundada por uma linha brilhante (setas) e distorções da imagem. (A) Corte parasagital oblíquo em T1, região da ATM, na posição de boca fechada, com artefato gerado por aparelho ortodôntico; (B) Corte axial ao nível da maxila, com artefato gerado por prótese metalo-cerâmica.

sordens da ATM, os quais eram baseados apenas em informações clínicas, uma vez que os exames por imagem disponíveis não permitiam a visualização de partes moles articulares ou o fazia de forma deficiente. E ainda, expunham o paciente à radiação ionizante, impedindo o estudo de grupos controle e de indivíduos em faixas etárias menores (crianças).

As informações que a imagens por RM dis- 


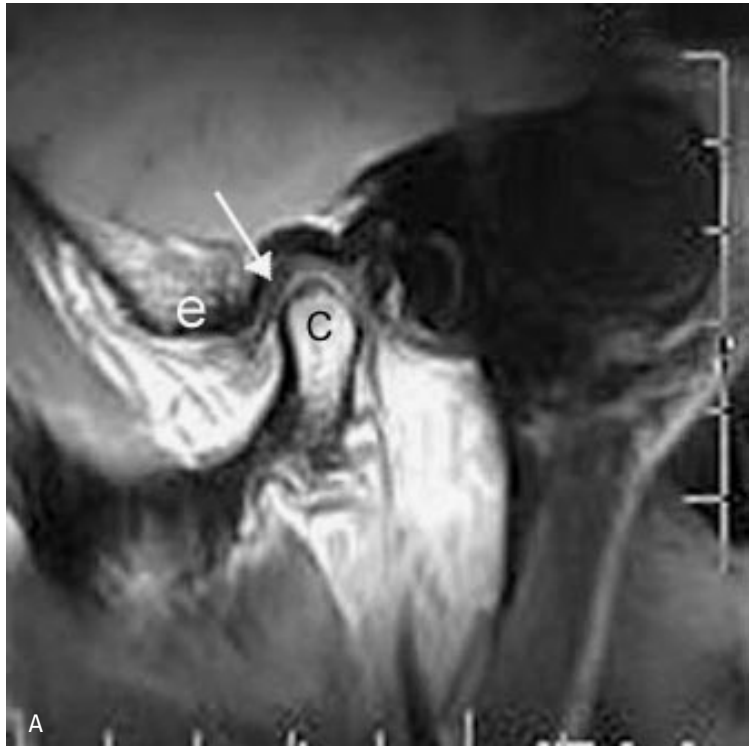

FIGURA 24 - ATM normal. (A) Corte parasagital oblíquo T1, na posição de boca fechada, em que se observa o disco articular caracterizado por um hiposinal, com o formato de "gravata borboleta", com sua banda posterior (seta) posicionada superiormente ao côndilo mandibular, e o contorno regular as superfícies articulares ( $c=$ côndilo, e = eminência articular). (B) Corte parasagital oblíquo T1, na posição de boca aberta, em que a translação condilar ao nível da eminência articular (e) e a relação do côndilo com a zona intermediária do disco determinam padrões de normalidade. É nesta posição que todas a estruturas da ATM podem ser visualizadas com detalhes, o que inclui o ligamento posterior do disco (Ip), caracterizado por 3 partes (duas partes fibrosas com hiposinal em T1 que ligam o disco superiormente ao osso temporal e inferiormente ao côndilo, e uma parte intermediária com isosinal em T1, rica em vasos, nervos e gordura). (C) Corte coronal oblíquo T1, na posição de boca fechada, em que o disco articular (setas) caracteriza-se por hiposinal em T1 e forma selar, superiormente ao côndilo.

ponibilizam incluem a localização e disposição do disco articular nas posições de boca aberta e fechada, ao longo de toda articulação. Deslocamentos anterior, látero-mediais e a associação dos mesmos (deslocamentos rotacionais)

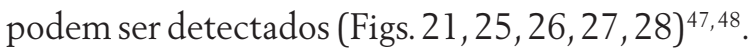
Contudo, as perfurações do disco e aderências capsulares são mais bem detectadas pela artrografia. Os detalhes das estruturas ósseas, como mencionado anteriormente, são melhor visualizados pela tomografia convencional ou pela TC, mas o contorno ósseo e delineamento cortical podem ser obtidas pela RM (Figs. 21, 24 a 28). Além disso, alterações da medula óssea do
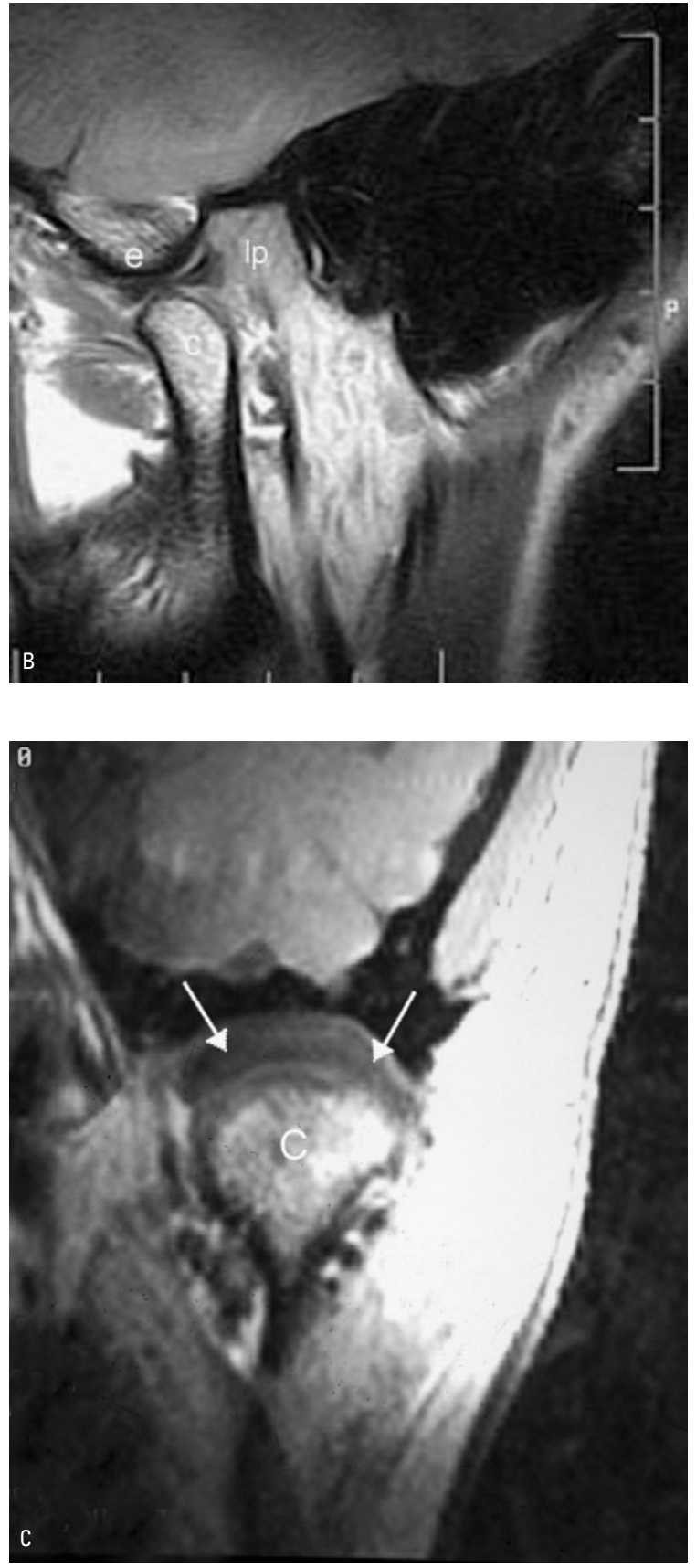

côndilo (Fig. 21), nos músculos e tecidos moles adjacentes podem ser diagnosticadas. A presença de proliferações teciduais intra-articulares, fibroses (Figs. 26, 27) e efusão (quantidade excessiva de líquido nos espaços articulares) (Figs. 26, 28, 29) também podem ser identificadas através de imagens por $\mathrm{RM}^{3,33}$. 

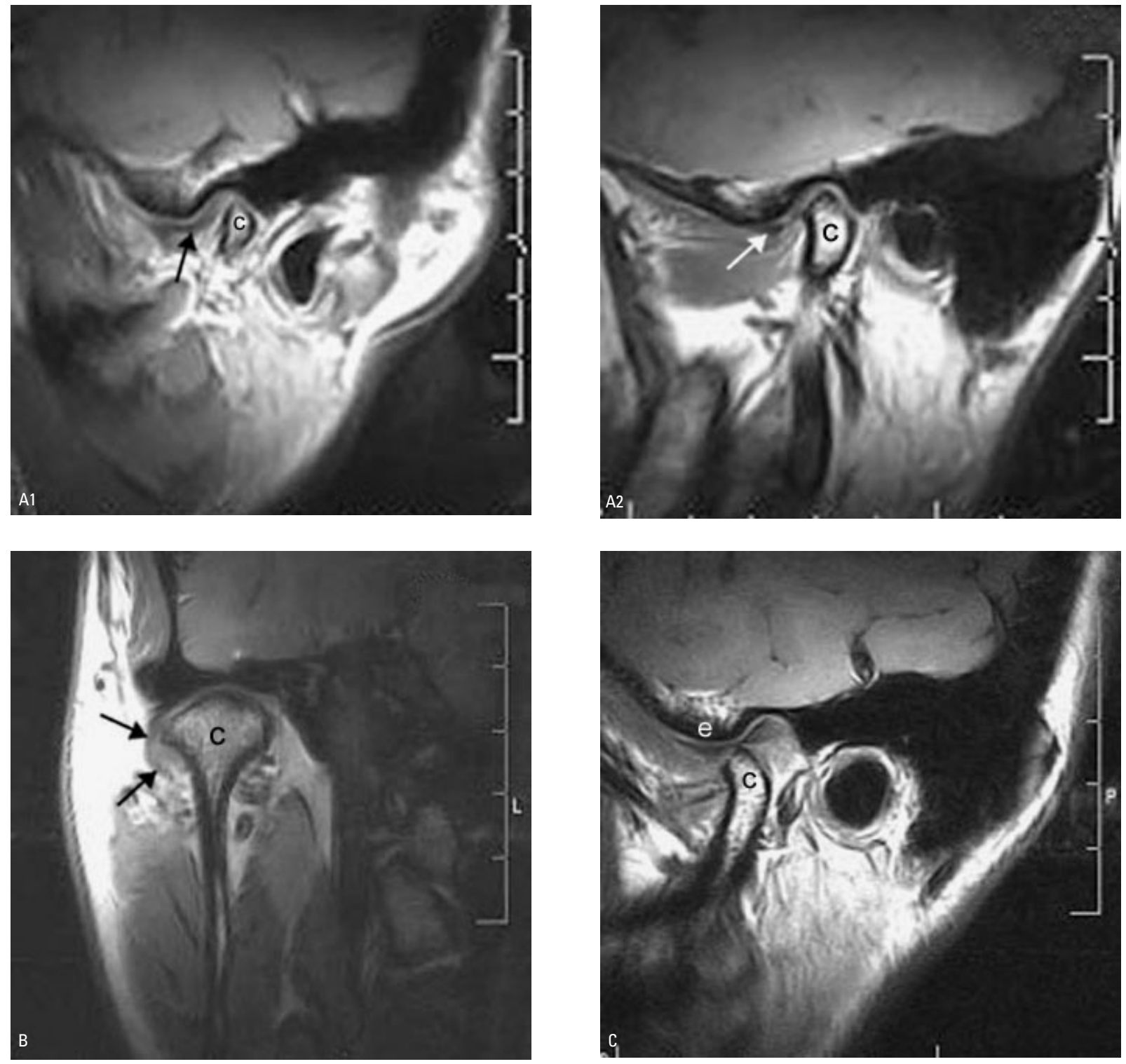

FIGURA 25 - Deslocamento rotacional bilateral com redução do disco articular da ATM. LADO DIREITO (A, B, C): Cortes parasagitais oblíquos T1, na posição de boca fechada (A1, A2), sendo que no corte mais lateral (A1) observa-se toda a extensão do disco articular (seta) deslocado anteriormente. No corte mais medial (A2), o disco permanece deslocado para anterior, mas apenas a sua banda anterior pode ser visualizada (seta), sugerindo um deslocamento lateral do mesmo, que pode ser confirmado no corte coronal oblíquo T1 em boca fechada (B), em que o disco (setas) encontra-se deslocado para o pólo lateral do côndilo. 0 corte parasagital oblíquo T1 em boca aberta (C) evidencia a redução do disco, que se interpõem entre eminência articular (e) e côndilo (c). Sendo assim, trata-se de um deslocamento ântero-lateral com redução do disco articular.

Deslocamentos do disco articular (Figs. 21, $25,26,27,29)$ têm sido associados às assimetrias faciais em pacientes jovens, situação em que as imagens por RM têm um importante papel de diagnóstico ${ }^{54}$.

A efusão (Figs. 26, 28, 29) e as alterações da medula óssea condilar (Fig. 21) tem sido re- feridas como fatores associados ao aumento da dor articular. Pacientes com efusão da ATM representam um subgrupo de dor e disfunção que apresentam lesões intra-articulares mais severas, do que aqueles com deslocamento do disco sem outras anormalidades articulares associadas ${ }^{33}$.

As imagens por RM também têm uma impor- 

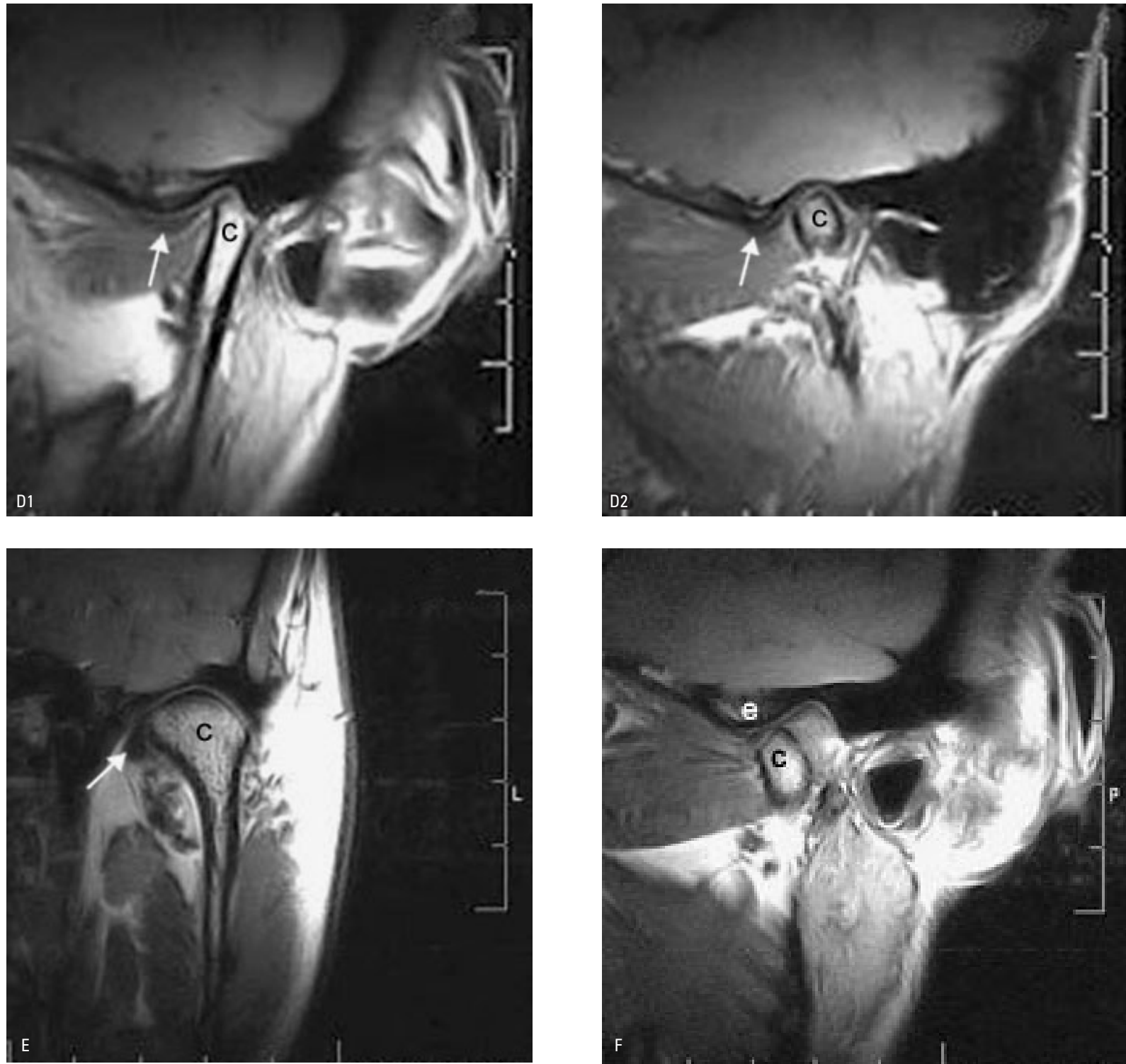

FIGURA 25 - (continuação) LADO ESQUERDO (D, E, F): Cortes parasagitais oblíquos T1, na posição de boca fechada (D1, D2), sendo que tanto no corte mais lateral (D1) quanto no mais medial (D2) o disco apresenta-se deslocado anteriormente, porém não pode ser visualizado em toda sua extensão (seta). No corte coronal oblíquo T1 em boca fechada (E), o disco (setas) encontra-se deslocado para o pólo medial do côndilo, determinando um deslocamento ântero-medial, cuja redução pode ser observada no corte parasagital oblíquo T1 em boca aberta (F), cuja translação condilar está aquém do ápice da eminência articular.

tante contribuição no diagnóstico das necroses avasculares (Fig. 21) e degeneração mixóide do disco articular, apesar do significado clínico desses achados serem controversos. As destruições do disco e a formação do pannus (inflamação da sinóvia) são achados freqüentes nos indivíduos com artrite reumatóide ativa ou outra artrite de origem inflamatória ${ }^{60}$.
A acurácia da RM para a detecção do posicionamento do disco tem demonstrado atingir $95 \%{ }^{3,47}$. Porém, a qualidade de diagnóstico desses exames pode variar amplamente, dependendo do nível de experiência tanto do técnico que realiza os exames, quanto do radiologista que interpreta as imagens. Outros fatores que podem alterar a qualidade do exame incluem: a intensidade do 

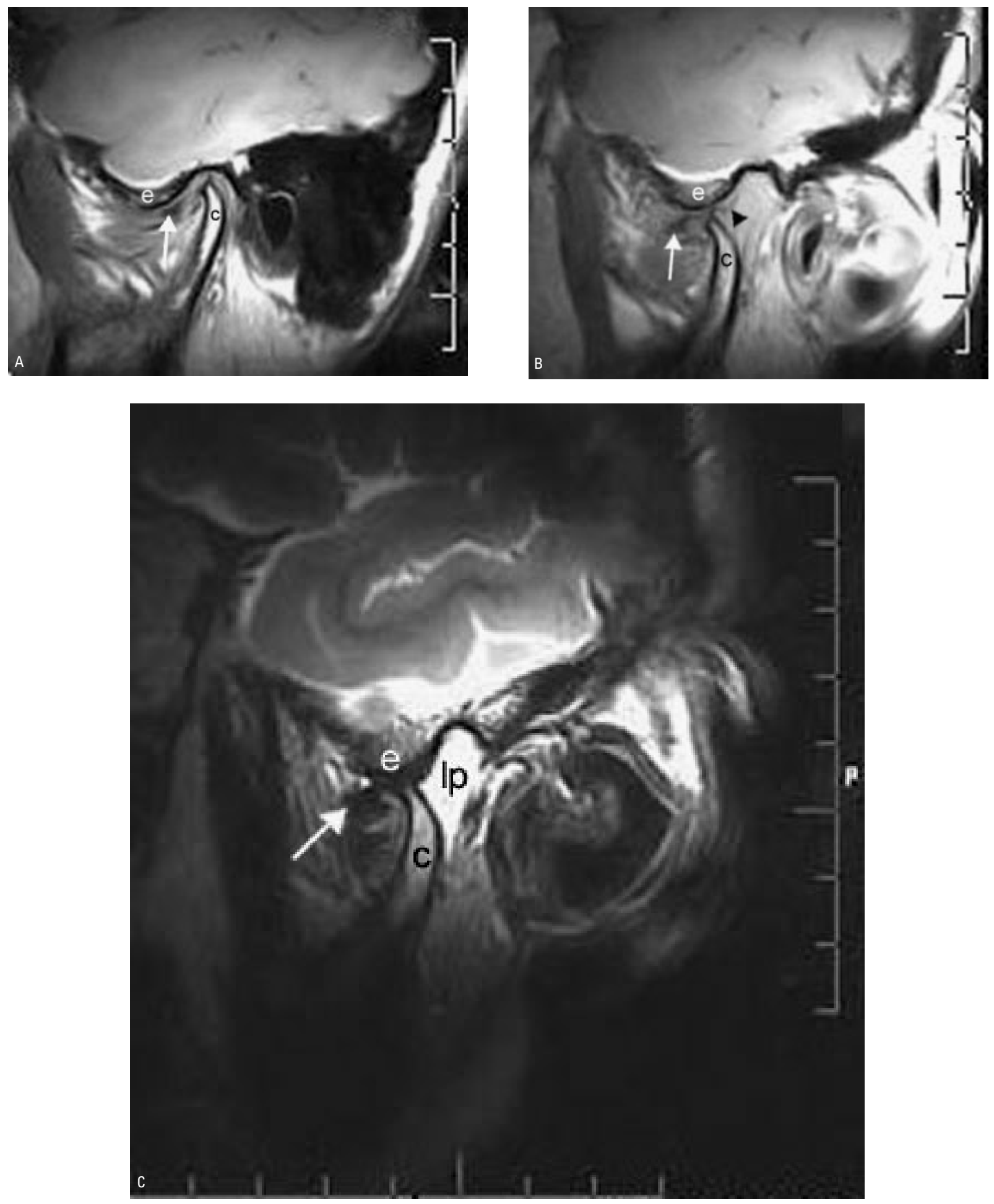

FIGURA 26 - Deslocamento anterior sem redução do disco articular e processo ósseo degenerativo da ATM. Corte parasagital T1 em boca fechada (A), em que se observa o disco deformado e deslocado anteriormente ao côndilo (seta). Côndilo mandibular (c) com formato triangular sugestivo de reabsorção. No corte parasagital oblíquo T1 em boca aberta (B) o côndilo (c) translada discretamente aquém do ápice da eminência articular (e) e o disco permanece deslocado anteriormente (seta). 0 hiposinal no ligamento posterior (Ip) é compatível com fibrose do ligamento (cabeça de seta). No corte parasagital oblíquo T2 (C), o hipersinal do espaço articular superior e do ligamento posterior (Ip) sugerem, respectivamente, efusão e processo inflamatório. 

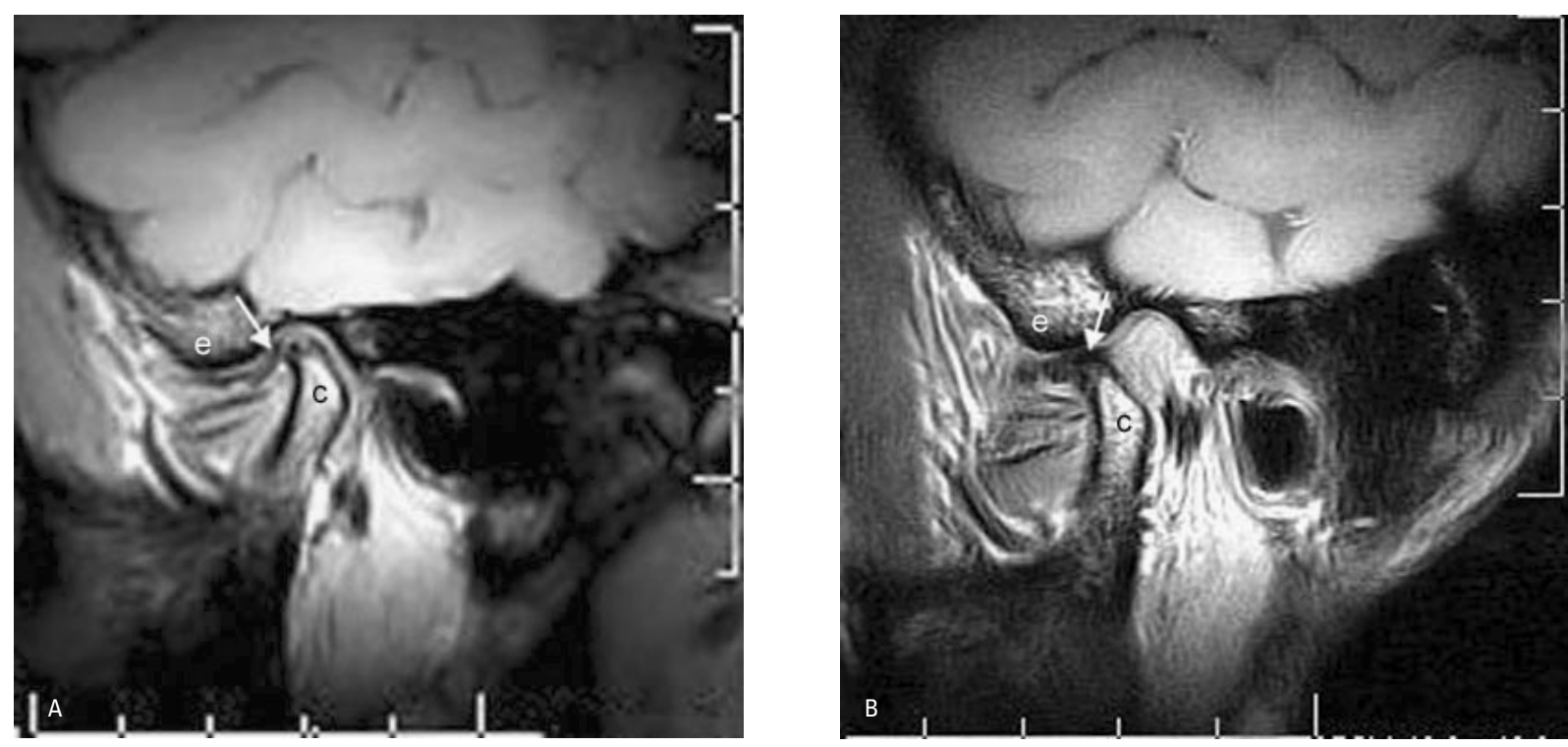

FIGURA 27 - Deslocamento anterior sem redução do disco articular, remodelação óssea condilar e fibrose do ligamento posterior. Os cortes parasagitais oblíquos T1 mostram o disco articular deslocado anteriormente ao côndilo (c) na posição de boca fechada (A), sem evidência de redução na posição de boca aberta (B). 0 hiposinal acentuado do ligamento posterior (seta), na região de junção com a banda posterior do disco, sugere fibrose do ligamento, também descrita como "pseudo disco". As estruturas lineares em hiposinal, abaixo e paralelamente ao disco articular, são tendões musculares, os quais, freqüentemente, podem ser confundidos com o disco articular, determinando um falso-positivo no diagnóstico das desordens intra-articulares. 0 aplainamento posterior do contorno condilar é sugestivo de remodelação óssea. (e - eminência articular; c - côndilo)

campo magnético, as bobinas de superfícies e os softwares do equipamento utilizado ${ }^{3}$.

\section{Avaliação do efeito de aparelhos que promo- vem o avanço ortopédico mandibular nas es- truturas da ATM}

O tratamento de pacientes com deslocamentos do disco articular da ATM utilizando placas reposicionadoras, com o objetivo de restabelecer uma relação fisiológica normal entre a cabeça da mandíbula (côndilo) e o disco, tem sido controverso. Um índice de sucesso de até 70\% tem sido descrito ${ }^{30,63}$.

Os estudos utilizando RM têm sido valiosos para o esclarecimento de quais as condições específicas sob as quais a terapia de reposicionamento do disco teria mais chances de ser eficaz. Alguns autores sugerem que as articulações com deslocamento com redução do disco (Fig. 25) possuem mais chances da recaptura do disco após a colocação dos dispositivos reposicionadores. E que, o deslocamento sem redução do disco (Figs. 26, 27), a presença de condições inflamatórias (Figs. 26, 28, 29), alterações morfológicas e deslocamentos mediais do disco (Fig. 25), são fatores negativos para o sucesso terapêutico com os dispositivos mencionados $^{31}$. Summer e Westesson ${ }^{63}$, em estudo longitudinal de pacientes tratados com placa reposicionadora, utilizando imagens por RM, encontraram uma maior eficácia do tratamento para os deslocamentos com redução, nos quais o disco estava deslocado apenas para a direção anterior. Nos casos em que havia o componente transverso no deslocamento do disco (Fig. 25), a terapia parece ter sido menos efetiva ${ }^{63}$. A possibilidade de recaptura do disco não foi associada apenas à posição, mas à configuração do complexo côndilo-disco, à integridade do ligamento posterior e ao grau de alterações degenerativas das estruturas intra-articulares (osteófitos, erosão condilar, adelgaçamento do disco articular). Essas informações diagnósticas influenciam na escolha do método de tratamento das desordens da ATM e nos seus 


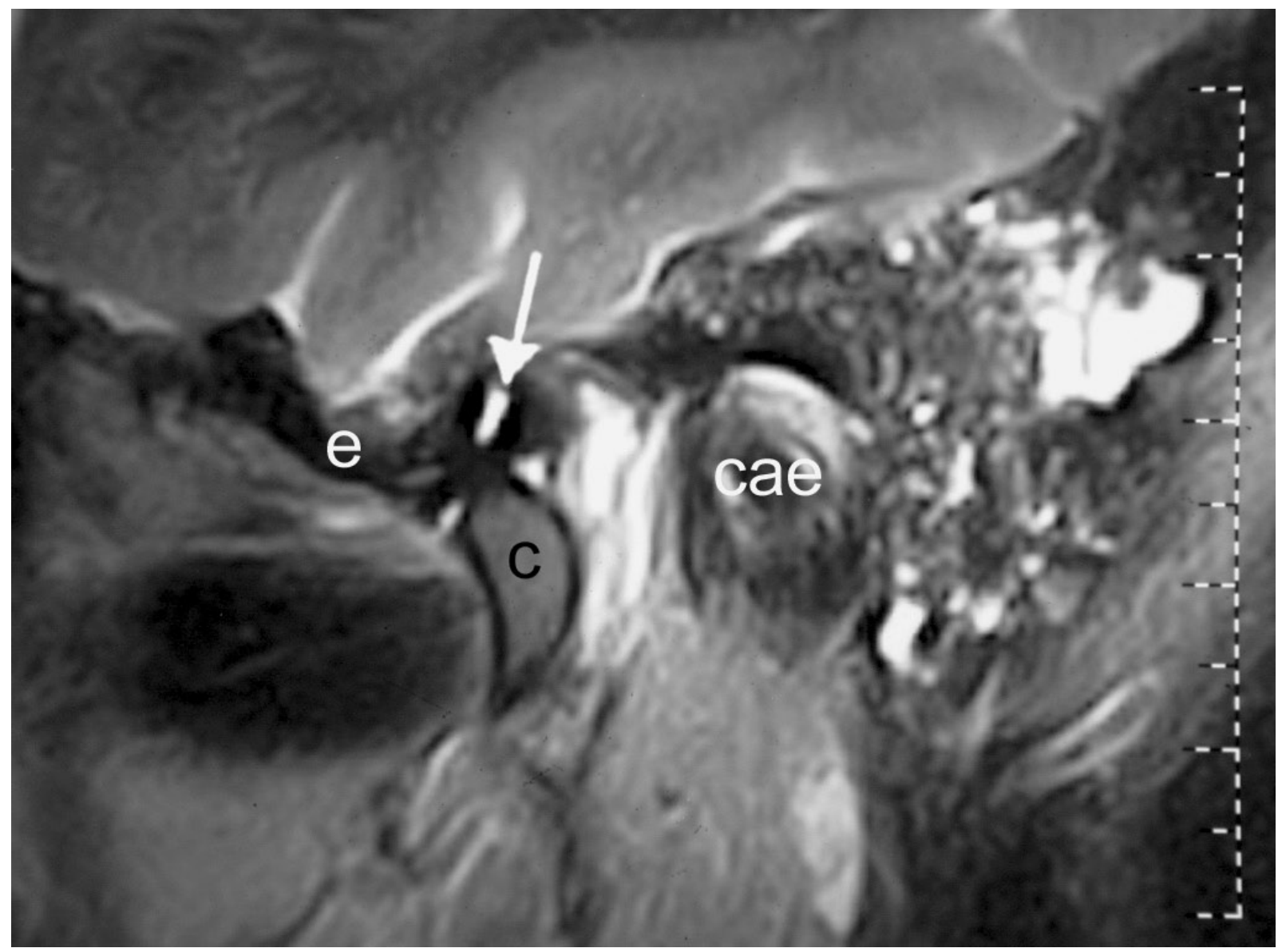

FIGURA 28 - Efusão da ATM e mastoidite. 0 corte parasagital oblíquo T2, na posição de boca aberta, mostra hipersinal dos espaços articulares (seta), o que é compatível com a presença de grande quantidade de fluido nos espaços articulares, provavelmente de natureza inflamatória (efusão), bem como nas células da mastóide (mastoidite). Translação condilar aquém do ápice da eminência articular (e), e disco articular bem posicionado entre eminência e o côndilo (c). (cae - conduto auditivo externo)
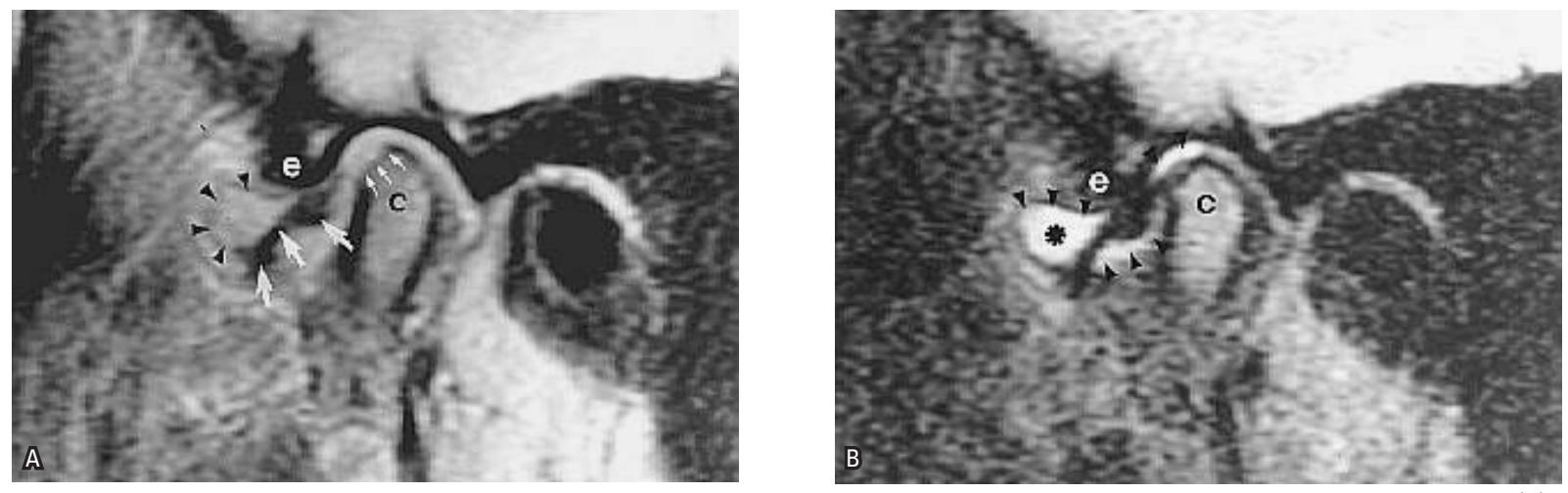

FIGURA 29 - Deslocamento anterior do disco articular e efusão. Cortes parasagitais oblíquos, na posição de boca fechada, ponderados em densidade de próton (A) e T2 (B). (A) Disco articular deslocado anteriormente ao côndilo (c), sem deformação significante (setas maiores apontam as três partes do disco: banda anterior, zona intermediária, banda posterior). 0 aumento significante do sinal do espaço articular superior (cabeças de seta) e discreto aplainamento do côndilo (setas pequenas) podem ser observados. (B) A acentuação do hipersinal dos espaços articulares superior e inferior em T2 (cabeças de seta), concentrados principalmente no recesso anterior do espaço superior (asterisco), é compatível com efusão. 

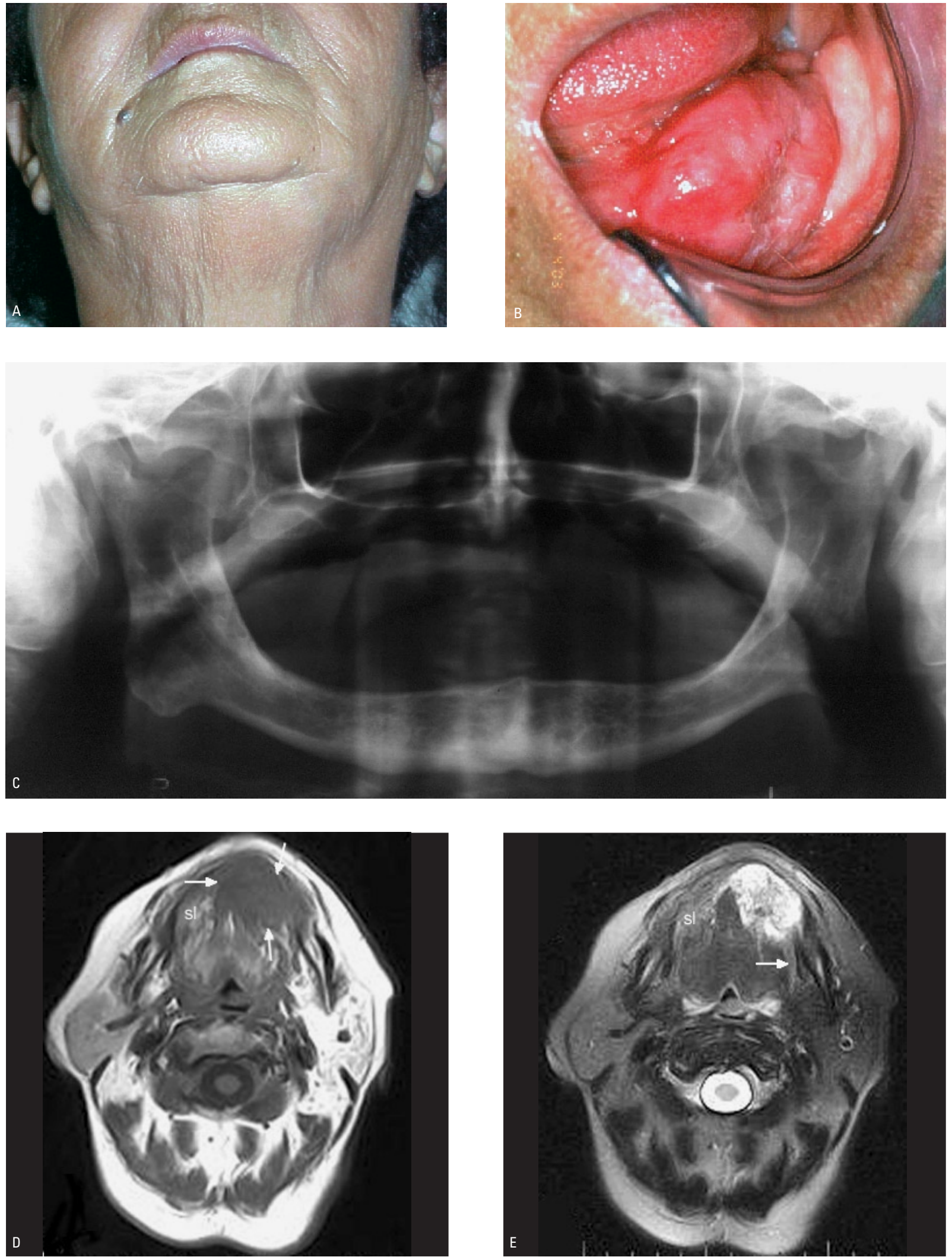

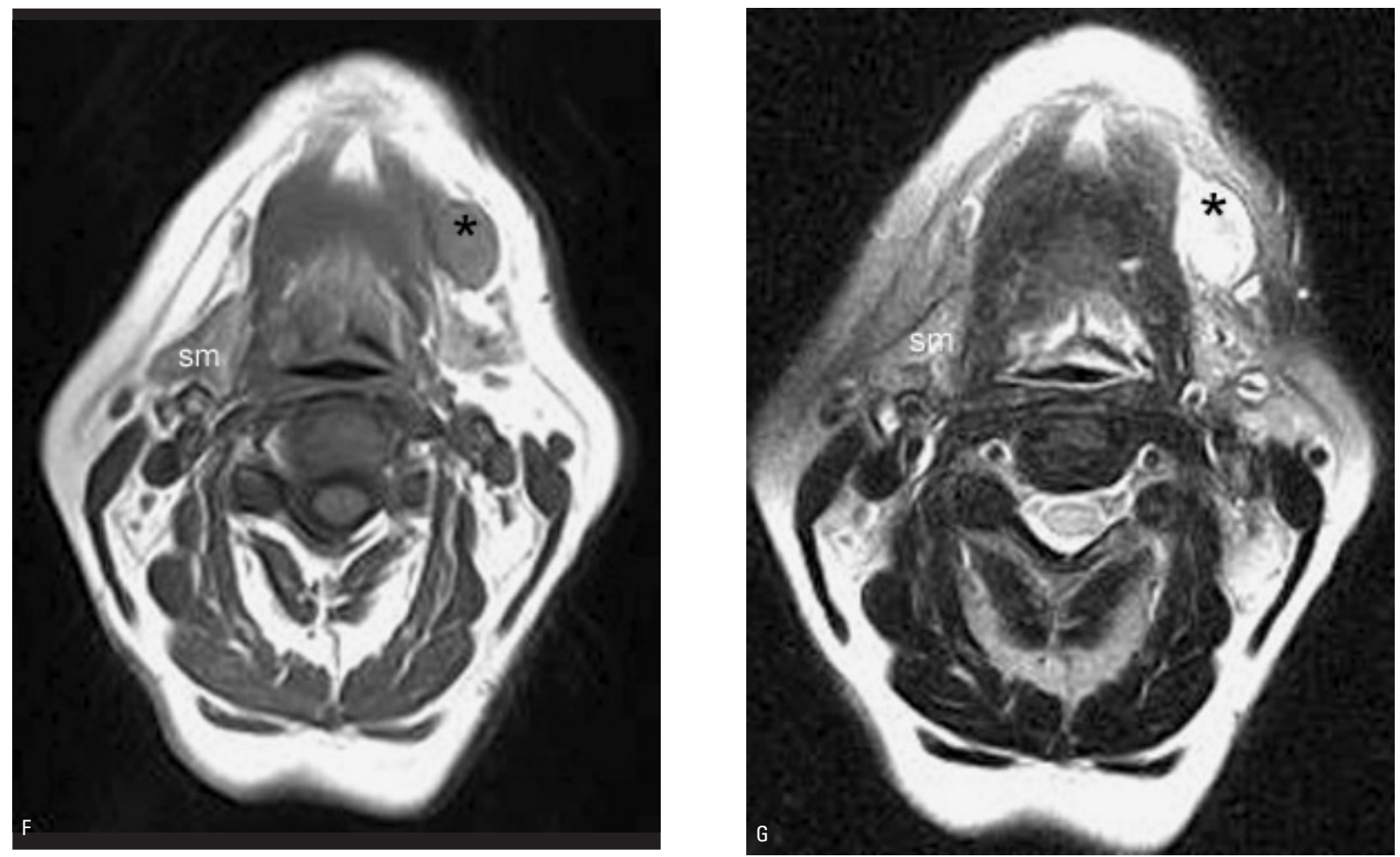

FIGURA 30 - Tumor maligno de glândula salivar na região de assoalho de boca. Paciente do gênero feminino, 60 anos, desdentada total, com queixa principal de úlcera no rebordo anterior da mandibula, percebida pela paciente há aproximadamente 5 meses da data da primeira consulta. A história médica inclui hipertensão sob controle medicamentoso. Ao exame intrabucal observou-se uma lesão nodular ulcerada, de aproximadamente 50 X $20 \mathrm{~mm}$, na região anterior esquerda do assoalho bucal, a qual estendia-se para a mucosa do rebordo alveolar (B). Um linfonodo submandibular endurecido foi identificado à palpação do lado esquerdo (A), o que sugeria tratar-se de linfonodo metastático. A radiografia panorâmica não revelou qualquer comprometimento ósseo (C). A biópsia incisional foi realizada e imagens por RM foram solicitadas, considerando a hipótese clínica de neoplasia de partes moles no assoalho bucal. 0s cortes axiais T1 (D) e T2 (E), nos mesmos níveis anatômicos, mostraram uma lesão expansiva e infiltrante, com margens parcialmente definidas, localizada no assoalho bucal a esquerda da linha média (D - setas). Seu epicentro estava na topografia da glândula sublingual (sl), com uma pequena extensão para a base da língua (D, E, H). A lesão apresentava um sinal hipointenso heterogêneo nas imagens em T1 (D) e hiperintenso em T2 (E), com um realce significante após injeção de meio de contraste (H)

resultados. Em articulações com deslocamentos sem redução (Fig. 26, 27) ou em estágios avançados das desordens intra-articulares (Fig. 21, 26), não é possível a obtenção de uma relação normal do complexo côndilo-disco utilizando as placas protrusivas ${ }^{7}$.

Desde 1979, o interesse na utilização do aparelho de Herbst para o tratamento da má oclusão Classe II tem aumentado. Este dispositivo ortopédico funcional, conhecido como "bite-jumping", promove um reposicionamento anterior da mandíbula em relação à maxila e modifica a posição sagital da articulação, o que tem gerado preocupações quanto aos possíveis efeitos deletérios para a $\mathrm{ATM}^{44}$.

Estudos utilizando imagens por RM sugerem que o tratamento com o aparelho de Herbst não resulta em qualquer alteração adversa na posição do disco e na função da ATM, sugerindo inclusive que ele poderia ser útil no tratamento de pacientes com deslocamento anterior do disco ${ }^{39,49,50 .}$ Contudo, uma recente revisão sistemática sobre o efeito deste tratamento ortopédico na morfologia da ATM sugere que há a necessidade de pesquisas aleatórias controladas, utilizando RM e tomografias para o estabelecimento dos efeitos a curto e longo prazo da terapia com o Herbst, sobre os tecidos ósseos e partes moles da $\mathrm{ATM}^{44}$.

Um estudo prospectivo longitudinal clínico e com imagens por RM avaliou os efeitos do tratamento com o aparelho ativador no complexo côndilo-disco e no ligamento posterior do disco. 

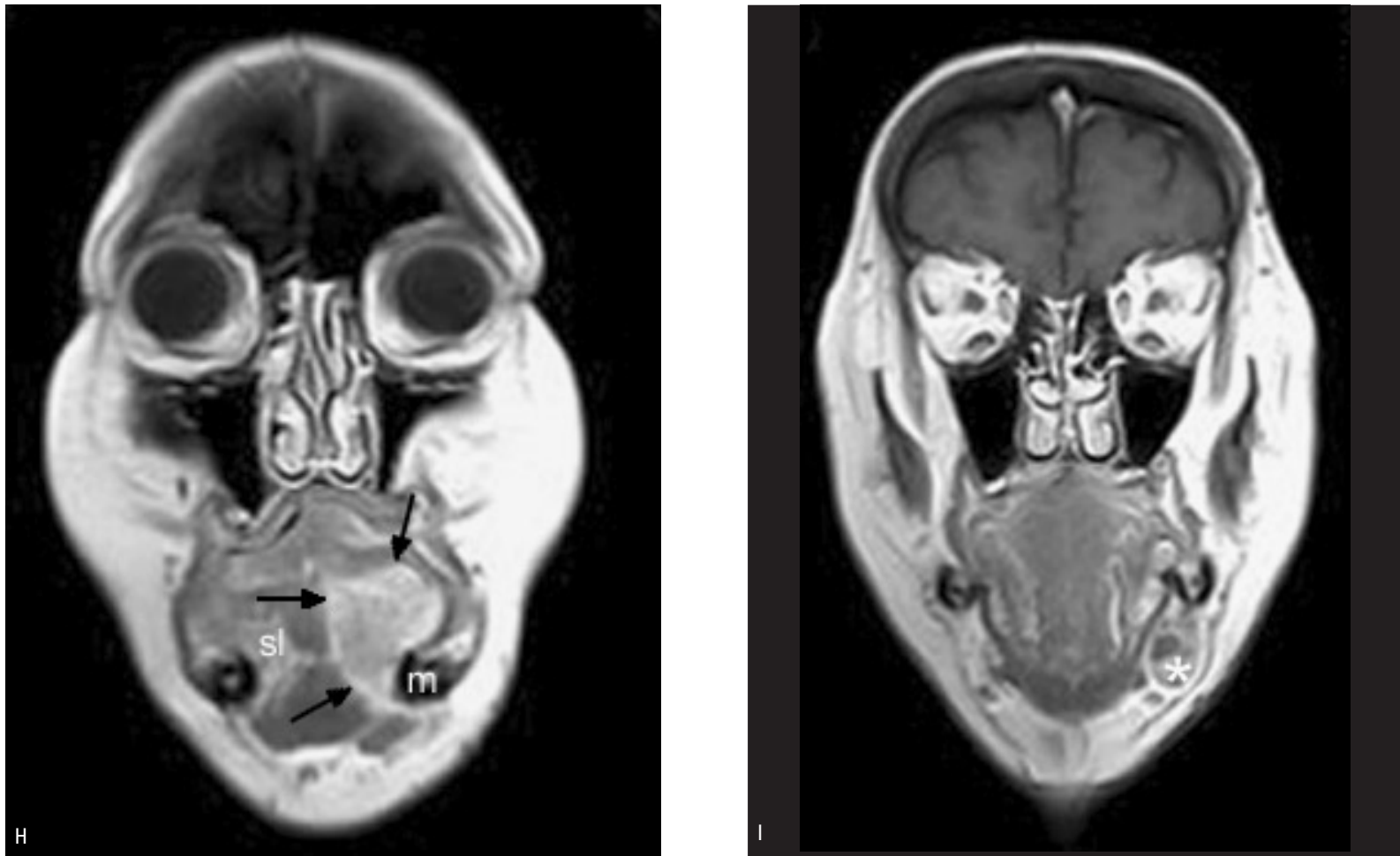

FIGURA 30 - (continuação) A massa tinha um formato de "gota d'água", cujo ápice parecia estar ligado à mucosa bucal (H - setas) (m - mandíbula). A congestão do ducto da glândula submandibular podia ser visualizada (E - seta), porém a morfologia do mesmo não foi significantemente alterada, visto que a trajetória dele através da neoplasia pôde ser identificada. Apesar da neoplasia sugerir três sítios etiológicos como hipóteses (glândula sublingual, células do ducto da glândula submandibular ou glândulas salivares menores), suas características de imagem sugerem que a glândula sublingual é a hipótese principal. Uma imagem nodular $( \pm 1,5 \mathrm{~cm})$ na região submandibular (asterisco), abaixo da lesão $(\mathbf{F}, \mathbf{G})(\mathrm{sm}$ - glândula submandibular), apresentando hipersinal heterogêneo em T2 (G), é indicativo de um linfonodo, no qual áreas circulares sem realce de contraste em T1 (I) sugere tratar-se de áreas císticas ou metastáticas. 0 resultado do anátomo-patológico foi compatível com um carcinoma mucoepidermóide do assoalho de boca. A paciente foi submetida à ressecção do tumor, mandibulectomia parcial e esvaziamento ganglionar cervical ipsilateral. A radioterapia e a quimioterapia não foram utilizadas. Recorrências locoregionais e metástases à distância não foram detectadas numa proservação de 6 meses. (Créditos do caso clínico: Central de Odontologia da Secretaria Estadual de Saúde, Equipe do Centro Goiano de Doenças da Boca da FO/UFG e do Serviço de Cabeça e Pescoço do Hospital Araújo Jorge da Associação de combate ao câncer em Goiás).

Dentre as conclusões destacam-se: a condição fisiológica do côndilo e disco, prévia ao tratamento, não foi afetada pela terapia; os discos deslocados, prévios ao tratamento, não foram reposicionados; a prevalência de uma capsulite no ligamento posterior aumentou durante o tratamento com o ativador $^{51}$

\section{Planejamento e avaliação pré e pós-cirurgia or- tognática}

Além dos aspectos estéticos, a reabilitação funcional de pacientes tratados pela cirurgia ortognática tem ganhado importância nos últimos anos. A cirurgia combinada com o tratamento ortodôntico tem alcançado resultados estéticos dentários e faciais satisfatórios.

O estabelecimento da posição condilar correta no interior da fossa mandibular é uma das dificuldades encontradas pelo cirurgião, durante a cirurgia ortognática de pacientes Classe II de Angle com desordens da ATM. As possíveis alterações morfométricas e morfológicas dos componentes da ATM também estão dentre as preocupações relacionadas ao paciente submetido à cirurgia ortognática $^{15}$

As imagens por RM têm tido um papel importante para o estudo das correlações entre imagens e achados clínicos, mostrando que uma melhora na posição do disco articular pode ser obtida, após o reposicionamento do complexo 
côndilo-disco pela cirurgia ortognática ${ }^{15}$. E ainda que, embora ocorram diferentes alterações na posição dos componentes ósseos da ATM após a osteotomia subcondilar da mandíbula, isto parece ser transitório, sem maiores alterações no resultado final para o paciente ${ }^{12}$.

Os protótipos estereolitográficos (Fig. 5) também podem ser obtidos a partir de imagens seccionais por $\mathrm{RM}^{25}$. De acordo com uma revisão realizada por Issa e colaboradores ${ }^{25}$, esses modelos constituem uma das técnicas de reconstrução tridimensional da região craniofacial por meio de imagens e são utilizados principalmente para aplicações clínicas em cirurgia bucomaxilofacial, o que inclui o planejamento e simulação de cirurgias ortognáticas. E ainda, na avaliação de anomalias craniofaciais; para reconstruções craniofaciais de defeitos ósseos e em traumatologia; para cranioplastias; para uma adaptação acurada de placas de reconstrução ou dispositivos de osteosíntese $^{37}$. Esta técnica pode ser empregada ainda, para reconstrução da orelha ${ }^{61}$ ou órbita ${ }^{22}$ e potencialmente aplicada nos estudos antropológicos ${ }^{21}$ ou de estimativa da idade facial ${ }^{43}$.

\section{Apnéia do sono}

As imagens por RM, a despeito do seu alto custo, são superiores à TC no estudo das vias aéreas superiores dos pacientes com apnéia obstrutiva do sono. Além de apresentar a maioria das vantagens da TC, soma-se a excelente resolução do espaço aéreo e dos tecidos moles adjacentes (especialmente a gordura), além da obtenção de secções sagitais, coronais e axiais diretas, sem reconstruções e sem a utilização de radiação ionizante (Figs. 20, 23). Isto permite a repetição do exame durante a vigília e o sono do paciente. Reconstruções tridimensionais do espaço aéreo e de partes moles como a parede lateral da faringe, a língua e o palato mole (importantes na modulação das alterações do calibre do espaço das vias aéreas superiores) podem ser obtidas.
Segundo Schwab ${ }^{58}$, por meio de estudos utilizando imagens por RM, indivíduos apnéicos apresentam língua e palato mole com dimensões aumentadas, e que o espaço aéreo dos mesmos tem o seu maior eixo no sentido ântero-posterior (estreitamento lateral) (Fig. 23).

A RM também tem sido utilizada para investigar o mecanismo pelo qual os dispositivos bucais podem ser utilizados para o tratamento da apnéia obstrutiva do sono. Esses estudos sugerem que o dispositivo bucal determina um alargamento da morfologia do espaço aéreo superior e mantém as vias aéreas livres, principalmente na porção posterior do palato mole (Fig. 23). O efeito do dispositivo bucal (reposicionador mandibular) está associado com o grau de alargamento da porção mais superior da bucofaringe. Assim, aqueles que têm uma língua pequena e uma faringe ampla podem ter bons resultados com o uso desses dispositivos ${ }^{16,58}$.

\section{Avaliação de condições patológicas potenciais na maxila e mandíbula}

A RM pode auxiliar no diagnóstico das lesões císticas e tumores odontogênicos e não odontogênicos da região bucomaxilofacial, por permitir a diferenciação entre o líquido e outros componentes como a queratina e produtos da degradação do sangue. Ela pode, ainda, contribuir na diferenciação entre um cisto e um tumor sólido ou misto (Figs. 18, 30). Contudo, o seu alto custo tem limitado a sua utilização na rotina da clínica odontológica $^{70}$.

A RM é a modalidade de escolha para o diagnóstico por imagem da maioria das lesões malignas que acometem a região bucomaxilofacial (Fig. 30). A alta resolução dos tecidos moles permite a visualização acurada da localização e extensão do tumor, especialmente os envolvimentos incipientes da medula óssea. As imagens sagitais e coronais, obtidas diretamente sem reconstruções, são importantes para o plano de tratamento e delineamento da extensão dessas neoplasias ${ }^{67}$. 


\section{DISCUSSÃO E CONCLUSÃO}

Os princípios da modalidade ideal e o futuro dos exames por imagens residem na determinação de uma anatomia o mais próximo do real em termos de precisão da orientação espacial, tamanho, forma e relação com as estruturas anatômicas circunjacentes, baixo custo e riqueza de detalhes tridimensionais. O desenvolvimento de tecnologias que reúnam estas qualidades inclui, dentre outras, as técnicas tomográficas e digitais, principalmente a TC e a RM.

Apesar da TC e da RM serem exames de alto custo e a TC proporcionar altas doses de radiação, em certas situações os benefícios são superiores aos riscos para a utilização dos mesmos na clínica de Ortodontia.

No tratamento de deformidades craniofaciais, em que as assimetrias apresentam registros inadequados quando técnicas radiográficas bidimensionais convencionais são utilizadas, a TC tem um importante papel, especialmente as reconstruções 3-D (Fig. 3). Ela oferece um melhor delineamento das estruturas ósseas da base do crânio e esqueleto facial (Figs. 4, 6, 16, 17) do que a radiografia convencional, além da possibilidade da caracterização de tecidos por meio da densitometria, e de medidas volumétricas dos $\operatorname{mesmos}^{26}$. Por outro lado, as imagens por RM são superiores à TC no estudo das vias aéreas superiores dos pacientes com apnéia obstrutiva do sono (Fig. 23), em particular por apresentar uma excelente resolução do espaço aéreo e dos tecidos moles (especialmente a gordura) e obtenção de imagens diretas em todos os planos anatômicos sem mudar o paciente de posição e sem a utilização de radiação ionizante ${ }^{57,58}$.

A confecção de biomodelos (protótipos estereolitrográficos) (Fig. 5) é um dos métodos sofisticados de reconstrução 3-D que vem se destacando no diagnóstico, planejamento e simulação cirúrgica, na avaliação longitudinal de pacientes tratados com cirurgia ortognática e de reconstrução facial, além da contribuição para estudos antropométicos. Esses modelos físicos são confeccionados a partir de imagens seccionais que podem ser obtidas por meio da TC ou $\mathrm{RM}$, as quais são processadas em um computador com softwares específicos, que guiam um dispositivo especial na confecção dos mesmos ${ }^{40}$, 53. Entretanto, alguns autores chamam a atenção para o elevado tempo de trabalho e o alto custo dos protótipos, quando comparados à técnica do articulador, sugerindo que aqueles deveriam ser reservados apenas para os casos mais complexos de desarmonias dentofaciais, por permitirem planejamentos de maior precisão ${ }^{14,53}$.

Em implantodontia, alternativa terapêutica importante para o tratamento de agenesias dentárias (especialmente na região anterior), a TC tem um papel de destaque, pois permite uma avaliação da espessura óssea vestíbulo-lingual ou vestíbulo-palatina (Fig. 9), o que não é viável com técnicas radiográficas convencionais. Ela é capaz de fornecer informações qualitativas sobre o osso cortical e trabecular de forma separada. Apesar da tomografia convencional ser o método seccional recomendado para o planejamento em casos de implantes unitários, considerada sua menor dose de radiação e menor custo, a TC permite a utilização de softwares de reconstrução de imagens específicos para a maxila e mandíbula, que conferem informações mais precisas e maior segurança para o profissional (Fig. 9). A avaliação da relação custo benefício deverá ser estabelecida caso a caso ${ }^{19,65}$.

Outras aplicações da TC que merecem destaque incluem:

- a sua superioridade na detecção de reabsorções dentárias associadas a dentes impactados, principalmente por permitir uma melhor visualização das superfícies vestibular e palatina (Fig. 10). Entretanto, o profissional deve estar alerta em relação à presença de artefatos adjacentes à reabsorção radicular nas imagens tomográficas ${ }^{23,29,45}$;

- o fornecimento de informações precisas quanto à localização e posicionamento de dentes 
retidos e impactados (Fig. 10) ${ }^{45}$;

- a determinação da extensão das reabsorções externas pela diferenciação entre a reabsorção superficial (cemento/dentina) e a que se estende para a polpa (Figs. 11, 12, 13) ${ }^{28}$;

- o diagnóstico de fraturas dentárias com uma suspeita clínica significante, não esclarecida por técnicas convencionais de imagem (Figs. 13, 14, 15). Os cortes axiais são ideais para o diagnóstico das fraturas verticais, uma vez que o plano é perpendicular à linha de fratura ${ }^{73}$.

A imagem por RM além de ser superior à TC na diferenciação dos tecidos moles, o é também por fornecer informações fisiológicas além das anatômicas (Figs. 18, 26, 28, 29, 30). Especial destaque tem sido dado à RM no estudo da ATM (Figs. 21, 24, 25, 26, 27, 28, 29). A TC fornece excelentes imagens dos componentes ósseos da articulação, especialmente para a detecção de sítios de destruição óssea incipientes, mas apenas as imagens por RM permitem uma visualização do disco articular e seus ligamentos. A acurácia da RM para o diagnóstico do posicionamento do disco tem atingido $95 \%{ }^{3,47}$. Além disso, é a única modalidade que identifica a presença de efusão e alterações da medula óssea condilar, sinais que tem sido associados ao aumento da dor $\operatorname{articular}^{33}$.

Os estudos utilizando RM têm sido valiosos para o esclarecimento de quais as condições específicas sob as quais a terapia de reposicionamento do disco teria mais chances de ser eficaz ${ }^{31}$. Este destaque se estende ainda, para o estudo das correlações entre as imagens e os achados clínicos, após o reposicionamento do complexo côndilo-disco pela cirurgia ortognática ${ }^{12,15}$.

Não existe uma única modalidade que forneça imagens de todos os componentes da articulação. TC e RM são usadas, freqüentemente, como exames complementares. Mas a qualidade de diagnóstico desses exames pode variar amplamente, dependendo do nível de experiência tanto do técnico que realiza os exames, quanto do radiologista que interpreta as imagens.
Especial atenção deve ser dada à possibilidade de artefatos de imagem que podem ser provocados pelos metais utilizados em Odontologia, desde as restaurações até os dispositivos ortodônticos. $\mathrm{Na}$ TC esses artefatos são em forma de "raios brilhantes" e na RM se caracterizam por áreas escuras, de baixo sinal (Fig. 22). A extensão desses artefatos, a depender do tipo de liga, pode se restringir aos dentes, como podem estender-se até a região de ATM e prejudicar ou inviabilizar a interpretação das imagens. Assim, na possibilidade do paciente necessitar de realizar exames tomográficos, em particular a RM, deve-se planejar o tipo de aparelho a ser instalado, preferindo os dispositivos estéticos e/ou de ligas que não sejam do tipo $\mathrm{Ni}-\mathrm{Cr}$ 18/8, associado à remoção dos arcos estabilizadores ${ }^{10,24,38}$.

Considerando todos os aspectos mencionados, a TC e a RM representam importantes instrumentos no diagnóstico, planejamento e avaliação do resultado de tratamentos relacionados à prática clínica da Ortodontia. Esses avanços do diagnóstico por imagens podem aumentar substancialmente as habilidades do profissional para identificar condições que não são detectadas com os métodos tradicionais. Porém, o conhecimento de aspectos básicos como as vantagens e desvantagens, indicações e contra-indicações das referidas técnicas, por parte do Cirurgião-dentista, é determinante para o uso racional das mesmas.

Não se pode esquecer que, por mais que essas técnicas envolvam alta tecnologia, elas continuam sendo exames complementares, cuja indicação deve estar baseada em um criterioso exame clínico do paciente e análise individual do custo benefício das mesmas.

Os resultados das imagens não correspondem, necessariamente, aos sinais e sintomas do paciente. $\mathrm{O}$ investimento na inter-relação clínico radiologista é uma ação determinante para a diferenciação profissional do generalista ou do especialista.

Enviado em: Agosto de 2004

Revisado e aceito: Setembro de 2004 


\title{
Seccional imaging techniques applied to Orthodontics: the advance of imaging diagnosis
}

\begin{abstract}
Imaging diagnosis has gone through many transformations in the last ten years. Revolutionary technology advances in computer science and energy sources being newly applied in the field of medicine are the main reasons for these transformations. The sectional imaging techniques, such as computed tomography (CT) and magnetic resonance imaging (MRI) have most of the principles and qualities of the ideal imaging modality. This includes the determination of anatomic truth in terms of accurate portrayal of spatial orientation, size, form and relationships of desired structures or features, which require assessment of three-dimensional details. The aim of this review, illustrate by clinical cases, is to provide an overview of the importance of CT and MRI in the orthodontic field.
\end{abstract}

Key words: Tomography. Magnetic resonance imaging. Orthodontics. Sectional imaging techniques

\section{REFERÊNCIAS}

1. ABBASZADEH, K.; HEFFEZ, L. B.; MAFEE, M. F. Effect of interference of metallic objects on interpretation of T1-weighted magnetic resonance images in the maxillofacial region. Oral Surg Oral Med Oral Pathol Oral Radiol Endod, St. Louis, v. 89, no. 6, p. 759-765, June 2000.

2. AU-YEUNG, K. M.; AHUJA, A.T.; CHING, A. S.; METREWELI, C. Dentascan in oral imaging. Clin Radiol, Edinburgh, v. 56, no. 9, p. 700-713, Sept. 2001.

3. BROOKS, S. et al. Imaging of temporomandibular joint: a position paper of the American Academy of Oral and Maxillofacial Radiology. Oral Surg Oral Med Oral pathol Oral Radiol Endod, St. Louis, v. 83, p. 609-618, 1997.

4. COCEANI, L. Oral structures and sleep disorders: a literature review. Int J Orofacial Myology, Seattle, v.29, p.15-28, Nov. 2003.

5. DEGUCHI, T. et al. The use of small titanium screws for orthodontic anchorage. J Dent Res, Alexandria, v. 82, no. 5 p. 377-381, May 2003.

6. DEVGE, C.; TJELLSTRON, A.; NELLSTROM, H. Magnetic resonance imaging in patients with dental implants: a clinical report. Int J Oral Maxillofac Implants, Lombard, v.12, no. 3 p. 354-359, May/June 1997

7. EBERHARD, D.; BANTLEON, H. P.; STEGER, W. The efficacy of anterior repositioning splint therapy studied by magnetic resonance imaging. Eur J Orthod, London, v.24, no. 4, p. 343-352, Aug. 2002

8. ERICSON, S.; KUROL, J. Incisor root resorptions due to ectopic maxillary canines imaged by computerized tomography: a comparative study in extracted teeth. Angle Orthod, Appleton, v.70, no. 4, p.276-283, Aug. 2000.

9. ERICSON, S.; KUROL, P. J. Resorption of incisors after ectopic eruption of maxillary canines: a CT study. Angle Orthod, Appleton, v.70, no. 6, p. 415-423, Dec. 2000.

10. FELLNER, $\mathrm{C}$. et al. Artifacts in MR imaging of the temporomandibular joint caused by dental alloys: a phantom model study at T1.5. Rofo Fortschr Geb Rontgenstr Neuen Bildgeb Verfahr, Stuttgart, v.166, no.5, p. 421-428, May 1997.

11. FERGUSON, K. A. The role of oral appliance therapy in the treatment of obstructive sleep apnea. Clin Chest Med, Philadelphia, v. 24, no.2, p.355-364, June 2003.

12. FERNANDEZ SAROMAN, J.; GOMEZ GONZALEZ, J. M.;
ALONSO DEL HOYO, J.; MONJE GIL, F. Morphometric and morphological changes in the temporomandibular joint after orthognathic surgery: a magnetic resonance imaging and computed tomography prospective study. J Craniomaxillofac Surg, Stuttgart, v.25, no.3, p.139-148, June 1997.

13. FRANCISCHONE, C. E. et al. Treatment for predictable multidisciplinary implantology, orthodontics, and restorative dentistry. Pract Proced Aesthet Dent, Mahwah,v.15, no. 4, p.321-326, May 2003.

14. FUHRMANN, R. A.; FROHBERG, U.; DIEDRICH, P. R. Treatment prediction with three-dimensional computer tomographic skull models. Am J Orthod Dentofacial Orthop, St. Louis, v.106, no.2, p.156-160, Aug.1994.

15. GAGGL, A. et al. Clinical and magnetic resonance finding in the temporomandibular joints of patients before and after orthognathic surgery. Br J Oral Maxillofac Surg, Edinburgh, v.37, no.1, p. 41-45, Feb. 1999

16. GAO, X. M.; ZENG, X. L.; FU, M. K.; HUANG, X. Z. Magnetic resonance imaging of the upper airway in obstructive sleep apnea before and after oral appliance therapy. Chin J Dent Res, New Malden, v. 2, no. 2, p. 27-35, May 1999.

17. GARG, A. K.; VICARI, A. Radiographic modalities for diagnosis and treatment planning in implant dentistry. Implant Soc, Cambridge, v. 5, no.5, p. 7-11, 1995.

18. GREENBERG, R. S. et al. Diagnostic testing. In:_Medical epidemiology. 2nd ed. New York: McGraw-Hill, 1995.

19. HARRIS, D. et al. E.A.O. guidelines for the use of diagnostic imaging in implant Dentistry: a consensus workshop organized by the European Association for Osseointegration in Trinity College Dublin. Clin Oral Implant Res, Copenhagen, v.13, p. 566-570, 2002.

20. HATCHER, D.C. Maxillofacial imaging. In: McNEILL, C. (Ed.). Science and Practice of occlusion, Chicago: Quintessence, 1997. p. 349-364.

21. HJALGRIM, H.; LYNNERUP, N.; LIVERSAGE, M.; ROSENKLINT, A. Stereolithography: potential application in anthropological studies. Am J Phys Anthropol, Philadelphia, v.97, p.329-333, 1995.

22. HOLCK, D. E.; BOYD, E. M.; NG, J.; MAUFFRA,Y, R.O. Benefits of stereolithography in orbital reconstruction. Ophthalmology, Philadelphia, v.106, p.1214-1218, 1999. 
23. HORVATH, M. et al. New trends in computed tomography of the head and neck. Curr Opin Radiol, Philadelphia, v.3, no.1, p. 109-113, Feb. 1991.

24. HUBALKOVA, H.; HORA, K.; SEIDL, Z.; KRASENSKY, J. Dental materials and magnetic resonance imaging. Eur J Prosthodont Restor Dent, Larkfield, v.10, no.3, p.125-130.

25. ISSA, B. et al. Assessment of the pore geometry of stereolithographic model by high resolution MRI. Mag Reson Imaging, New York, v.16, p. 651-453, 1998

26. KANE, A. A.; CHRISTENSEN, G. E.; VANNIER, M.W.; MARSH, J. L. Relationship between bone and muscles of mastication in hemifacial microsomia. Plast Reconstr Sur, Baltimore, v. 99, no. 4, p. 990-997, Apr. 1997.

27. KAWAMATA, A. et al. Three-dimensional computed tomography evaluation of postsurgical condilar displacement after mandibular osteotomy. Oral Surg Oral Med Oral Pathol Oral Radiol Endod, St. Louis, v. 85, no. 4, p.371-376, Apr. 1998.

28. KIM, E. et al. Computed tomography as a diagnostic aid for extracanal invasive resorption. J Endod, Baltimore, v.29, no.7, p.463-465, July 2003.

29. KRENNMAIR, G.; LENGLINGER, F. X.; TRAXLER, M. Imaging of unerupted and displaced teeth by cross-sectional CT scans. Int J Oral Maxillofac Surg, Copenhagen, v. 24, no. 6, p. 413-416, Dec. 1995.

30. KURITA, H. et al. Evaluation of disk capture with a splint repositioning appliance: clinical and critical assessment with MR imaging. Oral Sur Oral Med Oral Pathol Oral Radiol Endod, St. Louis, v. 85, no. 4, p.377-380, Apr. 1998.

31. KURITA, H.; OHTSUKA, A.; KURASHINA, K.; KOPP, S. A study of factors for successful splint capture of anteriorly displaced temporomandibular joint disc with disc repositioning appliance. J Oral Rehab, Oxford, v. 28, p. 651-657, 2001.

32. LANGLAIS, R. P. et al. Magnetic resonance imaging in Dentistry. Dent Clin North Am, Philadelphia, v. 44, no.2, p. 411-426, Apr. 2000.

33. LARHEIM, T. A.; WESTESSON, P. L.; SANO, T. MR grading of temporomandibular joint fluid: association with disk displacement categories, condyle marrow abnormalities and pain. Int J Oral Maxillofac Surg, Copenhagen, v.30, no. 2, p.104-112, Apr. 2001

34. LISSAC, M.; COUDERT, J. L.; BRIGUET, A.; AMIEL, M. Disturbances caused by dental materials in magnetic resonance imaging. Int Dent J, London, v. 42, no. 4, p. 229-233, Aug. 1992.

35. MANKOVICH, N. J.; ROBERTSON, D. R.; CHEESEMAN, A. M. Three-dimensional image display in medicine. J Digit Imaging, Philadelphia, v.3, no.2, p. 69-80, May 1990

36. $\mathrm{MOL}, \mathrm{A}$. Image processing tools for dental applications. Dent Clin North Am, Philadelphia, v. 44, no.2, p. 299-318, Apr. 2000.

37. MONAHAN, R. et al. Hemifacial microsomia. Etiology, diagnosis and treatment. J Am Dent Assoc, Chicago, v.132, no.10, p.1402-1408, Oct. 2001

38. OKANO, Y. et al. Magnetic resonance imaging diagnosis of the temporomandibular joint in patients with orthodontic appliances. Oral Surg Oral Med Oral Pathol Oral Radiol Endod, St. Louis, v. 95, no. 2, p. 255-263, Feb. 2003.

39. PANCHERZ, H.; RUF, S.; THOMALSKE-FAUBERT, C. Mandibular articular disk poisition changes during Herbst treatment: a prospective longitudinal MRI study. Am J Orthod Dentofacial Orthop, St. Louis, v.116, no.2, p. 207-214, Aug. 1999.

40. PAPADOPOULOS, M.A. et al. Three-dimensional craniofacial reconstruction imaging. Oral Surg Oral Med Oral Pathol Oral Radiol Endod, St. Louis, v. 93, no. 4, p.382-393, Apr. 2002.

41. PARKS, E.T. Computed tomography applications for dentistry. Dent Clin North Am, Philadelphia, v. 44, no.2, p.371-410, Apr. 2000.

42. PEENE, P. et al. Resorption of the lateral maxillary incisor: assessment by CT. J Comput Assist Tomogr, Hagerstown, v.14, no. 3, p. 427-429, May/June 1990.

43. PESSA, J. E. The potential role of stereolithography in the study of facial aging. Am J Orthod Dentofacial Orthop, St. Louis, v.119, p. 117-120, 2001.
44. POPOWICH, K.; MEBBE, B.; MAJOR, P. W. Effect of Herbst treatment on temporomandibular joint morphology: a systematic literature review. Am J Orthod Dentofacial Orthop, St. Louis, v.123, no. 4, p.388-394, Apr. 2003.

45. PREDA, L. et al. The use of spiral computed tomography in the localization of impacted maxillary canines. Dentomaxillofac Radiol, Tokyo, v.26, no. 4, p.236-241, July 1997.

46. QUITERO, J.C.; TROSIEN, A.; HATCHER, D.; KAPILA, S. Craniofacial imaging in orthodontics: historical perspective, current status, and future developments. Angle Orthod, Appleton, v. 69 , no. 6, p. 491-506, 1999.

47. RIBEIRO, R. F. Avaliação estrutural da articulação temporomandibular em crianças e adultos jovens assintomáticos através de imagens por Ressonância Magnética. 1996. 322 f. Tese (Doutorado)- Faculdade de Odontologia de Bauru, Universidade de São Paulo, Bauru, 1996.

48. RIBEIRO, R. F. et al. The prevalence of disc displacement in symptomatic and asymptomatic volunteers aged 6 to 25 years. J Orofac Pain, Carol Stream, v.11, no.1, p.37-47, Winter 1997.

49. RUF, S.; PANCHERZ, H. Does bite-jumping damage the TMJ? A prospective longitudinal clinical and MRI study of Herbst patients. Angle Orthod, Appleton, v.70, no.3, p.183-199, June 2000.

50. RUF, S.; PANCHERZ, H. Long-term TMJ effects of Herbst treatment: a clinical and MRI study. Am J Orthod Dentofacial Orthop, St. Louis, v.114, no.5, p.475-483, Nov. 1998.

51. RUF, S.; WUSTEN, B.; PANCHERZ, H. temporomandibular joint effects of activator treatment: a prospective longitudinal magnetic resonance imaging and clinical study. Angle Orthod, Appleton, v. 72, no.6, p. 527-540, Dec. 2002.

52. SALVOLINI, L.; BICHI, S. E; COSTARELLI, L.; DE NICOLA, M. Clinical applications of 2D and 3D CT imaging of the airways a review. Eur J Radiol, Stuttgart, v.34, no.1, p. 9-25, Apr. 2000.

53. SANTLER, G.; KARCHER. H.; GAGGL, A.; KERN, R. Stereolithography versus milled three-dimensional models: comparison of production method, indication, and accuracy. Comput Aided Surg, New York, v.3, no.5, p. 248-256, 1998.

54. SCHELLHAS, K. P.; POLLEI, S. R.; WILKES, C. H. Pediatric internal derangements of the temporomandibular joint: effect on facial development. Am J Orthod Dentofacial Orthop, St. Louis, v.104, no.1, p.51-59, July 1993.

55. SCHLEGEL, K.A.; KINNER, F.; SCHLEGEL, K.D. The anatomic basis for palatal implants in orthodontics. Int J Adult Orthodon Orthog Surg, Carol Stream, v.17, no.2, p.133-139, 2002.

56. SCHULTES, G.; GAGGL, A.; KARCHER, H. Changes in the dimensions of milled mandibular models after mandibular sagittal split osteotomies. Br J Oral Maxillofac Surg, Edinburgh, v.36, no.3, p.196-201, June 1998.

57. SCHWAB, R. J. Imaging for the snoring and sleep apnea patient. Dent Clin North Am, Philadelphia, v. 45, no. 4 p. 759-796, Oct. 2001.

58. SCHWAB, R. J. Upper airway imaging. Clin Chest Med, Philadelphia, v.19, no.1, p. 33-54, Mar. 1998.

59. SHAHLAIE, M. et al. Bone dentistry assessments of dental implant sites: Quantitative computed tomography. Int J Oral Maxillofac Implants, Lombard, v.18, p.224-231, 2003.

60. SMITH, H. J.; LARHEIM, T.A.; ASPESTRAND, F. Rheumatic and nonrheumatic disease in the temporomandibular joint: gadolinium-enhanced MR imaging. Radiology, [Illinois], v.185, p.229-234, 1992.

61. STAUDENMAIER, R.; NAUMANN, A.; AIGNER, J.; BRUNING, R. Ear reconstruction supported by a stereolithographic model. Plast Reconstr Surg, Baltimore, v.106, p.511-512, 2000.

62. SUGAWARA, J. et al. Treatment and posttreatment dentoalveolar changes following intrusion of mandibular molars with application of a skeletal anchorage system (SAS) for open bite correction. Int J Adult Orthodon Orthognath Surg, Corol Stream, v. 17, no. 4, p.243-253, 2002.

63. SUMMER, J. D.; WESTESSON, P. L. Mandibular repositioning can be effective in treatment of reducing TMJ disk displacement. A long-term clinical and MR imaging follow-up. Cranio, Chattanooga, v.15, no. 2, p.107-120, Apr. 1997. 
64. THILANDER, B. Os implantes dentários na Ortodontia do futuro. In: CARELS, C.; WILLEMS, G. O futuro da Ortodontia. Maringá: Dental Press, 2003. p.129-140.

65. TYNDALL, D. A.; BROOKS, S. L. Selection criteria for dental implant site imaging: a position paper of the American Academy of Oral and Maxillofacial Radiology. Oral Surg Oral Med Ora Pathol Oral Radiol Endod, St. Louis, v. 89, no.5, p. 630-637, May 2000

66. VAN DER, STELT, P. F. Principles of digital imaging. Dent Clin North Am, Philadelphia, v. 44, no.2, p.237-248, Apr. 2000.

67. VAN RENSBURG, L. J.; NORTJÉ,C .J. Magnetic resonance imaging and computed tomography of malignant disease of the jaws. Oral Maxillofac Surg Clin North Am, Philadelphia, v. 4, no.1, p.75-111, Feb. 1992.

68. VANNIER, M.W. et al. Three-dimensional dental imaging by spiral CT. A progress report. Oral Surg Oral Med Oral Pathol Oral Radiol Endod, St. Louis, v. 84, no.5, p.561-570, Nov. 1997
69. VOGL, T. J.; BALZER, J.: MACK, M. STEGER, W. Diagnostic imaging techniques. In:__ Differential diagnosis in head and neck imaging: a systematic approach to the radiologic evaluation of the head and neck region and the interpretation of difficult cases. Stuttgart: Thieme, 1999. p.7-10.

70. WEBER, A. L. Imaging of cysts and benign odontogenic tumors of the jaw. Oral Maxillofac Surg Clin North Am, Philadelphia, v. 4, no.1, p. 61-74, Feb. 1992.

71. YAMADA, K. et al. Condilar bony change and craniofacial morphology in orthodontic patients with temporomandibular disorders (TMD) symptoms: a pilot study using helical computed tomography and magnetic resonance imaging. Clin Orthod Res, Copenhagen, v.2, no.3, p.133-142, Aug. 1999.

72. YOUSEM, D. M.; MONTONE, K.T. Head and neck lesions radiologic pathologic correlations. Radiol Clin North Am Philadelphia, v.36, p. 983, 1998.

73. YOUSSEFZADEH, S. et al. Dental vertical root fractures: value of CT in detection. Radiology, [Illinois?], v. 210, no. 2. p.545549, Feb. 1999.
Endereço para correspondência

Rejane Faria Ribeiro-Rotta

Rua C235, no. 1323, apto. 1501, Edifício Leblon

Setor Nova Suíça, Goiânia-GO

CEP: 74280-130

ribe@ih.com.br 